\title{
Anglemetry of neural axis cell differentiation genes by structural pressurotopy of DNA loop strand segment tropy in reference to tissue macro-compliance
}

\author{
Hemant Sarin®
}

\begin{abstract}
Background: Even as the eukaryotic stranded DNA is known to heterochromatinize at the nuclear envelope in response to mechanical strain, the precise mechanistic basis for alterations in chromatin gene transcription in differentiating cell lineages has been difficult to determine due to limited spatial resolution for detection of shifts in reference to a specific gene in vitro. In this study, heterochromatin shift during euchromatin gene transcription has been studied by parallel determinations of DNA strand loop segmentation tropy nano-compliance (esebssiwaago $T_{\mathrm{Q}}$ units, linear $\mathrm{nl}$ ), gene positioning angulation in linear normal twodimensional (2-D) $z, y$-vertical plane (anglemetry, ${ }^{9}$, horizontal alignment to the $z, x$-plane (vectormetry; $m_{A}, m_{M}$, a.u.), and by pressuromodulation mapping of differentiated neuron cell sub-class operating range for neuroaxis gene expression in reference to tissue macro-compliance $\left(P_{\text {eff }}\right)$.

Methods: The esebssiwaago $T_{\mathrm{Q}}$ effective pressure unit $\left(P_{\mathrm{eff}}\right)$ maxima and minima for horizontal gene intergene base segment tropy loop alignment were determined $(n=224)$; the $P_{\text {eff }}$ esebssiwaago $T_{Q}$ quotient were determined $(n=28)$ for analysis of gene intergene base loop segment tropy structure nano-compliance $(n=28 ; n=188)$; and gene positioning anglemetry and vectormetry was performed $(n=42)$. The sebs intercept-to-sebssiwa intercept quotient for linear normalization was determined $\left(b_{\text {sebs }} / b_{\text {sebssiwa }}\right)$ by exponential plotting of sub-episode block sum (sebs) $\left(x_{1}, y_{1} ; x_{2}, y_{2}\right)$ and sub-episode block sum split integrated weighted average (sebssiwa) functions was performed, and the sebs - sebssiwa function residuals were determined. The effective cell pressure $\left(P_{\text {eff }}\right)$-to-angle conversion factor was determined, $\Theta_{A}=(1 \mathrm{E}+02)\{0.90-[(0.000+a \geq x<0.245)(1.208)]$ form was applied for anisotropic gene anglemetry, and the $\Theta_{M}=(1 E+02)\{0.90-[1.208(0.245 \geq x \leq m)]$ form was applied for mesotropic gene anglemetry. Two-step Tukey range t-test was performed for inter-group comparisons of $b_{\text {sebs }} / b_{\text {sebssiva }}$ quotients and sebs - sebssiwa normalized residuals between tier $1\left(P_{\text {eff }} \leq 0.200 ; n=11\right)$ and tier $2\left(P_{\text {eff }}>0.200 \leq 0.300 ; n=6\right)$, between tier 1 and tier $3\left(P_{\text {eff }}>0.300 ; n=8\right)$, and between tier 3 and tier $2(\alpha=0.05)$.

(Continued on next page)
\end{abstract}

Correspondence: hemantsarin74@gmail.com

Freelance Investigator in Translational Science and Medicine (unaffiliated),

833 Carroll Road, Charleston, West Virginia, USA

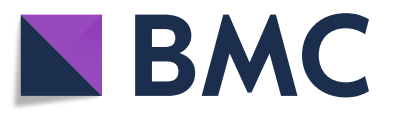

(c) The Author(s). 2019 Open Access This article is distributed under the terms of the Creative Commons Attribution 4.0 International License (http://creativecommons.org/licenses/by/4.0/), which permits unrestricted use, distribution, and reproduction in any medium, provided you give appropriate credit to the original author(s) and the source, provide a link to the Creative Commons license, and indicate if changes were made. The Creative Commons Public Domain Dedication waiver (http://creativecommons.org/publicdomain/zero/1.0/) applies to the data made available in this article, unless otherwise stated. 
(Continued from previous page)

Results: Based on the results of this study, I) heterochromatin strand DNA loop micro-segmentation structural nanocompliance is either amorphousity, anisotropy or mesotropy loop segment forms perceiving various grades of the asymmetric tropy viscosity effect, where between 3-to-5 and 8-to-11 genes are arranged as one or two in-tandem alternating anisotropic and mesotropic gene(s), or as in-tandem anisotropic or mesotropic genes in juxtaposition separated by intergene tropy base distance; for example, the anisotropy loop segment form between positions - 12 to + 15 in reference LMNA $\left(P_{\text {eff, }} 0.184 ; \theta_{A}=68.4^{0}\right)$ on human $1 \mathrm{q} 22(+)$ is: 5'-0.234- $\left(a_{-} 12\right)-0.272\left(m_{-11}\right)-0.229\left(a_{-}-10\right)-0.211\left(a_{-}\right)-0.269\left(m_{-8}\right)-$ $0.144\left(a_{-7}\right)-0.314\left(m_{-6}\right)-0.268\left(m_{-5}\right)-0.176\left(a_{-4}\right)-0.260\left(m_{-3}\right)-0.259\left(m_{-2}\right)-0.270\left(m_{-1}\right)-0.184\left(a_{0}\right)-0.135\left(m_{+1}\right)-$ $0.395\left(m_{+2}\right)-0.146\left(a_{+3}\right)-0.212\left(a_{+4}\right)-0.336\left(m_{+5}\right)-0.287\left(m_{+6}\right)-0.153\left(a_{+7}\right)-0.283\left(m_{+8}\right)-0.193\left(a_{+9}\right)-0.269\left(m_{+10}\right)-$ $0.199\left(a_{+11}\right)-0.146\left(a_{+12}\right)-0.190\left(a_{+13}\right)-0.188\left(a_{+14}\right)-0.243\left(a_{+15}\right)-3{ }^{\prime}$, which begins at the $5^{\prime}$ end with DAP3 $(P$ eff 0.234); II) mesotropy loop form genes are positioned between 11.7 and $60.4^{0}$ (CD34) in the $z, y$-vertical plane, whereas anisotropy loop form genes positioned between 60.5 and $82.3^{\circ}$ (MIR4537) in the $z, y$-vertical plane; III) the relationship between effective pressure and momentum is inverse proportionality, $P_{\text {eff }}(0.064 \geq x<0.245) \cdot m_{\mathrm{A}}=P_{\text {eff }}$ $(0.245 \geq x \leq 0.648) \cdot m_{M}$; IV) the interval for peripheral lower motor neuron (Imn) gene expression is definable as being between a $P_{\text {eff }}$ of 0.434 and 0.311 (> 0.305), between a $P_{\text {eff }}$ of 0.305 and 0.213 for cerebrocortical upper motor neurons, between a $P_{\text {eff }}$ of 0.318 and 0.203 for hippocampocortical neurons, and between a $P_{\text {eff }}$ of 0.298 and 0.217 for basal ganglia spiny neurons; therefore, there exists an inverse relationship between effective range of whole cell compliance and tissue macro-compliance ( $R_{\text {effective whole cell compliance }} \cdot T_{\text {macro-compliance }}=\mathrm{k}$ ), in which case the range for mesenchymal cell (MSC) gene expression is delineable as being between a Peff of 0.648 and $<=0.118$ esebssiwaagoTQ units; and $V$ ) $R G S 18\left(P_{\text {eff }} 0.205 ; \theta_{M}=65.2^{\circ}\right), R G S 16\left(P_{\text {eff }} 0.251 ; \theta_{M}=59.7^{0} ;\right.$ human paralog of murine $\left.R G S 4\right)$, Inc-RXFP4-5 ( $P_{\text {eff }} 0.314 ; \theta_{M}=$ 52.1 $1^{0}$; pituit), RGS13 $\left(P_{\text {effi }} 0.360, \theta_{\mathrm{M}}=46.5^{\circ}\right)$, CEACAM1 $\left(P_{\text {effi }} 0.384 ; \theta_{\mathrm{M}}=43.6^{0}\right), \operatorname{SLC} 25 A 44\left(P_{\text {eff }} 0.395 ; \theta_{\mathrm{M}}=42.3^{0}\right)$ and $R G S 21$ $\left(P_{\text {effi }} 0.413 ; \theta_{M}=40.1^{9}\right)$ are expressed within the lower motor neuron (Imn)-upper motor neuron (umn) neural cell axis; and TSACC ( $\left.P_{\text {eff, }} 0.336 ; \theta_{M}=49.4^{\circ}\right)$ and JUND $\left(P_{\text {eff, }} 0.344 ; \theta_{M}=48.4^{0}\right)$ are non-cell specific developmental biomarkers.

Conclusions: Based on the findings of this study considered together, the precise mechanistic basis for alterations in chromatin gene transcription eukaryotic stranded heterochromatin arranged by structural pressurotopy nano-compliance in DNA stand loop segments is effective cell pressure $\left(P_{\text {eff }}\right)$ regulated shifting of transcriptionally active DNA in-between the inner nuclear envelope margin and the peripheral nucleoplasm edge and the $z, x$-plane horizontal alignment of a gene by gene specific $P_{\text {eff }}$ within the cell specific effective range of whole cell compliance in reference to tissue macrocompliance. The findings of this study are therefore applicable to the further study of changes in gene transcription in response to applied mechanical strain-mediated alterations in nuclear envelope deformability in silico.

Keywords: Membrane proteins, Lamins, Nuclear pore, Mechanical loading, Substrate stiffness, Viscosity, Growth factor, Small molecule, Stem cell, Cell differentiation

\section{Introduction}

Non-constitutively less active heterochromatin and constitutively more active heterochromatin commonly known as euchromatin are the two forms of eukaryotic euchromatic chromatins [1-5]. Adenine and thymine nucleobase-rich G-banded DNA of heterochromatin binds to less hydrophilic staining dyes such as 4',6-diamidino-2-phenylindole (DAPI; $-4.37 \mathrm{~nm}^{-1}$ ) with cationicity sufficiently separated in space $(1+$ SS $1+)$, whereas guanine and cytosine nucleobase-rich R-banded DNA of constitutive heterochromatin (euchromatin) binds to more hydrophilic dyes such as Oligomycin $\left(-6.75 \mathrm{~nm}^{-1}\right)$ with polyhydroxylated hydrophilicity sufficiently separated in space $(\mathrm{OH}$ SS OH), which is more transcriptionally-active due to protein affinity interactions of the same [5, 6], both of which are loosely wound around the nucleosome core histone proteins in the pressurized state of a cell. Adenine and T-rich G-banded non-constitutive heterochromatin resides in affinity with non-histone polypeptides lamin A/C or B1/B2 [7-13], from which genes are episodically-transcribed in fully-differentiated cells [1-5], in contrast to $\mathrm{G}$ and $\mathrm{C}$-rich R-banded constitutive heterochromatin resides in affinity with nuclear pore complex subunits rather than in affinity with the lamins and lamin-associated proteins, from which regulatory housekeeping genes are transcribed $[1-5,11]$. During the $G_{o}$ resting transcriptionally active cell stage, both of the chromatins are located in one of two locations in the nucleus, either at the inner nuclear membrane-bound to lamins $\mathrm{A} / \mathrm{C}$ or $\mathrm{B} 1 / \mathrm{B} 2$ via lamin-associated polypeptides (LAP) polypeptides (LAP) 1 and 2 isoforms and emerin (EMD), or closer to the center at peripheral edge central nucleoplasm interface during the non-transcription of lamin/lamin-associated polypeptides [14-18], during which there is differential gene transcription [15] in comparison to that at the inner nuclear membrane in apposition to nuclear pore complex subunits [16].

During the DNA synthesis stage [1-3], both forward and reverse strands of early and late-replicating 
chromatins become DNA polymerase substrates when replication forks form at defined intervals resembling radial loops at the inner nuclear membrane [19-22], a process that continues at the nuclear envelope to the point of MKI67 protein expression [23], which is a 359 $\mathrm{kDa} \mathrm{G}_{2}$ interphase enzyme involved in translocation of tetraploid chromatin from the inner nuclear membrane to the nuclear center by mass effect, as the nuclear envelope dissolutes and chromatids align at the metaphase plate. A mass effect mechanism has been suggested for horizontal alignment of DNA during the $\mathrm{S}$ phase is the $900 \mathrm{kDa}$ molecular weight of multi-subunit DNA polymerase during which multiple assembled DNA polymerases simultaneously walk forward $(+)$ or reverse $(-)$ strand intergene segments at replication forks based on recent determinations that during the process of gene transcription the DNA synthesis $\left(\mathrm{S}_{1}\right)$ phase begins when effective cell pressure $\left(P_{\text {eff }}\right)$ increases into the 0.261 to 0.283 (PCNA) pressure units range [24-28].

Nuclear envelope elastance $(E)$ responses to pressure application and alterations in initial envelope elastance to tonicity or dynamic strain over time have been studied by micropipette aspiration techniques in LMNA (-/-) or emerin $(E M D,-/ y)$ gene-deficient cells $(J$, creep compliance; $\mathrm{kpa}^{-1} \cdot \mathrm{sec}^{-1}$; $\alpha$ power) [29-35]; cell morphology alterations in response to grades of substrate stiffness have been studied by spectrophotometry of gel viscoelasticity (G'; Pa) and cell tissue tensional homeostasis by traction force microscopy [36, 37]; and cell mechanosensitivity changes and nuclear deformability alterations in response to mechanical loading during pharmacological application in vitro studied by the chromatin condensation parameter (CCP, \%) and the nucleus deformability index (NDI, \%; NAR, a.u.) [38-41], in addition to differential gene transcription in mesenchymal stem and transformed cells studied in situ by qRT-PCR mRNA expression, based on the findings of which mechanoforce transduction can be defined as downstream molecular signaling events that result in alterations in chromatin gene transcription [28].

It has been recently hypothesized that alterations in cell membrane compliance in relation to mitochondrial membrane compliance results in increases or decreases in effective cell pressure secondary to that alterations in cell membrane compliance by membrane domain-binding of growth factors and small molecule ligand binding to cell surface receptors [24-27]. The modes of cellular pressurization in the biological system in vivo is have been further defined as the combination of (a) synergistic positive macro-pressuromodulation due to the presence of a rigidified extracellular matrix or cortical bone, which increases effective cell pressure, or non-synergistic negative macro-pressuromodulation due to the presence of surrounding cells, which decreases effective cell pressure; and (b) positve or negative micro-pressuromodulation at cell membrane domains by way of endocrine, paracrine and autocrine small molecule hormones, growth factors and cytokines, which either increases or decreases effective cell pressure. Therefore, the effective cell pressure for horizontal alignment of gene tropy and maximal gene transcription is related to cell compliance by Compliancecell membrane micro-pressuromulation + Elastance $_{\text {cell membrane integ- }}$ rin-to-collagen or sub-cortical bone macro-pressuromodulation Pressure $_{\text {effective intracellular }}=\mathrm{k}$ during synergistic macro-

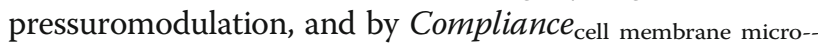

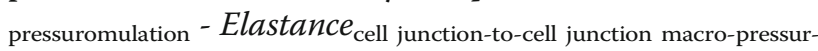

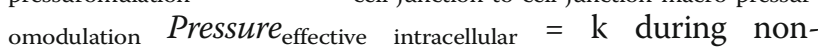
synergistic macro-pressuromodulation, where $P_{\text {effective intra- }}$ cellular $\left(P_{\text {eff }}\right)=P_{\text {effective intranuclear }}$.

A fractional measure has been recently developed to quantify the effective intracellular pressure required to horizontally align a gene for its maximal transcription, as there are non-specific avidity associations of nuclear protoplasm proteins and non-coding RNAs in a tropic manner with the intergene segment bases of genes located upstream and downstream with respect to a gene; and represents the $5^{\prime} \rightarrow 3^{\prime}$ reading direction intergene distance tropy that needs to be overcome for a gene to horizontally align for transcription and has a specificity and sensitivity of $100 \%$ as validated [25]. This measure, the episodic sub-episode block sums split-integrated weighted average-averaged gene overexpression tropy quotient (esebssiwaago $T_{\mathrm{Q}}$ ). The esebssiwaago $T_{\mathrm{Q}}$, a physical property of a gene, is less than 0.245 units for infra-pressuromodulated anisotropic genes, and in between 0.245 and 0.745 units for supra-pressuromodulated mesotropic genes.

Even as the eukaryotic stranded chromatin has shown to be heterochromatinized to various degrees at the nuclear envelope in response to application of mechanical strain in vitro, the precise mechanistic basis for alterations in chromatin gene transcription in differentiating cell lineages has been difficult to determine due to limited spatial resolution for detection of shifts in reference to specific genes in vitro. Therefore, in this study heterochromatin DNA strand loop structure gene positioning angulation in the $z, y$-vertical plane is studied by segmentation of DNA strand loops in terms of mesotropy and anisotropy utilizing the sebs intercept-to-sebssiwa intercept linearization quotient, $b_{\text {sebs }} / b_{\text {sebssiwa }}$, for validation of linear normalization and the effective cell pressure unit $\left(P_{\text {eff }}\right)$-to-gene angulation conversion factor for gene anglemetry and momentum vectormetry analysis in linear nl two-dimensional (2-D) protoplasmic cell space; henceforth, these normalized heterochromatin gene angulation parameters are applied for determination of the 
esebssiwaago $T_{\mathrm{Q}}$-based pressuromodulation map for gene expression of the subtypes of neuronal cells that constitute the peripheral to central nervous system neuroaxis in correlation with changes in tissue macro-compliance.

\section{Methods}

\section{Selection of genes for study}

Human chromatin forward and reverse strand genes were sampled from 17 of 24 chromosome loci for determination of minima and maxima effective intracellular pressure unit $\left(P_{\text {eff }}\right)$ for the episodic sub-episode block sums split-integrated weighted average-averaged gene overexpression tropy quotient (esebssiwaago $T_{\mathrm{Q}}$ ), $n=224$ [25-27]; the sampled representative genes include ch 14 ( $n=188$, heavy chain immunoglobin locus, native and recombined) [26, 27], ch 1 (PDPN, S100A2, S100A14, CDH11, SELE, CD34, PTPRC and CR2; $n=8)$, ch 2 (TGFA), ch 3 (ACPP), ch 4 (CD38), ch 6 (PRR3, PRDM1, ENPP1), ch 7 (ABCB1, FOXP2), ch 10 (MRC1, MKI67), ch 11 (SORL1, MS4A1, RAG1, RAG2), ch 12 (BTG1, CD27, AICDA, ESPL1), ch 14 (IFI27), ch 16 (CDH11, CD19), ch 17 (CD79B), ch 16 (PHLPP, ZCCHC2), ch 19 (CD79A), ch 20 (CD20, PCNA), ch 22 (APOBEC3A, $A P O B E C 3, A P O B E C 3 H)$ and ch 23-X (DMD) [25-27]. Three different sets of additional genes were selected for study: 1) twenty-eight sequentially located protein coding and non-coding RNA genes in native positions on the Ch $1 \mathrm{q}$ arm forward $(+)$ strand in reference to $L M N A$ for the $P_{\text {eff }}$ esebssiwaago $T_{\mathrm{Q}}$-based sub-analysis study of native intergene base loop segment tropy structure nano-compliance $(n=28) ; 2)$ protein coding genes located on various chromosomes and overexpressed during cell differentiation were selected for $P_{\text {eff }}$ esebssiwaago $T_{\mathrm{Q}}$-based sub-analysis study of gene angulation positioning in the linear normalized $z, y$-vertical plane and momentum vectormetry to the $z, x$-horizontal plane $(n=28)$, and include genes involved in cell membrane adhesion (CD34, CEACAM1), cell membrane ligand binding (INSL3, ENPP1), extracellular matrix formation (COL1A1, COL2A1, COL6A1, CCN2), cell cycle regulation (RGS13, RGS4, RGS1), inner nuclear envelope matrix stabilization (LMNA, LMNB1, LMNB2, EMD, NUMA1), transcriptional regulation (MYC, JUND, SOX18, PRKCH, EGR1, ESRRB, GABPA, NFE2L2), NFkB survival pathway (IER3), oxygen sensing (CYGB), and in B-cell function (PRDM1, MIR4537); and 3) protein coding genes located on various chromosomes and overexpressed during central-to-peripheral neural cell differentiation were selected for predictive sub-analysis study of neural axis gene overexpression in reference to tissue macrocompliance by esebssiwaago $T_{\mathrm{Q}}$-based effective intracellular pressure units $(n=14)$, and include genes involved in neurotransmitter ligand binding (DRD1, DRD2, DRD3,
GRIN1), synaptic cleft stabilization (UNC13A, SHANK2), cell cycle regulation (RGS21, RGS2, RGS16, RGS18), nuclear RNA splicing (RBFOX3), transcriptional regulation (SOX1, SOX14), and in oxygen sensing (NGB).

Gene locus coordinates were mined as per the GRch38/hg38 gene location classification system at Gene Cards (https://www.genecards.org) and LNCipedia (https://lncipedia.org). Genes were stratified by gene locus episode and initial sub-episode block structure (SEB) as either Episode 2 (> 11,864 $\leq 265,005$ bases; 5 SEB), Episode $3(\leq 11,864 ; 7 \mathrm{SEB})$ and for Episode $4(>265$, $005<607,463 ; 9$ SEB), Episode 5 ( $\geq 607,463<2,242$, 933; $11 \mathrm{SEB})$ or Episode 6 ( $\geq 2,242,933 ; 13 \mathrm{SEB})$ to determine the initial sub-episode block structure count for determination of the episodic sub-episode block sums split-integrated weighted average-averaged gene overexpression tropy quotient were determined [25-27].

\section{Determination of native gene location intergene base segment loop tropy and strand loop structure in reference to $L M N A$}

The sequentially located gene locus gene loop segment tropies in reference to $L M N A$ on ch 1q22 (+) for sub-group structural analysis included DAP3, MSTO2P, PIR32612, LOC100132108, SYT11, GC01P155896, lnc-RXFP4-5, RXFP4, lnc-RXFP4-2, ENSG00000224276 / LOC105371729, GC01P156042 (LAMTOR2), RAB25, LMNA, SEMA4A, SLC25A44, PMF1BGLAP, TMEM79, TSACC, RHBG, ENSG00000237390, lncTTC24-5, Inc-TTC24-4, ENSG00000260460, Inc-TTC24-1, GC01P156524, TTC24, NAXE, HALPN2 and BCAN from 5' to 3 ' end $(n=28)$.

The esebssiwaago $T_{\mathrm{Q}}$-based $\Sigma$ intergene base segment tropy was determined as the integrated upstream part anisotropic sub-episode block sum (uppasebs), downstream part anisotropic sub-episode block sum ( sebs), the upstream part mesotropic sub-episode block sum (uppmsebs) and the downstream part anisotropic sub-episode block sum (dppasebs) by the final sequentially integrated $(\delta)$ paired point tropy quotient $\left(\operatorname{prp} T_{\mathrm{Q}}\right)$ point of final sub-episode block structure based on which the gene intergene base segment loop structure was determined in terms of segmental anisotropy, segmental mesotropy or segmental amorphousosity for the respective genes in native configuration in reference to the $L M N A$ gene locus.

\section{Determination of the linearization quotient for $z, y$-plane gene anglemetry by exponential function plotting of sebs and sebssiwa}

Genes selected for sub-group analysis anglemetry include episode $2(n=14)$, episode $3(n=11)$, episode 4 $(n=2)$ and episode $6(n=1), n=28$. Episode 2 genes selected for sub-group study include (ch, strand) $L M N A$ (1q22, +), RGS13 (1q31.2, +), CD34 (1q32.2, -), LMNB1 
(5q23.2, +), PRDM1 (6q21, +), ENPP1 (6q23.2, +), NUMA1 (11q13.3-q13.4, -), COL2A1 (12q13.11, -), ESRRB (14q24.3, +), COL1A1 (17q21.33, -), CYGB (17q25.1, -), CEACAM1 (19q13.2, -), GABPA (21q21.3, +) and COL6A1 (21q22.3, +); episode 3 genes selected for sub-group study include RGS4 (1q23.3, +), RGS1 (1q31.2, +), EGR1 (5q31.2, +), IER3 (6q21.33, -), CCN2 (6q23.2, -), MYC (8q24.21, +), MIR4537 (14q32.3, -), INSL3 (19q13.11, -), JUND (19q13.11, -), SOX18 (20q13.33, -) and EMD (Xq28, +); the episode 4 genes selected for sub-group study include LMNB2 (19q13.3, -) and PRKCH (14q32.2, +); and the episode 6 gene(s) selected for sub-group study include NFE2L2 (2q31.2, -).

The esebssiwaago $T_{\mathrm{Q}}$-based uppasebs, dppasebs, uppmsebs, and dppasebs and the correlate upstream part anisotropic sub-episode block sum split integrated weighted average (uppasebssiwa), downstream part anisotropic sub-episode block sum split integrated weighted average (dppasebssiwa), the upstream part mesotropic sub-episode block sum split integrated weighted average (uppmsebssiwa), and the downstream part anisotropic sub-episode block sum split integrated weighted average (dppasebssiwa) were determined. The $y$-intercept exponential function for each sub-group analysis gene locus sub-episode block sum (sebs; upstream part, upp; downstream part, $d p p$ ) and sub-episode block sum split integrated weighted average (sebssiwa; upstream, downstream) was plotted $\left(x_{1}, y_{1}\right.$; $x_{2}, y_{2}$ ) for determination of the normalized uppasebs, uppmsebs::uppasebssiwa, uppmsebssiwa effect; the $x$ intercept plot was utilized for determination of the normalized dppasebs, dppmsebs::dppasebssiwa, dppmsebssiwa effect when the uppasebs and uppmsebs sums parteffect was equivalent; and a hybrid intercept plot was utilized in case of equivalent magnitude ratio uppasebs : dppasebs and uppmsebs : dppmsebs sums part-effects. Each function is represented in form, $b \cdot \mathrm{e}^{m \cdot \mathrm{x}}$, where $b$ represents the downstream anisotropic effect. The $y$ - or $x$ sebs intercept to sebssiwa intercept quotient for linearization was determined in form, $b_{\text {sebs }} / b_{\text {sebssiwa }}$. The sub-episode block sum (sebs) - sub-episode block sum split integrated weighted average (sebssiwa) was determined as the normalized subtractive residual for each function, adjusted residual.

\section{3-tier pairwise statistical comparison of $b_{\text {sebs }} / b_{\text {sebssiwa }}$ linearization quotients and sebs - sebssiwa residuals by esebssiwaago $T_{\mathrm{Q}}$ stratum}

Sub-group analysis genes were stratified by $P_{\text {eff }}$ interval in $\leq 0.200,>0.200 \leq 0.300$ and $>0.300$ tiers for pairwise comparisons of the $b_{\text {sebs }} / b_{\text {sebssiwa }}$ intercept linearization quotient and subtractive residual determinations of uppasebs, dppasebs, uppmsebs, dppmsebs and correlate uppasebssiwa, dppasebssiwa, uppmsebssiwa, dppmsebssiwa as independent sums and averages for genes with non-nil residual normalizing adjustments. Two-step Tukey range t-test was performed for inter-group comparisons of $b_{\text {sebs }} / b_{\text {sebssiwa }}$ quotients and sebs - sebssiwa normalized residuals between tier $1\left(P_{\text {eff }} \leq 0.200 ; n=11\right)$ and tier $2\left(P_{\text {eff }}>0.200 \leq 0.300 ; n=6\right)$, between tier 1 and tier $3\left(P_{\text {eff }}>0.300 ; n=8\right)$, and between tier 3 and tier $2(\alpha=0.05)$; likewise comparisons were performed for determination of differences in $\Sigma$ intergene tropy between the tiers $(\alpha=0.05)$.

Determination of the effective pressure unit quotient to angle conversion factor gene anglemetry from the $z, y$ vertical to $z, x$-horizontal plane

The pressure unit to angle conversion factor was determined in reference to the $z, x$-axis horizontal plane and two-dimensional gene anglemetry analysis was performed for the sub-group analysis genes $(n=28 ; n=14)$. The $\Theta_{\mathrm{A}}=(1 \mathrm{E}+02)\{0.90-[(0.000+a \geq x<0.245)$ (1.208)] form was applied for anisotropic gene anglemetry, where $a$ is the minimum pressure for anisotropic gene expression, and the $\Theta_{M}=(1 \mathrm{E}+02)\{0.90-[1.208$ $(0.245 \geq x \leq m)$ ] form was applied for mesotropic gene anglemetry, where $m$ is the maximum pressure for mesotropic gene expression $(n=224)$, based on linear regression of the esebssiwaago $T_{\mathrm{Q}} \mathrm{s}$ of the gene set of the study $\left(R^{2}=1\right)$. Gene position arc distance in the $z, y$-vertical plane in reference to the $z, x$-horizontal plane was defined for anisotropic and mesotropic genes based on gene anglemetry thetas, $\Theta_{\mathrm{A}}$ and $\Theta_{M}$. The hypotenusal intergene tropy base distance for anisotropic genes was then defined as $d_{\mathrm{A}}$ for anisotropic genes, and as $d_{\mathrm{M}}$ for mesotropic genes, in which case $d$ is the final sub-episode block sum of intergene tropy base distance for anisotropic genes (ASEB) or for mesotropic genes (MESEB). The $\Sigma$ intergene base tropy distance is defined in reference to the horizontal line of unity $\left(H_{0}\right)$ as either $d_{\mathrm{A}} \cdot \sin$ $\Theta_{\mathrm{A}}$ for anisotropic genes and as $d_{\mathrm{M}} \cdot \sin \Theta_{\mathrm{M}}$ for mesotropic genes, wherein the arc gene tropy intergene base distance is definable as $d_{M} \cdot \sin \Theta_{M}$ in reference to the line of unity; and wherein the $\Sigma$ hypotenusal gene intergene tropy distance $d_{\mathrm{A}}$ (or $d_{\mathrm{M}}$ ) is defined as a non-component scalar at $H_{0}=0^{\circ}$ in which case $d_{\mathrm{A}}$

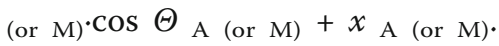

\section{Vectormetry for $z$, x-plane horizontal alignment of anisotropic and mesotropic genes}

Vectormetry for horizontal alignment of anisotropic and mesotropic genes was performed empirically for anisotropic and mesotropic genes based on the $z, y$-vertical plane position angle, $\Theta_{\mathrm{A}}$ for anisotropic genes and $\Theta_{M}$ for mesotropic genes, and effective cell pressure $\left(P_{\text {eff }}\right)$ for horizontal alignment, $P_{\text {eff }}(0.000+a \geq x<0.245)$ for anisotropic and $P_{\text {eff }}(0.245 \geq x \leq 0.745-m)$ for 
mesotropic. Defined knowns were applied for vectormetry, where momental vector, $\boldsymbol{m}$, is a product of the mass of DNA-associated nuclear proteins $(\mathrm{m})$ and the velocity of gene tropy to horizontal (v). The origination momentum vector for chromatin-associated protein viscosity at intergene segment effect was then defined as $\boldsymbol{m}_{\mathrm{ch}}$ tropy; the initial origination momentum vector for nuclear membrane nucleoplasm chromatin-associated protein viscosity at intergene segment effect was then defined as $\boldsymbol{m}_{\mathrm{ch}} \mathrm{nmn}$ tropy; and the origination gravitational momentum vector was then defined as $\boldsymbol{m}_{\text {pro-grav ch tropy }}$ The effective momentum, $\boldsymbol{m}_{\text {eff, }}$ for $z$, $x$-horizontal plane alignment of anisotropic gene tropy was then defined, $\boldsymbol{m}_{\mathrm{A}}\left(\boldsymbol{m}_{\mathrm{ch}}\right.$ tropy $\left.-\boldsymbol{m}_{\text {pro-grav ch tropy }}\right)$; and the effective momentum for $z$, $x$-horizontal plane alignment of mesotropic gene tropy was then defined, $\boldsymbol{m}_{\mathrm{M}}\left[\boldsymbol{m}_{\mathrm{ch}}\right.$ tropy + $\boldsymbol{m}_{\mathrm{ch}}$ nmn tropy $\left.\left(-\boldsymbol{m}_{\text {pro-grav ch tropy }}\right)\right]$. The relationship between effective pressure $\left(\boldsymbol{P}_{\text {eff }}\right)$ and momentum $\left(\boldsymbol{m}_{\text {eff }}\right)$ was definable for anisotropic gene horizontal alignment $\left(\boldsymbol{m}_{\mathrm{A}}\right)$ and mesotropic gene horizontal alignment $\left(\boldsymbol{m}_{\mathrm{M}}\right)$.

\section{Determination of the heterochromatinization parameters for neural axis cell differentiation genes}

Genes selected for sub-group analysis include episode $2(n=5)$, episode $3(n=5)$ and episode 4,5 or $6(n=4)$, $n=14$. Episode 2 genes selected for sub-group study include (ch, strand) UNC13A (19p13.11, -), RGS21 (1q31.2, +), SOX1 (13q34, +), DRD2 (11q23.2, -), GRIN1 $(9 \mathrm{q} 34.3,+)$; episode 3 genes selected for sub-group study include NGB (14q24.3, -), RGS2 (1q31.2, +), RGS16 (1q23.3, -), SOX14 (3q22.3, +), DRD1 $(5 \mathrm{q} 35.2,+)$ and EGR1 $(5 \mathrm{q} 31.2,+)$; the Episode 4 genes selected for subgroup study include RGS18 (1q31.2, +) and DRD3 (3q13.31, -); and the Episode 5 to 6 genes selected for sub-group study include RBFOX3 (17q25.3, -) and SHANK2 (11q13.3-q13.4, -).

The uppasebs, dppasebs, uppmsebs, dppasebs, uppasebssiwa, dppasebssiwa, uppmsebssiwa and dppasebssiwa were determined as per the esebssiwaago $T_{\mathrm{Q}}$ method and its adjusted residual $\left(x_{1}, y_{1} ; x_{2}, y_{2}\right)$. The exponential function pair was $y$-intercept or reverse $x$-intercept plotted for determination of the sebs-to-sebssiwa intercept linearization quotient $\left(b_{\text {sebs }} / b_{\text {sebssiwa }}\right)$. The uppesebssiwaaldppesebssiwaa quotient effective intracellular pressure $\left(P_{\text {eff }}\right)$ was then determined for classifying of predicted gene overexpression of the genes selected for neural axis cell differentiation. Two-dimensional gene anglemetry analysis was performed for the mesotropic and anisotropic gene set by effective pressure for gene expression for determination of gene position in the $z, y$-vertical plane position angle $\left(\Theta_{A}, \Theta_{M}\right)$. The tropy of the intergene base segments and interposed gene segment bases was determined as the hypotenusal $\Sigma$ gene intergene base segment tropy for $z, y$-plane to $z, x$-horizontal plane alignment.

\section{Results}

Sequentially located forward strand native genes in $5^{\prime} \rightarrow$ $3^{\prime}$ chronology on ch $1 \mathrm{q} 22$ in reference to $L M N A$ by $P_{\text {eff }}$ esebssiwaago $T_{\mathrm{Q}}$ units

$D A P 3$ is a 2 A 5 initial and final SEB gene locus with a $\Sigma$ intergene base segment tropy of $3.09108 \mathrm{E}+05$ bases at position -12. Sequential integration $\left(\int\right)$ to the final esebssiwaggo $_{\mathrm{Q}}$ for DAP3 is $0.093,0.157,0.210,0.247$. The final uppesebssiwaa and dppesebssiwaa for DAP3 are $1.1196 \mathrm{E}+04$ and $4.7835 \mathrm{E}+04$ intergene bases. The $P_{\text {eff }}$ for gene locus DAP3 is 0.234 esebssiwaago $T_{\mathrm{Q}}$ units.

$M S T O 2 P$ is a $3 \mathrm{M} 7$ initial and final SEB gene locus with a $\Sigma$ intergene base segment tropy of $5.94486 \mathrm{E}+05$ bases at position -11 . Sequential integration $(\delta)$ to the final esebssiwaago $T_{\mathrm{Q}}$ for $M S T O 2 P$ is $0.680,0.417,0.358,0.340$, $0.309,0.269$ (DfC). The final uppesebssiwaa and dppesebssiwaa for MSTO2P are 1.8354E + 04 and 6.7448E + 04 intergene bases. The $P_{\text {eff }}$ for gene locus $M S T O 2 P$ is 0.272 esebssiwaago $T_{\mathrm{Q}}$ units (Table 1; Figs. 1, 2 and 3).

PIR32612 is a 3 A 7 initial and final SEB gene locus with a $\Sigma$ intergene base segment tropy of $5.26775 \mathrm{E}+05$ intergene bases at position - 10 . Sequential integration $(\delta)$ to the final esebssiwaago $T_{\mathrm{Q}}$ for PIR32612 is $0.0002,0.242$, $0.261,0.247,0.279,0.248$. The final uppesebssiwaa and dppesebssiwaa for PIR32612 are 1.3367E + 04 and 5.8380E +04 intergene bases. The $P_{\text {eff }}$ for gene locus PIR32612 is 0.229 esebssiwaago $T_{\mathrm{Q}}$ units (Table 1; Figs. 1, 2 and 3).

LOC100132108 is a 3 A 7 initial and final SEB gene locus with a $\Sigma$ intergene base segment tropy of $5.82948 \mathrm{E}$ +05 intergene bases at position -9. Sequential integration $(\delta)$ to the final esebssiwaago $T_{\mathrm{Q}}$ for $L O C 100132108$ is $0.262,0.357,0.258,0.198,0.225,0.205$. The final uppesebssiwaa and dppesebssiwaa for LOC100132108 are $1.4504 \mathrm{E}+04$ and $6.8778 \mathrm{E}+04$ intergene bases. The $P_{\text {eff }}$ for gene locus $L O C 100132108$ is $0.211{\text { esebssiwaago } T_{\mathrm{Q}}}$ units (Table 1; Figs. 1, 2 and 3).

SYT11 is a 2 A 5 initial and final SEB gene locus with a $\Sigma$ intergene base segment tropy of $4.15371 \mathrm{E}+05$ intergene bases at position -8. Sequential integration $(\delta)$ to the final esebssiwaago $T_{\mathrm{Q}}$ for $S Y T 11$ is $0.166,0.401$, $0.333,0.266$. The final uppesebssiwaa and dppesebssiwaa for SYT11 are 1.8089E + 04 and 6.7250E + 04 intergene bases. The $P_{\text {eff }}$ for gene locus SYT11 is 0.269 esebssiwaago $T_{\mathrm{Q}}$ units (Table 1; Figs. 1, 2 and 3).

GC01P155896 is a 3 A $7(+1)$ ACM final SEB gene locus with a $\Sigma$ intergene base segment tropy of 1.201927E + 06 intergene bases at position -7. Sequential integration $(\delta)$ to the final esebssiwaago $T_{\mathrm{Q}}$ for GC01P155896 is $0.188,0.330,0.205,0.198,0.144$, $0.138,0.131$. The final uppesebssiwaa and dppesebssiwaa for GC01P155896 are 1.8900E + 04 and $1.31341 \mathrm{E}+05$ intergene bases. The $P_{\text {eff }}$ for gene locus GC01P155896 is 0.144 esebssiwaago $T_{\mathrm{Q}}$ units (Table 1; Figs. 1, 2 and 3). 


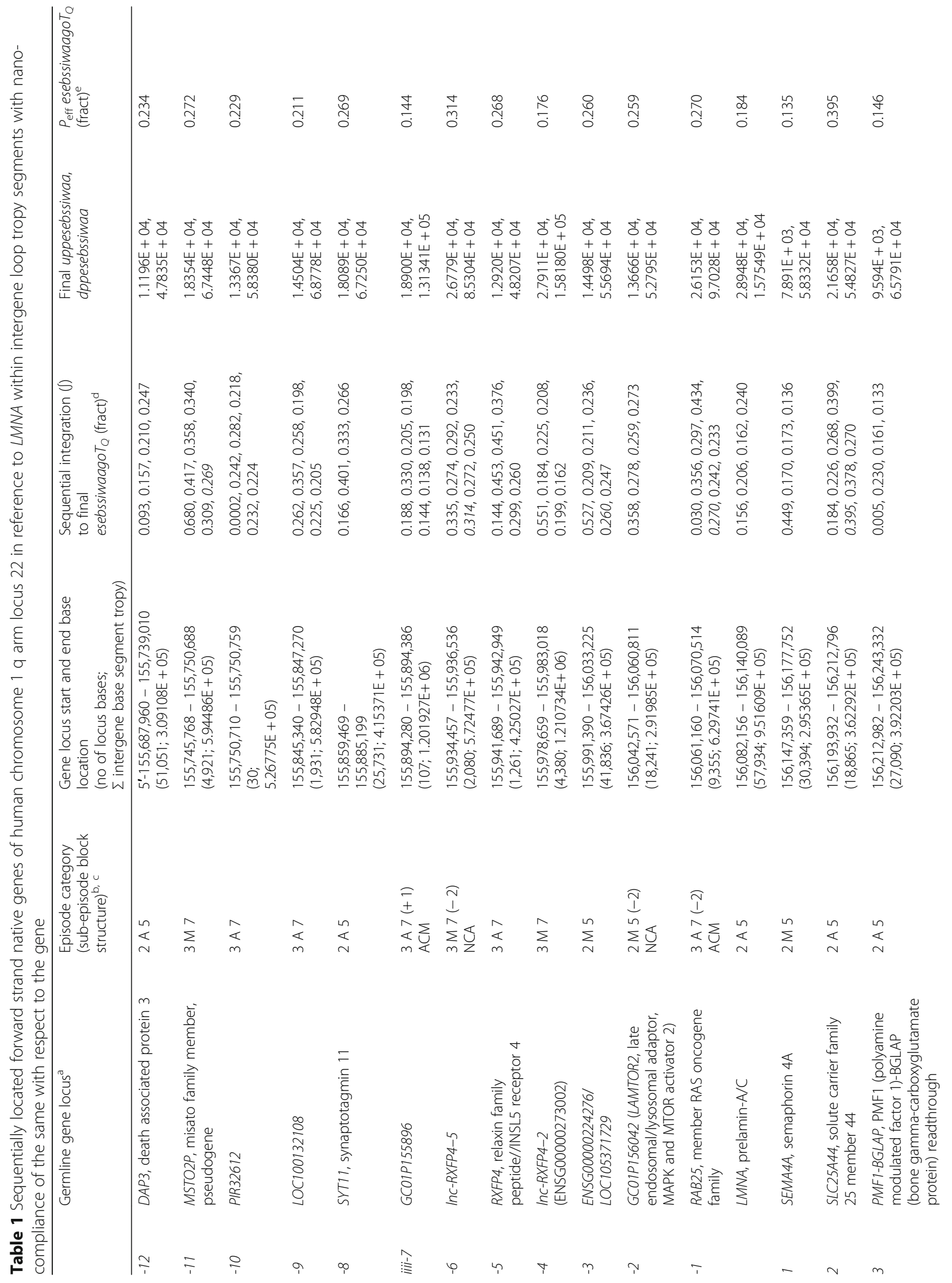




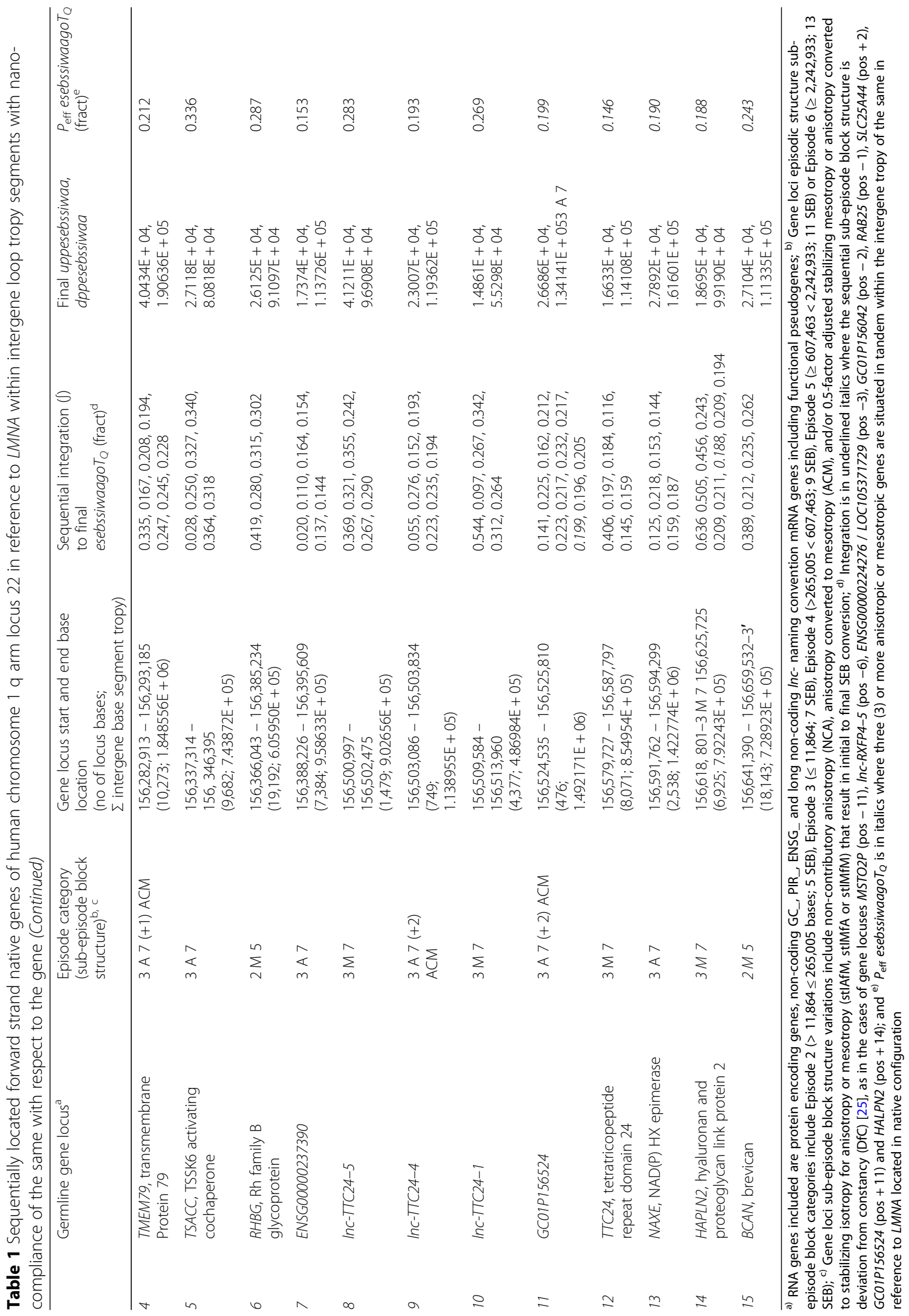




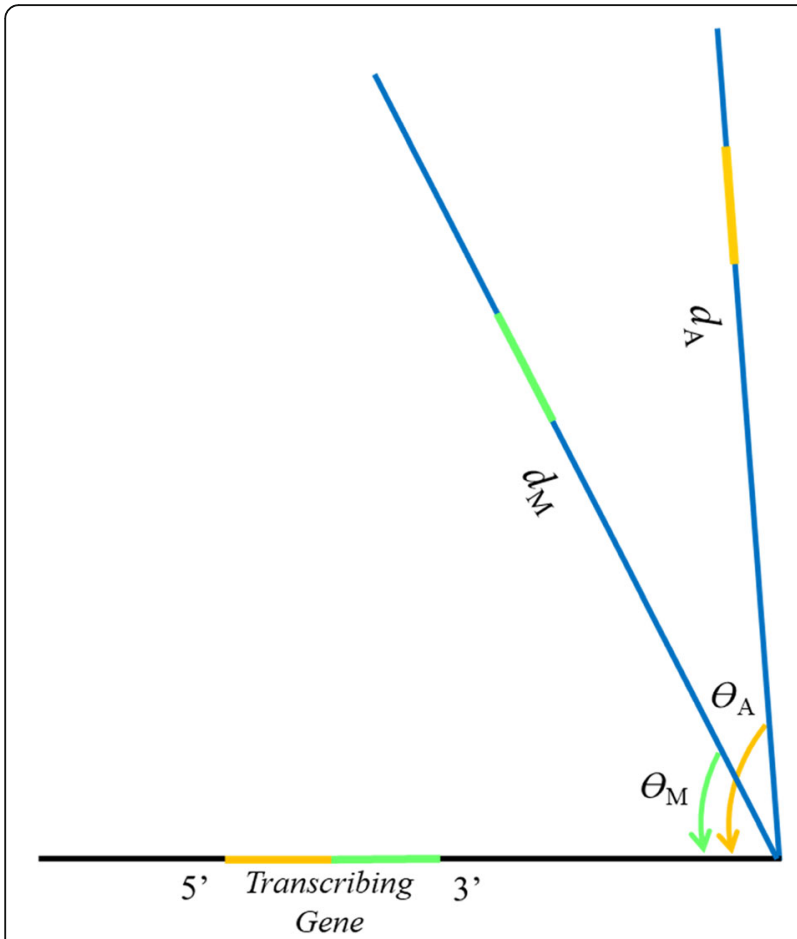

Fig. 1 Angulation of intergene base arc distance tropy in reference to the $z, x$-axis horizontal plane for amorphous heterochromatin loop segment genes. Amorphous heterochromatin strand loop micro-structural segmentation is a series of intergene base distanceseparated alternating anisotropic (a) and mesotropic genes $(m)$ in the form of one or two in-tandem anisotropic or mesotropic genes of the same at angulation $\left(\Theta_{A}, \Theta_{M}\right)$ in the $z, y$-vertical axis plane. The prelamin-A/C gene ( $\left.P_{\text {eff }}, 0.184\right)$-containing amorphous form heterochromatin strand loop segment for example is arranged as LMNA $\left(\Theta_{\mathrm{A}}=67.8^{\circ}\right)$-SEMA4A $\left(\Theta_{\mathrm{A}}=73.7^{\circ}\right)$-SLC25A44 $\left(\Theta_{\mathrm{M}}=42.3^{0}\right)$-PMF1$\operatorname{BGLAP}\left(\Theta_{\mathrm{A}}=72.4^{0}\right)-$ TMEM79 $\left(\Theta_{\mathrm{A}}=64.4^{0}\right)-$ TSACC $\left(\Theta_{\mathrm{M}}=49.4^{0}\right)-R H B G$ $\left(\Theta_{M}=55.3^{\circ}\right)$ in series from $5^{\prime}$ to $3^{\prime}$ on human ch $1 \mathrm{q} 22$ at positions +1 through +6 in reference to LMNA. As shown is an anisotropic gene within its hypotenusal gene intergene base distance tropy positioned at angulation, $\Theta_{\mathrm{A}} \leq 82.3^{\circ}$ in the $z, y$-vertical plane with $\Sigma$ gene + intergene base distance, $d_{\mathrm{A}} \cdot \sin \Theta_{\mathrm{A}}$, juxtaposed to a mesotropic gene within its hypotenusal gene intergene base distance tropy positioned at angulation, $\Theta_{M} \geq 11.7^{\circ}$, from the horizontal line of unity in a heterochromatin strand amorphous form loop segment. A transcribable gene can be either an anisotropic segment loop gene $\left(\Theta_{A}\right)$ or a mesotropic gene segment loop gene $\left(\Theta_{M}\right)$ in an amorphous segment loop of alternating in-tandem genes. Legend. $d_{A}$, hypotenusal distance of anisotropic gene intergene tropy bases; $d_{\mathrm{M}}$, hypotenusal distance of mesotropic gene intergene tropy bases. Note: 3', downstream

lnc-RXFP4-5 is a 3 M 7 (-2) NCA final SEB gene locus with a $\Sigma$ intergene base segment tropy of 5.72477E +05 intergene bases at position -6. Sequential integration $\left(\int\right)$ to the final esebssiwaago $T_{\mathrm{Q}}$ for $\operatorname{lnc}-R X F P 4-5$ is $0.335,0.274,0.292,0.233,0.314$ (DfC), 0.272, 0.250 . The final uppesebssiwaa and dppesebssiwaa for lncRXFP4-5 are 2.6779E + 04 and 8.5304E + 04 intergene bases. The $P_{\text {eff }}$ for gene locus lnc-RXFP4-5 is 0.314 esebssiwaago $T_{\mathrm{Q}}$ units (Table 1; Figs. 1, 2 and 3).
RXFP4 is a 3 A 7 initial and final SEB gene locus with a $\Sigma$ intergene base segment tropy of $4.25027 \mathrm{E}+05$ intergene bases at position -5 . Sequential integration $(\delta)$ to the final esebssiwaago $T_{\mathrm{Q}}$ for RXFP4 is $0.144,0.453$, $0.451,0.376,0.299,0.260$. The final uppesebssiwaa and dppesebssiwaa for RXFP4 are 1.2920E + 04 and 4.8207E +04 intergene bases. The $P_{\text {eff }}$ for gene locus RXFP4 is 0.268 esebssiwaago $T_{\mathrm{Q}}$ units (Table 1; Figs. 1, 2 and 3).

lnc-RXFP4-2 is a 3 M 7 initial and final SEB gene locus with a $\Sigma$ intergene base segment tropy of $1.210734 \mathrm{E}+$ 06 intergene bases at position -4 . Sequential integration $\left(\int\right)$ to the final esebssiwaago $T_{\mathrm{Q}}$ for $\operatorname{lnc}-\mathrm{RXFP4-2}$ is 0.551 , $0.184,0.225,0.208,0.199,0.162$. The final uppesebssiwaa and dppesebssiwaa for lnc-RXFP4-2 are 2.7911E + 04 and $1.58180 \mathrm{E}+05$ intergene bases. The $P_{\text {eff }}$ for gene locus $\operatorname{lnc-RXFP4}$ is 0.176 esebssiwaago $T_{\mathrm{Q}}$ units (Table 1; Figs. 1, 2 and 3).

ENSG00000224276 / LOC105371729 is a 2 M 5 initial and final SEB gene locus with a $\Sigma$ intergene base segment tropy of $3.67426 \mathrm{E}+05$ intergene bases at position -3 . Sequential integration $(\delta)$ to the final esebssiwaago $T_{\mathrm{Q}}$ for ENSG00000224276 / LOC105371729 is 0.527, 0.209, 0.211, $0.236,0.260$ (DfC), 0.247. The final uppesebssiwaa and dppesebssiwaa for ENSG00000224276 / LOC105371729 are $1.4498 \mathrm{E}+04$ and $5.5694 \mathrm{E}+04$ intergene bases. The $P_{\text {eff }}$ for gene locus ENSG00000224276/LOC105371729 is 0.260 esebssiwaago $T_{\mathrm{Q}}$ units (Table 1; Figs. 1, 2 and 3).

GC01P156042 (LAMTOR2) is a 2 M 5 (-2) ACM final SEB gene locus with a $\Sigma$ intergene base segment tropy of $2.91985 \mathrm{E}+05$ intergene bases at position -2 . Sequential integration $(\delta)$ to the final esebssiwaago $T_{\mathrm{Q}}$ for GC01P156042 (LAMTOR2) is 0.358, 0.278, 0.259 (DfC), 0.273 . The final uppesebssiwaa and dppesebssiwaa for GC01P156042 (LAMTOR2) are 1.3666E + 04 and $5.2795 \mathrm{E}+04$ intergene bases. The $P_{\text {eff }}$ for gene locus GC01P156042 (LAMTOR2) is 0.259 esebssiwaago $T_{\mathrm{Q}}$ units (Table 1; Figs. 1, 2 and 3).

$R A B 25$ is a 3 A 7 (-2) ACM final SEB gene locus with a $\Sigma$ intergene base segment tropy of $6.29741 \mathrm{E}+05$ intergene bases at position - 1 . Sequential integration $(\delta)$ to the final esebssiwaago $T_{\mathrm{Q}}$ for $R A B 25$ is $0.030,0.356$, $0.297,0.434,0.270$ (DfC), 0.242, 0.233. The final uppesebssiwaa and dppesebssiwaa for RAB25 are 2.6153E + 04 and $9.7028 \mathrm{E}+04$ intergene bases. The $P_{\text {eff }}$ for gene locus $R A B 25$ is 0.270 esebssiwaago $T_{\mathrm{Q}}$ units (Table 1; Figs. 1, 2 and 3).

$L M N A$ is a 2 A 5 initial and final SEB gene locus with a $\Sigma$ intergene base segment tropy of $9.51609 \mathrm{E}+05$ intergene bases at position 0 . Sequential integration $(\delta)$ to the final esebssiwaago $T_{\mathrm{Q}}$ for $L M N A$ is $0.156,0.206,0.162$, 0.240 . The final uppesebssiwaa and dppesebssiwaa for $L M N A$ are $2.8948 \mathrm{E}+04$ and $1.57549 \mathrm{E}+04$ intergene bases. The $P_{\text {eff }}$ for gene locus $L M N A$ is 0.184 esebssiwaago $T_{\mathrm{Q}}$ units (Table 1; Figs. 1, 2 and 3). 


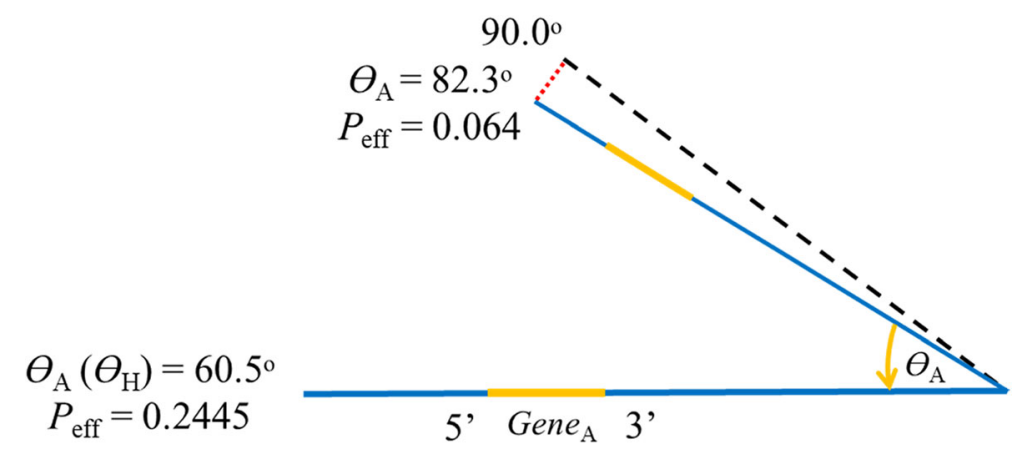

Fig. 2 Angulation of intergene base arc distance tropy in reference to the $z, x$-axis horizontal plane for anisotropic heterochromatin loop segment genes. Anisotropic heterochromatin strand loop micro-structural arrangement is a series of $\geq 3$ intergene base distance-separated genes perceiving the asymmetric tropy viscosity effect with nano-compliance of the same, $\Theta_{\mathrm{A}}$, IncRNA class gene GC01P156524 ( $\left.P_{\text {eff, }} 0.199\right)$-containing anisotropic form heterochromatin strand loop segment for example is arranged as GC01P156524 $\left(\Theta_{\mathrm{A}}=66^{\circ}\right)-\operatorname{TTC24}\left(\Theta_{\mathrm{A}}=72.4^{\circ}\right)-N A X E\left(\Theta_{\mathrm{A}}=67.0^{0}\right)$ HALPN2 $\left(\Theta_{A}=67.3^{\circ}\right)$-BCAN $\left(\Theta_{A}=60.6^{\circ}\right)$ in series from $5^{\prime}$ to $3^{\prime}$ on human ch 1 q22 at positions +11 through +15 in reference to LMNA. As shown is a gene of an anisotropic heterochromatin segment loop positioned at $\Theta_{A}=60.49^{\circ}\left(P_{\text {eff }}, 0.2445\right)$ in the $z, y$-axis plane is transcriptionally active at $\Theta_{\mathrm{A}}=\Theta_{\mathrm{H}}$, and ch 14q32.3 reverse strand (-) IGH_ immunoglobin heavy chain locus gene, MIR4537, positioned at the upper limit of angulation $\Theta_{\mathrm{A}}$ $=82.3^{\circ}$, aligns for $z, x$-horizontal plane transcription at a $P_{\text {eff }}=0.064$ esebssiwaago $T_{\mathrm{Q}}$ units. Legend. $\Theta_{\mathrm{H}}$, zero degree horizontal axis line of unity; $d_{A}$, hypotenusal distance of anisotropic gene intergene tropy bases; $d_{A} \sin \Theta_{A}$, distance to horizontal for anisotropic gene intergene tropy distance; $d_{\mathrm{A}}$ at $H_{0}=0^{0}, d_{\mathrm{A}} \cdot \cos \Theta_{\mathrm{A}}+x_{\mathrm{A}} ; P_{\text {effective intracellular pressure }}\left(P_{\text {eff }}\right)=P_{\text {effective intranuclear pressure }}$

SEMA4A is a 2 M 5 initial and final SEB gene locus with a $\Sigma$ intergene base segment tropy of $2.95365 \mathrm{E}+05$ intergene bases at position +1 . Sequential integration $\left(\int\right)$ to the final esebssiwaago $T_{\mathrm{Q}}$ for $S E M A 4 A$ is $0.449,0.170$, 0.173 . The final uppesebssiwaa and dppesebssiwaa for SEMA4A are $7.891 \mathrm{E}+03$ and $5.8332 \mathrm{E}+04$ intergene bases. The $P_{\text {eff }}$ for gene locus for SEMA4A is 0.135 esebssiwaago $T_{\mathrm{Q}}$ units (Table 1; Figs. 1, 2 and 3).

SLC25A44 is a 2 A 5 initial and final SEB gene locus with a $\Sigma$ intergene base segment tropy of $3.62292 \mathrm{E}+05$ intergene bases at position +2 . Sequential integration $(\delta)$ to the final esebssiwaago $T_{\mathrm{Q}}$ for $S L C 25 A 44$ is 0.184 ,

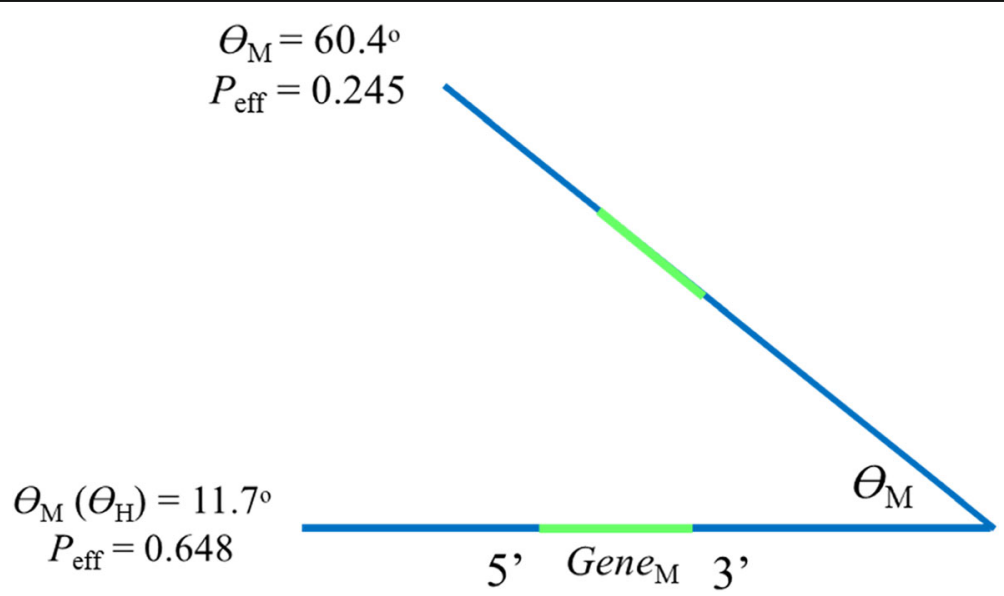

Fig. 3 Angulation of intergene base arc distance tropy in reference to the $z, x$-axis horizontal plane mesotropic heterochromatin loop segment genes. Mesotropic heterochromatin strand loop micro-structural arrangement is a series of $\geq 3$ intergene base distance-separated genes perceiving the lesser grade asymmetric tropy viscosity effect with nano-compliance of the same, $\Theta_{M}$. RNA/ncRNA class gene locus ENSG00000224276 / LOC105371729 ( $P_{\text {eff, }}$ 0.260)-containing mesotropic form heterochromatin strand loop segment consisting of three genes inseries is arranged as ENSG00000224276 / LOC105371729 $\left(\Theta_{M}=58.6^{\circ}\right)$-GC01P156042 (LAMTOR2) $\left(\Theta_{M}=58.7^{\circ}\right)-R A B 25\left(\Theta_{M}=57.4^{\circ}\right)$ from $5^{\prime}$ to $3^{\prime}$ on the forward (+) strand of human ch 1q22 at positions -3 through -1 in reference to LMNA; and the heavy chain immunoglobin gene locus (IGH_) containing mesotropic form heterochromatin strand loop segment consisting of 8 diversity genes in-series is arranged as $1 G H D 1-20(n f)\left(\Theta_{\mathrm{M}}=\right.$ $\left.41^{0}\right)-I G H D 6-19\left(\Theta_{M}=52.7^{0}\right)-I G H D 5-18\left(\Theta_{M}=59.3^{0}\right)-I G H D 4-17\left(\Theta_{M}=52.5^{0}\right)-I G H D 3-16\left(\Theta_{M}=52.8^{0}\right)-I G H D 2-15\left(\Theta_{M}=54.5^{0}\right)-I G H D 1-14\left(\Theta_{M}=54.7^{0}\right)-$ IGHD6-13 $\left(\Theta_{M}=55.4^{\circ}\right)$ from $3^{\prime}$ to $5^{\prime}$ on the reverse (-) strand of human ch $14 q 32.3$ in native configuration. As shown is a gene of a mesotropic heterochromatin segment loop positioned at the lower limit of angulation $\Theta_{M}=11.7^{0}$ in the $z, y$-vertical plane that horizontally aligns for transcription in $z, x$-axis at a $P_{\text {eff }}$ of 0.648 esebssiwaago $T_{\mathrm{Q}}$ units. Legend. $\Theta_{\mathrm{H}}$, zero degree horizontal; $d_{\mathrm{M}}$, hypotenusal distance of anisotropic gene intergene tropy bases; $d_{M} \sin \Theta_{M}$, distance to horizontal for anisotropic gene intergene tropy distance; $d_{M}$ at $H_{0}=0^{0}, d_{M} \cdot \cos \Theta_{M}+x_{M} ; P_{\text {effective }}$ 
$0.226,0.268,0.399,0.395$ (DfC), 0.378, 0.270. The final uppesebssiwaa and dppesebssiwaa for SLC25A44 are $2.1658 \mathrm{E}+04$ and 5.4827E +04 intergene bases. The $P_{\text {eff }}$ for gene locus for $S L C 25 A 44$ is 0.395 esebssiwaago $_{\mathrm{Q}}$ units (Table 1; Figs. 1, 2 and 3).

PMF1-BGLAP is a 2 A 5 initial and final SEB gene locus with a $\Sigma$ intergene base segment tropy of 3.92203E +05 intergene bases at position +3 . Sequential integration $(\delta)$ to the final esebssiwaago $T_{\mathrm{Q}}$ for PMF1-BGLAP is $0.005,0.230,0.161,0.133$. The final uppesebssiwaa and dppesebssiwaa for PMF1-BGLAP are 9.594E + 03 and $6.5791 \mathrm{E}+04$ intergene bases. The $P_{\text {eff }}$ for gene locus for PMF1-BGLAP is 0.146 esebssiwaagoT $T_{\mathrm{Q}}$ units (Table 1; Figs. 1, 2 and 3).

TMEM79 is a 3 A $7(+1)$ ACM final SEB gene locus with a $\Sigma$ intergene base segment tropy of $1.848556 \mathrm{E}+06$ intergene bases at position +4 . Sequential integration $(\delta)$ to the final esebssiwaago $T_{\mathrm{Q}}$ for TMEM79 is $0.335,0167$, $0.208,0.194,0.247,0.245,0.228$. The final uppesebssiwaa and dppesebssiwaa for TMEM79 are 4.0434E + 04 and $1.90636 \mathrm{E}+05$ intergene bases. The $P_{\text {eff }}$ for gene locus for TMEM79 is 0.212 esebssiwaago $T_{\mathrm{Q}}$ units (Table 1; Figs. 1, 2 and 3).

TSACC is a 3 A 7 initial and final SEB gene locus with a $\Sigma$ intergene base segment tropy of 7.43872E + 05 intergene bases at position +5 . Sequential integration $(\delta)$ to the final esebssiwaago $T_{\mathrm{Q}}$ for TSACC is $0.028,0.250$, $0.327,0.340,0.364,0.318$. The final uppesebssiwaa and dppesebssiwaa for TSACC are 2.7118E + 04 and 8.0818E + 04 intergene bases. The $P_{\text {eff }}$ for gene locus for TSACC is 0.336 esebssiwaago $T_{\mathrm{Q}}$ units (Table 1; Figs. 1, 2 and 3).

$R H B G$ is a 2 M 5 initial and final SEB gene locus with a $\Sigma$ intergene base segment tropy of $6.05950 \mathrm{E}+05$ intergene bases at position +6 . Sequential integration $(\delta)$ to the final esebssiwaago $T_{\mathrm{Q}}$ for $R H B G$ is $0.419,0.280$, $0.315,0.302$. The final uppesebssiwaa and dppesebssiwaa for $R H B G$ are $2.6125 \mathrm{E}+04$ and 9.1097E + 04 intergene bases. The $P_{\text {eff }}$ for gene locus for $R H B G$ is 0.287 esebssiwaago $T_{\mathrm{Q}}$ units (Table 1; Figs. 1, 2 and 3).

ENSG00000237390 is a 3 A 7 initial and final SEB gene locus with a $\Sigma$ intergene base segment tropy of 9.58633E +05 intergene bases at position +7 . Sequential integration $(f)$ to the final esebssiwaago $T_{\mathrm{Q}}$ for ENSG00000237390 is $0.020,0.110,0.164,0.154,0.137$, 0.144. The final uppesebssiwaa and dppesebssiwaa for ENSG00000237390 are 1.7374E + 04 and 1.13726E + 05 intergene bases. The $P_{\text {eff }}$ for gene locus for ENSG00000237390 is 0153 esebssiwaago $T_{\mathrm{Q}}$ units (Table 1; Figs. 1, 2 and 3).

lnc-TTC24-5 is a $3 \mathrm{M} 7$ initial and final SEB gene locus with a $\Sigma$ intergene base segment tropy of $9.02656 \mathrm{E}+05$ intergene bases at position +8 . Sequential integration $(\delta)$ to the final esebssiwaago $T_{\mathrm{Q}}$ for $\operatorname{lnc}-T T C 24-5$ is 0.369 , $0.321,0.355,0.242,0.267,0.290$. The final uppesebssiwaa and dppesebssiwaa for lnc-TTC24-5 are 4.1211E + 04 and $9.6908 \mathrm{E}+04$ intergene bases. The $P_{\text {eff }}$ for gene locus for $\operatorname{lnc}-T T C 24-5$ is 0.283 esebssiwaago $T_{\mathrm{Q}}$ units (Table 1; Figs. 1, 2 and 3).

lnc-TTC24-4 is a 3 A $7(+1)$ ACM final SEB gene locus with a $\Sigma$ intergene base segment tropy of $1.138955 \mathrm{E}+$ 05 intergene bases at position +9 . Sequential integration $\left(\int\right)$ to the final esebssiwaago $T_{\mathrm{Q}}$ for $\operatorname{lnc}$-TTC24-4 is 0.055 , $0.276,0.152,0.193,0.223,0.235,0.194$. The final uppesebssiwaa and dppesebssiwaa for lnc-TTC24-4 are $2.3007 \mathrm{E}+04$ and 1.19362E +05 intergene bases. The $P_{\text {eff }}$ for gene locus for lnc-TTC24-4 is 0.193 esebssiwaa$g o T_{\mathrm{Q}}$ units (Table 1; Figs. 1, 2 and 3).

$\operatorname{lnc}-T T C 24-1$ is a $3 \mathrm{M} 7$ initial and final SEB gene locus with a $\Sigma$ intergene base segment tropy of $4.86984 \mathrm{E}+05$ intergene bases at position +10 . Sequential integration $(\delta)$ to the final esebssiwaago $T_{\mathrm{Q}}$ for $\operatorname{lnc}-T T C 24-1$ is 0.544 , $0.097,0.267,0.342,0.312,0.264$. The final uppesebssiwaa and dppesebssiwaa for lnc-TTC24-1 are 1.4861E + 04 and $5.5298 \mathrm{E}+04$ intergene bases. The $P_{\text {eff }}$ for gene locus for lnc-TTC24-1 is 0.269 esebssiwaago $T_{\mathrm{Q}}$ units (Table 1; Figs. 1, 2 and 3).

GC01P156524 is a 3 A $7(+2)$ ACM final SEB gene locus with a $\Sigma$ intergene base segment tropy of $1.492171 \mathrm{E}+06$ intergene bases at position +11 . Sequential integration $(\delta)$ to the final esebssiwaago $T_{\mathrm{Q}}$ for GC01P156524 is $0.141,0.225,0.162,0.212,0.223,0.217$, 0.232, 0.217, 0.199 (DfC), 0.196, 0.205. The final uppesebssiwaa and dppesebssiwaa for GC01P156524 are $2.6686 \mathrm{E}+04$ and $1.34141 \mathrm{E}+05$ intergene bases. The $P_{\text {eff }}$ for gene locus for GC01P156524 is 0.199 esebssiwaa$g o T_{\mathrm{Q}}$ units (Table 1; Figs. 1, 2 and 3).

TTC24 is a 3 M 7 initial and final SEB gene locus with a $\Sigma$ intergene base segment tropy of $8.54954 \mathrm{E}+05$ intergene bases at position +12 . Sequential integration $(\delta)$ to the final esebssiwaago $T_{\mathrm{Q}}$ for TTC24 is $0.406,0.197,0.184$, $0.116,0.145,0.159$. The final uppesebssiwaa and dppesebssiwaa for TTC24 are 1.6633E + 04 and 1.14108E + 05 intergene bases. The $P_{\text {eff }}$ for gene locus for TTC24 is 0.146 esebssiwaago $T_{\mathrm{Q}}$ units (Table 1; Figs. 1, 2 and 3).

NAXE is a $3 \mathrm{M} 7$ initial and final SEB gene locus with a $\Sigma$ intergene base segment tropy of $1.422774 \mathrm{E}+06$ intergene bases at position +13 . Sequential integration $(\delta)$ to the final esebssiwaago $T_{\mathrm{Q}}$ for $N A X E$ is $0.125,0.218$, $0.153,0.144,0.159,0.187$. The final uppesebssiwaa and dppesebssiwaa for NAXE are 2.7892E + 04 and 1.61601E + 05 intergene bases. The $P_{\text {eff }}$ for gene locus for NAXE is 0.190 esebssiwaago $T_{\mathrm{Q}}$ units (Table 1; Figs. 1, 2 and 3).

HAPLN2 is a $3 \mathrm{M} 7$ initial and final SEB gene locus with a $\Sigma$ intergene base segment tropy of 7.92243E + 05 intergene bases at position +14 . Sequential integration $(\delta)$ to the final esebssiwaago $T_{\mathrm{Q}}$ for HAPLN2 is 0.636 , $0.505,0.456,0.243,0.209,0.211,0.188$ (DfC), 0.209, 0.194. The final uppesebssiwaa and dppesebssiwaa for 
HAPLN2 are 1.8695E + 04 and 9.9190E + 04 intergene bases. The $P_{\text {eff }}$ for gene locus for HAPLN2 is 0.188 esebssiwaago $T_{\mathrm{Q}}$ units (Table 1; Figs. 1, 2 and 3).

$B C A N$ is a $2 \mathrm{M} 5$ initial and final SEB gene locus with a $\Sigma$ intergene base segment tropy of 7.28923E + 05 intergene bases at position +15 . Sequential integration $(\delta)$ to the final esebssiwaago $T_{\mathrm{Q}}$ for $B C A N$ is $0.389,0.212$, $0.235,0.262$. The final uppesebssiwaa and dppesebssiwaa for $B C A N$ are $2.7104 \mathrm{E}+04$ and $1.11335 \mathrm{E}+05$ intergene bases. The $P_{\text {eff }}$ for gene locus for $B C A N$ is 0.243 esebssiwaago $_{\mathrm{Q}}$ units (Table 1; Figs. 1, 2 and 3).

\section{Anisotropic gene intergene tropy sub-episode block sum for linear two-dimensional $z, y$-plane anglemetry}

The uppasebs, dppasebs, uppmsebs and dppasebs for anisotropic gene locus MIR4537 are 7.232E + 03, 1.72400E $+05,5.896 \mathrm{E}+03$ and 1.1694E + 04. The uppasebssiwa, dppasebssiwa, uppmsebssiwa and dppasebssiwa for anisotropic gene locus MIR4537 are 2.411E + 03, 5.7467E $+04,1.474 \mathrm{E}+03$ and 2.934E + 03. The sebs and sebssiwa exponential function pair for anisotropic gene locus MIR4537 is $5.799 \mathrm{E}+03 e^{8 \mathrm{E}-03 \mathrm{x}}$ and $1.424 \mathrm{E}+03 e^{1.72 \mathrm{E}+02 \mathrm{x}}$. The $b_{\text {sebs }} / b_{\text {sebssiwa }}$ linearization quotient for anisotropic gene locus MIR4537 is 4.07 . The sebs - sebssiwa residual for anisotropic gene locus MIR4537 is 4,821, 114,933, 4, 422 and 8,770. The uppesebssiwaa and dppesebssiwaa for anisotropic gene MIR4537 are 1.942E + 03 and $3.0195 \mathrm{E}+04$. The esebssiwaago $T_{\mathrm{Q}}$ for anisotropic gene locus MIR4537 is 0.064. Anisotropic gene locus MIR4537 is positioned at angle $\Theta_{\mathrm{A}}=82.2^{0}$ in the $z, y$ axis vertical plane.

The uppasebs, dppasebs, uppmsebs and dppasebs for anisotropic gene locus COL2A1 are 9.2758E + 04, $1.390995 \mathrm{E}+06,6.4607 \mathrm{E}+04$ and 1.46229E + 05. The uppasebssiwa, dppasebssiwa, uppmsebssiwa and dppasebssiwa for anisotropic gene locus COL2A1 are 3.0919E $+04,4.63665 \mathrm{E}+05,3.2304 \mathrm{E}+04$ and 7.3115E + 04 . The sebs and sebssiwa exponential function pair for anisotropic gene locus COL2A1 is $6.1920 \mathrm{E}+04 e^{3 \mathrm{E}-07 \mathrm{x}}$ and $2.8989 \mathrm{E}+04 e^{2 \mathrm{E}-06 \mathrm{x}}$. The $b_{\text {sebs }} / b_{\text {sebssiwa }}$ linearization quotient for anisotropic gene locus COL2A1 is 2.14. The sebs - sebssiwa residual for anisotropic gene locus COL2A1 is $61,839,927,330,32,304$ and 73,115 . The uppesebssiwaa and dppesebssiwaa for anisotropic gene locus COL2A1 are 3.1611E + 04 and 2.68390E + 05. The esebssiwaago $T_{\mathrm{Q}}$ for anisotropic gene locus $C O L 2 A 1$ is 0.118. Anisotropic gene locus COL2A1 is positioned at angle $\quad \mathrm{A}=75.8^{0}$ in the $z, y$-axis vertical plane (Table 2).

The uppasebs, dppasebs, uppmsebs and dppasebs for anisotropic gene locus RGS4 are 8.1560E + 04, 1.196076E + 06, 1.01032E + 05 and 1.85608E + 05. The uppasebssiwa, dppasebssiwa, uppmsebssiwa and dppasebssiwa for anisotropic gene locus RGS4 are 2.7187E + 04, 3.98692E + 05, 2.5258E + 04 and 4.6402E + 04. The sebs and sebssiwa exponential function pair for anisotropic gene locus $R G S 4$ is $7.8415 \mathrm{E}+04 e^{2 \mathrm{E}-07 \mathrm{x}}$ and $2.5014 \mathrm{E}+04 \quad e^{2 \mathrm{E}-07 \mathrm{x}}$. The $b_{\text {sebs }} / b_{\text {sebssiwa }}$ linearization quotient for anisotropic gene locus RGS4 is 3.14. The sebs - sebssiwa residual for anisotropic gene locus $R G S 4$ is $54,373,797,384,75,774$ and 139,206 . The uppesebssiwaa and dppesebssiwaa for anisotropic gene locus RGS4 are $2.6223 \mathrm{E}+04$ and $2.22547 \mathrm{E}+05$. The esebssiwaa$g o T_{\mathrm{Q}}$ for anisotropic gene locus RGS4 is 0.118 . Anisotropic gene locus RGS4 is positioned at angle $\Theta_{\mathrm{A}}=75.8^{0}$ in the $z, y$-axis vertical plane (Table 2).

The uppasebs, dppasebs, uppmsebs and dppasebs for anisotropic gene locus $M Y C$ are $8.8269 \mathrm{E}+04$, $1.042981 \mathrm{E}+06,8.5825 \mathrm{E}+04$ and $2.27872 \mathrm{E}+05$. The uppasebssiwa, dppasebssiwa, uppmsebssiwa and dppasebssiwa for anisotropic gene locus $M Y C$ are 2.9423E + 04, 3.47660E + 05, 4.2913E + 04 and 1.13936E + 05. The sebs and sebssiwa exponential function pair for anisotropic gene locus $M Y C$ is $8.8964 \mathrm{E}+04 e^{3 \mathrm{E}-08 \mathrm{x}}$ and $2.4479 \mathrm{E}+04 e^{2 \mathrm{E}-06 \mathrm{x}}$. The $b_{\text {sebs }} / b_{\text {sebssiwa }}$ linearization quotient for anisotropic gene locus $M Y C$ is 3.63 . The sebs sebssiwa residual for anisotropic gene locus $M Y C$ is 58 , 846, 695,321, 42,913 and 113,936. The uppesebssiwaa and dppesebssiwaa for anisotropic gene locus $M Y C$ are $3.6168 \mathrm{E}+04$ and $2.30798 \mathrm{E}+05$. The esebssiwaago $T_{\mathrm{Q}}$ for anisotropic gene locus $M Y C$ is 0.157 . Anisotropic gene locus $M Y C$ is positioned at angle $\Theta_{\mathrm{A}}=71.0^{\circ}$ in the $z, y$-axis vertical plane (Table 2).

The uppasebs, dppasebs, uppmsebs and dppasebs for anisotropic gene locus LMNA are 4.3403E + 04, 5.73397E $+05,8.6878 \mathrm{E}+04$ and 2.47931E + 05. The uppasebssiwa, dppasebssiwa, uppmsebssiwa and dppasebssiwa for anisotropic gene locus $L M N A$ are $1.4468 \mathrm{E}+04,1.91132 \mathrm{E}+05$, $4.3439 \mathrm{E}+04$ and $1.23966 \mathrm{E}+05$. The sebs and sebssiwa exponential function pair for anisotropic gene locus LMNA is $6.65237 \mathrm{E}+05 e^{2 \mathrm{E}-05 \mathrm{x}}$ and $1.92333 \mathrm{E}+05 e^{6 \mathrm{E}-06 \mathrm{x}}$. The $b_{\text {sebs }} / b_{\text {sebssiwa }}$ linearization quotient for anisotropic gene locus $L M N A$ is 3.46 . The sebs - sebssiwa residual for anisotropic gene locus $L M N A$ is $28,935,382,265,43,439$ and 123,966. The uppesebssiwaa and dppesebssiwaa for anisotropic gene locus LMNA are 2.8995E + 04 and $1.57549 \mathrm{E}+05$. The esebssiwaago $T_{\mathrm{Q}}$ for anisotropic gene locus $L M N A$ is 0.184 . Anisotropic gene locus $L M N A$ is positioned at angle $\Theta_{\mathrm{A}}=67.8^{\circ}$ in the $z, y$-axis vertical plane (Table 2).

The uppasebs, dppasebs, uppmsebs and dppasebs for anisotropic gene locus CCN2 are 1.21423E + 05, $1.117098 \mathrm{E}+06,1.21173 \mathrm{E}+05$ and $3.42644 \mathrm{E}+05$. The uppasebssiwa, dppasebssiwa, uppmsebssiwa and dppasebssiwa for anisotropic gene locus CCN2 are $3.0356 \mathrm{E}+04,2.79275 \mathrm{E}+05,3.0293 \mathrm{E}+04$ and $8.5661 \mathrm{E}+04$. The sebs and sebssiwa exponential function pair for anisotropic gene locus CCN2 is $1.21063 \mathrm{E}+05 e^{3 \mathrm{E}-09 \mathrm{x}}$ and $3.0266 \mathrm{E}+04 \quad e^{1 \mathrm{E}-08 \mathrm{x}}$. The 


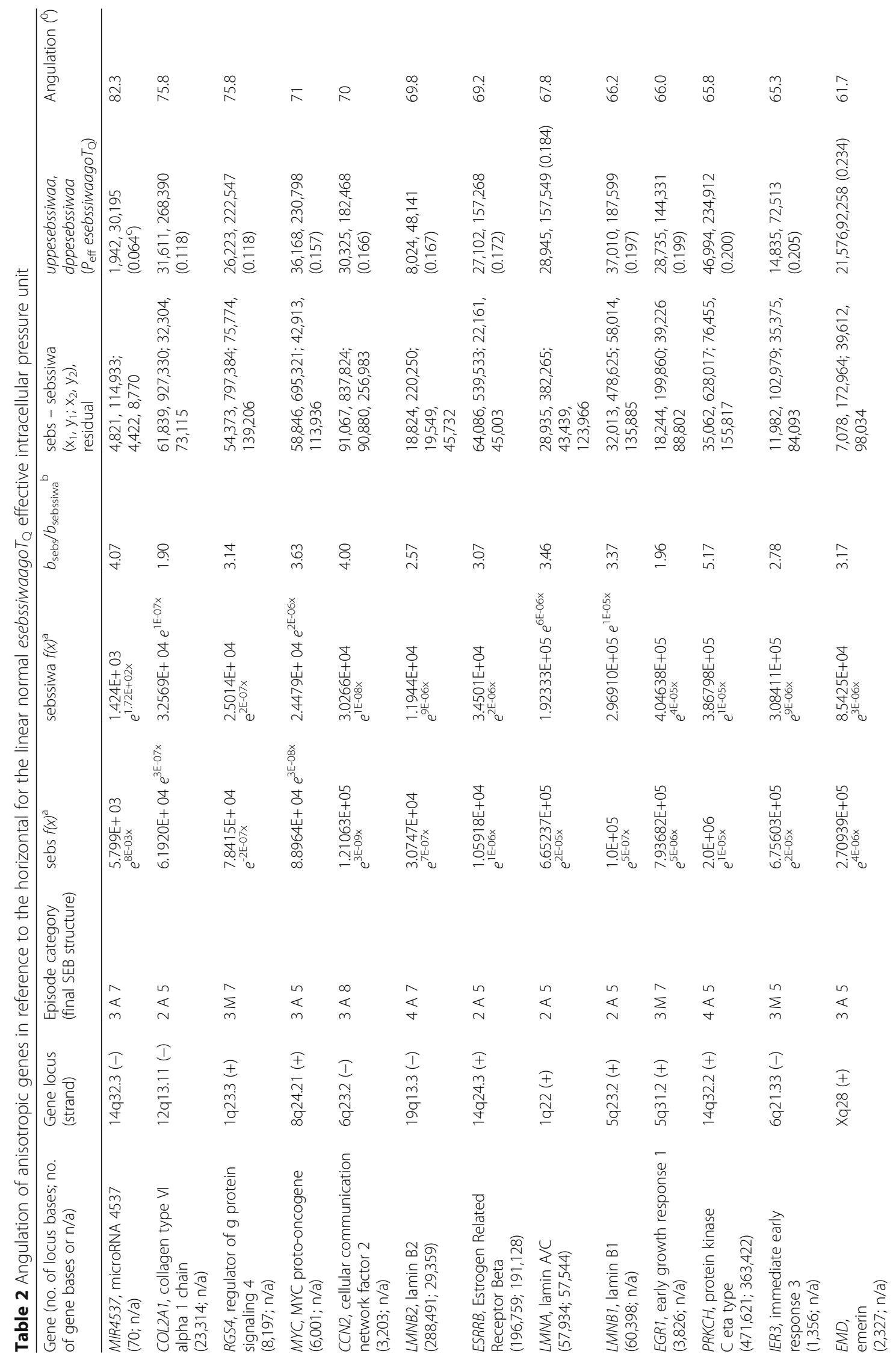




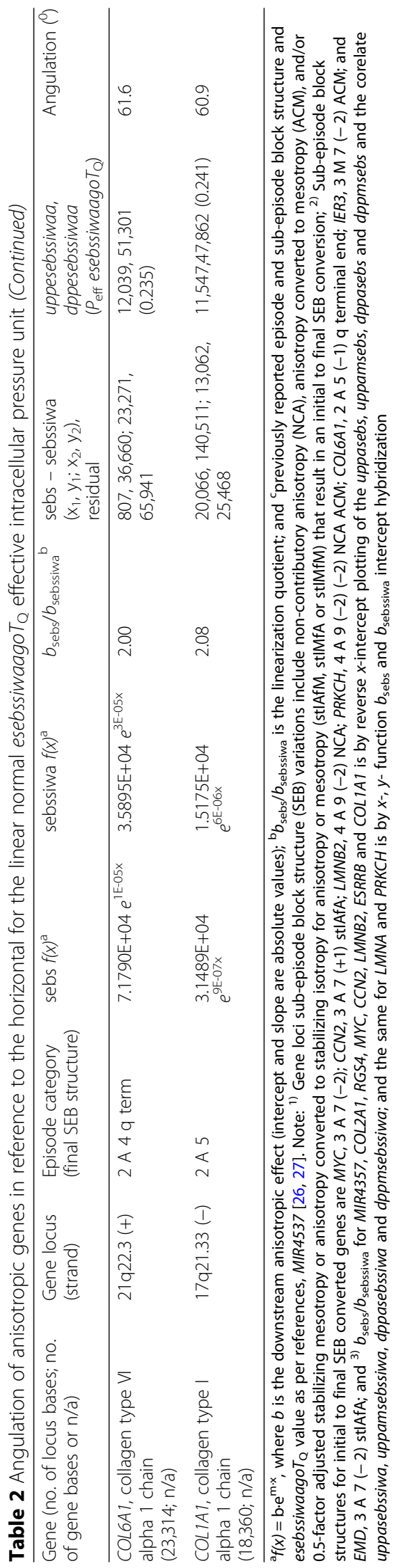


$b_{\text {sebs }} / b_{\text {sebssiwa }}$ linearization quotient for anisotropic gene locus CCN2 is 4.00 . The sebs - sebssiwa residual for anisotropic gene locus CCN2 is 91,067, 837,824, 90,880 and 256,983. The uppesebssiwaa and dppesebssiwaa for anisotropic gene locus CCN2 are 3.0325E + 04 and $1.82468 \mathrm{E}+05$. The esebssiwaago $T_{\mathrm{Q}}$ for anisotropic gene locus $\mathrm{CCN} 2$ is 0.166 . Anisotropic gene locus CNN2 is positioned at angle $\Theta_{\mathrm{A}}=70.0^{\circ}$ in the $z$, $y$-axis vertical plane (Table 2).

The uppasebs, dppasebs, uppmsebs and dppasebs for anisotropic gene locus ESRRB are 9.6129E + 04, 8.08599E + 05, 4.4321E + 04 and 9.0006E + 04. The uppasebssiwa, dppasebssiwa, uppmsebssiwa and dppasebssiwa for anisotropic gene locus ESRRB are 3.2043E + $04,2.69533 \mathrm{E}+05,2.2161 \mathrm{E}+04$ and 4.5003E + 04. The sebs and sebssiwa exponential function pair for anisotropic gene locus ESRRB is $1.05918 \mathrm{E}+04 e^{1 \mathrm{E}-06 \mathrm{x}}$ and $3.4501 \mathrm{E}+04 e^{2 \mathrm{E}-06 \mathrm{x}}$. The $b_{\text {sebs }} / b_{\text {sebssiwa }}$ linearization quotient for anisotropic gene locus ESRRB is 3.07. The sebs - sebssiwa residual for anisotropic gene locus ESRRB is 64,086, 539,533, 22,161 and 45,003. The uppesebssiwaa and dppesebssiwaa for anisotropic gene locus ESRRB are $2.7102 \mathrm{E}+04$ and $1.57268 \mathrm{E}+05$. The esebssiwaago $T_{\mathrm{Q}}$ for anisotropic gene locus ESRRB is 0.172 . Anisotropic gene locus ESRRB is positioned at angle $\Theta_{\mathrm{A}}=69.2^{\circ}$ in the $z, y$-axis vertical plane (Table 2).

The uppasebs, dppasebs, uppmsebs and dppasebs for anisotropic gene locus LMNB1 are 4.8020E + 04, $7.17938 \mathrm{E}+05,1.16027 \mathrm{E}+05$ and $2.71770 \mathrm{E}+05$. The uppasebssiwa, dppasebssiwa, uppmsebssiwa and dppasebssiwa for anisotropic gene locus $L M N B 1$ are $1.6007 \mathrm{E}$ $+04,2.39313 \mathrm{E}+05,5.8014 \mathrm{E}+04$ and $1.35885 \mathrm{E}+05$. The sebs and sebssiwa exponential function pair for anisotropic gene locus $L M N B 1$ is $1.0 \mathrm{E}+05 e^{5 \mathrm{E}-07 \mathrm{x}}$ and $2.96910 \mathrm{E}+05 e^{1 \mathrm{E}-05 \mathrm{x}}$. The $b_{\text {sebs }} / b_{\text {sebssiwa }}$ linearization quotient for anisotropic gene locus $L M N B 1$ is 3.37. The sebs - sebssiwa residual for anisotropic gene locus $L M N B 1$ is $32,013,478,625,58,014$ and 135,885. The uppesebssiwaa and dppesebssiwaa for anisotropic gene locus LMNB1 are $3.7010 \mathrm{E}+04$ and $1.87599 \mathrm{E}+05$. The esebssiwaa$g o T_{\mathrm{Q}}$ for anisotropic gene locus $L M N B 1$ is 0.197 . Anisotropic gene locus $L M N B 1$ is positioned at angle $\Theta_{\mathrm{A}}=$ $66.2^{0}$ in the $z, y$-axis vertical plane (Table 2).

The uppasebs, dppasebs, uppmsebs and dppasebs for anisotropic gene locus EGR1 are 5.4733E + 04, 5.99581E $+05,1.56904 \mathrm{E}+05$ and 3.55209E + 05. The uppasebssiwa, dppasebssiwa, uppmsebssiwa and dppasebssiwa for anisotropic gene locus EGR1 are 1.8244E + 04, 1.99860E $+05,3.9226 \mathrm{E}+04$ and $8.8802 \mathrm{E}+04$. The sebs and sebssiwa exponential function pair for anisotropic gene locus EGR1 is $7.93682 \mathrm{E}+05 e^{5 \mathrm{E}-06 \mathrm{x}}$ and $4.04638 \mathrm{E}+05 e^{4 \mathrm{E}-05 \mathrm{x}}$. The $b_{\text {sebs }} / b_{\text {sebssiwa }}$ linearization quotient for anisotropic gene locus EGR1 is 1.96. The sebs - sebssiwa residual for anisotropic gene locus EGR1 is $36,489,399,721,117,678$ and 266,407. The uppesebssiwaa and dppesebssiwaa for anisotropic gene locus EGR1 are 2.8735E + 04 and $1.44331 \mathrm{E}+05$. The esebssiwaago $T_{\mathrm{Q}}$ for anisotropic gene locus EGR1 is 0.199. Anisotropic gene locus EGR1 is positioned at angle $\Theta_{\mathrm{A}}=66.0^{\circ}$ in the $z, y$-axis vertical plane (Table 2).

The uppasebs, dppasebs, uppmsebs and dppasebs for anisotropic gene locus PRKCH are 5.2593E + 04, 9.42026E + 05, 1.52911E + 05 and 3.11633E + 05. The uppasebssiwa, dppasebssiwa, uppmsebssiwa and dppasebssiwa for anisotropic gene locus $P R K C H$ are 1.7531E $+04,3.14009 \mathrm{E}+05,7.6456 \mathrm{E}+04$ and $1.55816 \mathrm{E}+05$. The sebs and sebssiwa exponential function pair for anisotropic gene locus $P R K C H$ is $1.129582 \mathrm{E}+06$

$e^{6 \mathrm{E}-06 \mathrm{x}}$ and $3.56470 \mathrm{E}+05 e^{1 \mathrm{E}-05 \mathrm{x}}$. The $b_{\text {sebs }} / b_{\text {sebssiwa }}$ linearization quotient for anisotropic gene locus $P R K C H$ is 3.17. The sebs - sebssiwa residual for anisotropic gene locus PRKCH is $35,062,628,017,79,455$ and 155,817 . The uppesebssiwaa and dppesebssiwaa for anisotropic gene locus PRKCH are 4.6994E + 04 and 2.34912E + 05 . The esebssiwaago $T_{\mathrm{Q}}$ for anisotropic gene locus $P R K C H$ is 0.200 . Anisotropic gene locus $P R K C H$ is positioned at angle $\Theta_{\mathrm{A}}=65.8^{\circ}$ in the $z, y$-axis vertical plane (Table 2).

The uppasebs, dppasebs, uppmsebs and dppasebs for anisotropic gene locus LMNB2 are 2.0538E + 04, $2.16613 \mathrm{E}+05,3.4762 \mathrm{E}+04$ and $8.6623 \mathrm{E}+04$. The uppasebssiwa, dppasebssiwa, uppmsebssiwa and dppasebssiwa for anisotropic gene locus LMNB2 are 5.135E + 03, 5.4153E + 04, 1.1587E + 04 and 2.8874E + 04. The sebs and sebssiwa exponential function pair for anisotropic gene locus $L M N B 2$ is $4.9363 \mathrm{E}+04 e^{4 \mathrm{E}-06 \mathrm{x}}$ and $2.9359 \mathrm{E}+04 e^{3 \mathrm{E}-06 \mathrm{x}}$. The $b_{\text {sebs }} / b_{\text {sebssiwa }}$ linearization quotient for anisotropic gene locus $L M N B 2$ is 1.68 . The sebs - sebssiwa residual for anisotropic gene locus $L M N B 2$ is $15,404,162,460,23,175$ and 57,749. The uppesebssiwaa and dppesebssiwaa for anisotropic gene locus LMNB2 are $8.361 \mathrm{E}+03$ and $4.1514 \mathrm{E}+04$. The esebssiwaago $T_{\mathrm{Q}}$ for anisotropic gene locus $L M N B 2$ is 0.201 . Anisotropic gene locus $L M N B 2$ is positioned at angle $\Theta_{\mathrm{A}}=65.7^{\circ}$ in the $z, y$-axis vertical plane (Table 2).

The uppasebs, dppasebs, uppmsebs and dppasebs for anisotropic gene locus IER3 are 2.3964E + 04, 2.05958E $+05,5.3063 \mathrm{E}+04$ and 1.26140E + 05. The uppasebssiwa, dppasebssiwa, uppmsebssiwa and dppasebssiwa for anisotropic gene locus IER3 are 1.1982E + 04, 1.02979E $+05,1.7688 \mathrm{E}+04$ and $4.2047 \mathrm{E}+04$. The sebs and sebssiwa exponential function pair for anisotropic gene locus IER3 is $6.75603 \mathrm{E}+05 e^{2 \mathrm{E}-05 \mathrm{x}}$ and $3.08411 \mathrm{E}+05$ $e^{9 \mathrm{E}-06 \mathrm{x}}$. The $b_{\text {sebs }} / b_{\text {sebssiwa }}$ linearization quotient for anisotropic gene locus IER3 is 2.78 . The sebs - sebssiwa residual for anisotropic gene locus IER3 is 11,982, 102, 979, 35,375 and 84,093. The uppesebssiwaa and dppesebssiwaa for anisotropic gene locus IER3 are $1.4835 \mathrm{E}+$ 04 and 7.2513E +04 . The esebssiwaago $T_{\mathrm{Q}}$ for 
anisotropic gene locus IER3 is 0.205. Anisotropic gene locus IER3 is positioned at angle $\Theta_{\mathrm{A}}=65.3^{0}$ in the $z, y$ axis vertical plane (Table 2).

The uppasebs, dppasebs, uppmsebs and dppasebs for anisotropic gene locus EMD are 1.0617E + 04, 2.59446E $+05,7.9224 \mathrm{E}+04$ and $1.96068 \mathrm{E}+05$. The uppasebssiwa, dppasebssiwa, uppmsebssiwa and dppasebssiwa for anisotropic gene locus $E M D$ are $3.539 \mathrm{E}+03,8.6482 \mathrm{E}+$ $04,3.9612 \mathrm{E}+04$ and $9.8034 \mathrm{E}+04$. The sebs and sebssiwa exponential function pair for anisotropic gene locus $E M D$ is $2.70939 \mathrm{E}+05 e^{4 \mathrm{E}-06 \mathrm{x}}$ and $8.5425 \mathrm{E}+04 e^{3 \mathrm{E}-06 \mathrm{x}}$. The $b_{\text {sebs }} / b_{\text {sebssiwa }}$ linearization quotient for anisotropic gene locus $E M D$ is 3.17. The sebs - sebssiwa residual for anisotropic gene locus $E M D$ is 7,078, 172,964, 39,612 and 98,034 . The uppesebssiwaa and dppesebssiwaa for anisotropic gene locus $E M D$ are $2.1576 \mathrm{E}+04$ and $9.2258 \mathrm{E}+$ 04. The esebssiwaago $T_{\mathrm{Q}}$ for anisotropic gene locus $E M D$ is 0.234 . Anisotropic gene locus $E M D$ is positioned at angle $\Theta_{\mathrm{A}}=61.7^{0}$ in the $z, y$-axis vertical plane (Table 2).

The uppasebs, dppasebs, uppmsebs and dppasebs for anisotropic gene locus COL6A1 are 1.614E + 03, $7.3320 \mathrm{E}+04,4.6541 \mathrm{E}+04$ and 1.31882E + 05. The uppasebssiwa, dppasebssiwa, uppmsebssiwa and dppasebssiwa for anisotropic gene locus COL6A1 are 8.07E + 02, 3.6660E + 04, 2.3271E + 04 and 6.5941E + 04. The sebs and sebssiwa exponential function pair for anisotropic gene locus COL6A1 is 7.1790E+04 $e^{1 \mathrm{E}-05 \mathrm{x}}$ and $3.5895 \mathrm{E}+04 e^{3 \mathrm{E}-05 \mathrm{x}}$. The $b_{\text {sebs }} / b_{\text {sebssiwa }}$ linearization quotient for anisotropic gene locus COL6A1 is 2.00. The sebs - sebssiwa residual for anisotropic gene locus COL6A1 is $807,36,660,23,271$ and 65,941 . The uppesebssiwaa and dppesebssiwaa for anisotropic gene locus COL6A1 are 1.2039E + 04 and 5.1301E + 04. The esebs-

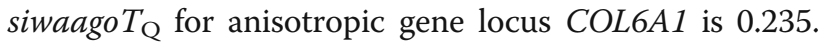
Anisotropic gene locus COL6A1 is positioned at angle $\Theta_{\mathrm{A}}=61.6^{0}$ in the $z, y$-axis vertical plane (Table 2).

The uppasebs, dppasebs, uppmsebs and dppasebs for anisotropic gene locus COL1A1 are 3.0099E + 04, 2.10767E + 05, 2.6123E + 04 and 5.0936E + 04. The uppasebssiwa, dppasebssiwa, uppmsebssiwa and dppasebssiwa for anisotropic gene locus COL1A1 are $1.0033 \mathrm{E}+04,7.0256 \mathrm{E}+04,1.3062 \mathrm{E}+04$ and $2.5468 \mathrm{E}+04$. The sebs and sebssiwa exponential function pair for anisotropic gene locus COL1A1 is $4.4873 \mathrm{E}+04 e^{1 \mathrm{E}-06 \mathrm{x}}$ and $4.8093 \mathrm{E}+04 e^{2 \mathrm{E}-05 \mathrm{x}}$. The $b_{\text {sebs }} /$ $b_{\text {sebssiwa }}$ linearization quotient for anisotropic gene locus COL1A1 is 2.08. The sebs - sebssiwa residual for anisotropic gene locus COL1A1 is 20,066, 140,511, 13,062 and 25,468. The uppesebssiwaa and dppesebssiwaa for anisotropic gene locus COL1A1 are 1.1547E +04 and $4.7862 \mathrm{E}+04$. The esebssiwaago $T_{\mathrm{Q}}$ for anisotropic gene locus COL1A1 is 0.241 . Anisotropic gene locus COL1A1 is positioned at angle $\Theta_{\mathrm{A}}=69.2^{\circ}$ in the $z, y$-axis vertical plane (Table 2).
Mesotropic gene intergene tropy sub-episode block sum exponential functions for linear two-dimensional $z, y$ plane anglemetry

The uppasebs, dppasebs, uppmsebs and dppasebs for mesotropic gene locus CYGB are 3.5180E + 04, 2.22499E $+05,4.6604 \mathrm{E}+04$ and 1.07321E +05 . The uppasebssiwa, dppasebssiwa, uppmsebssiwa and dppasebssiwa for mesotropic gene locus $C Y G B$ are $1.7590 \mathrm{E}+04,1.11250 \mathrm{E}+05$, $2.3302 \mathrm{E}+04$ and $5.3661 \mathrm{E}+04$. The sebs and sebssiwa exponential function pair for mesotropic gene locus $C Y G B$ is $6.0565 \mathrm{E}+04 e^{2 \mathrm{E}-06 \mathrm{x}}$ and $3.0282 \mathrm{E}+04 e^{5 \mathrm{E}-06 \mathrm{x}}$. The $b_{\text {sebs }} /$ $b_{\text {sebssiwa }}$ linearization quotient for mesotropic gene locus $C Y G B$ is 2.00. The sebs - sebssiwa residual for mesotropic gene locus $C Y G B$ is $17,590,111,250,23,302$ and 53,661 . The uppesebssiwaa and dppesebssiwaa for mesotropic gene locus $C Y G B$ are $2.0446 \mathrm{E}+04$ and $8.2455 \mathrm{E}+04$. The esebssiwaago $T_{\mathrm{Q}}$ for mesotropic gene locus $C Y G B$ is 0.248 . Mesotropic gene locus $C Y G B$ is positioned at angle $\Theta_{M}=$ $60.0^{\circ}$ in the $z, y$-axis vertical plane.

The uppasebs, dppasebs, uppmsebs and dppasebs for mesotropic gene locus RGS1 are 1.79174E + 05, 1.237585E + 06, 3.68331E + 05 and 6.86424E + 05. The uppasebssiwa, dppasebssiwa, uppmsebssiwa and dppasebssiwa for mesotropic gene locus RGS1 are 8.9587E + $04,6.18793 \mathrm{E}+05,1.84166 \mathrm{E}+05$ and $3.43212 \mathrm{E}+05$. The sebs and sebssiwa exponential function pair for mesotropic gene locus $R G S 1$ is $9.03665 \mathrm{E}+05 e^{1 \mathrm{E}-06 \mathrm{x}}$ and $4.51832 \mathrm{E}+05 e^{3 \mathrm{E}-06 \mathrm{x}}$. The $b_{\text {sebs }} / b_{\text {sebssiwa }}$ linearization quotient for mesotropic gene locus RGS1 is 2.00 . The sebs sebssiwa residual for mesotropic gene locus RGS1 is 89 , 587, 616,793, 184,166 and 343,212. The uppesebssiwaa and dppesebssiwaa for mesotropic gene locus RGS1 are $1.36876 \mathrm{E}+05$ and $4.81002 \mathrm{E}+05$. The esebssiwaago $T_{\mathrm{Q}}$ for mesotropic gene locus RGS1 is 0.285 . Mesotropic gene locus RGS1 is positioned at angle $\Theta_{\mathrm{M}}=55.6^{\circ}$ in the $z$, $y$-axis vertical plane (Table 3 ).

The uppasebs, dppasebs, uppmsebs and dppasebs for mesotropic gene locus ENPP1 are 2.7027E + 04, $1.71207 \mathrm{E}+05,6.1750 \mathrm{E}+04$ and 1.44916 +05 . The uppasebssiwa, dppasebssiwa, uppmsebssiwa and dppasebssiwa for mesotropic gene locus ENPP1 are 9.009E $+03,5.7169 \mathrm{E}+04,3.0875 \mathrm{E}+04$ and $7.2458 \mathrm{E}+04$. The sebs and sebssiwa exponential function pair for mesotropic gene locus ENPP1 is $1.94930 \mathrm{E}+05 e^{5 \mathrm{E}-06 \mathrm{x}}$ and $5.1723 \mathrm{E}+04 e^{1 \mathrm{E}-05 \mathrm{x}}$. The $b_{\text {sebs }} / b_{\text {sebssiwa }}$ linearization quotient for mesotropic gene locus ENPP1 is 3.77 . The sebs - sebssiwa residual for mesotropic gene locus ENPP1 is 18,018, 114,138, 30,875 and 72,458. The uppesebssiwaa and dppesebssiwaa for mesotropic gene locus ENPP1 are 1.9942E + 04 and 6.4814E + 04. The esebssiwaago $T_{\mathrm{Q}}$ for mesotropic gene locus ENPP1 is 0.308. Mesotropic gene locus ENPP1 is positioned at angle $\Theta_{M}=52.8^{0}$ in the $z, y$-axis vertical plane (Table 3). 


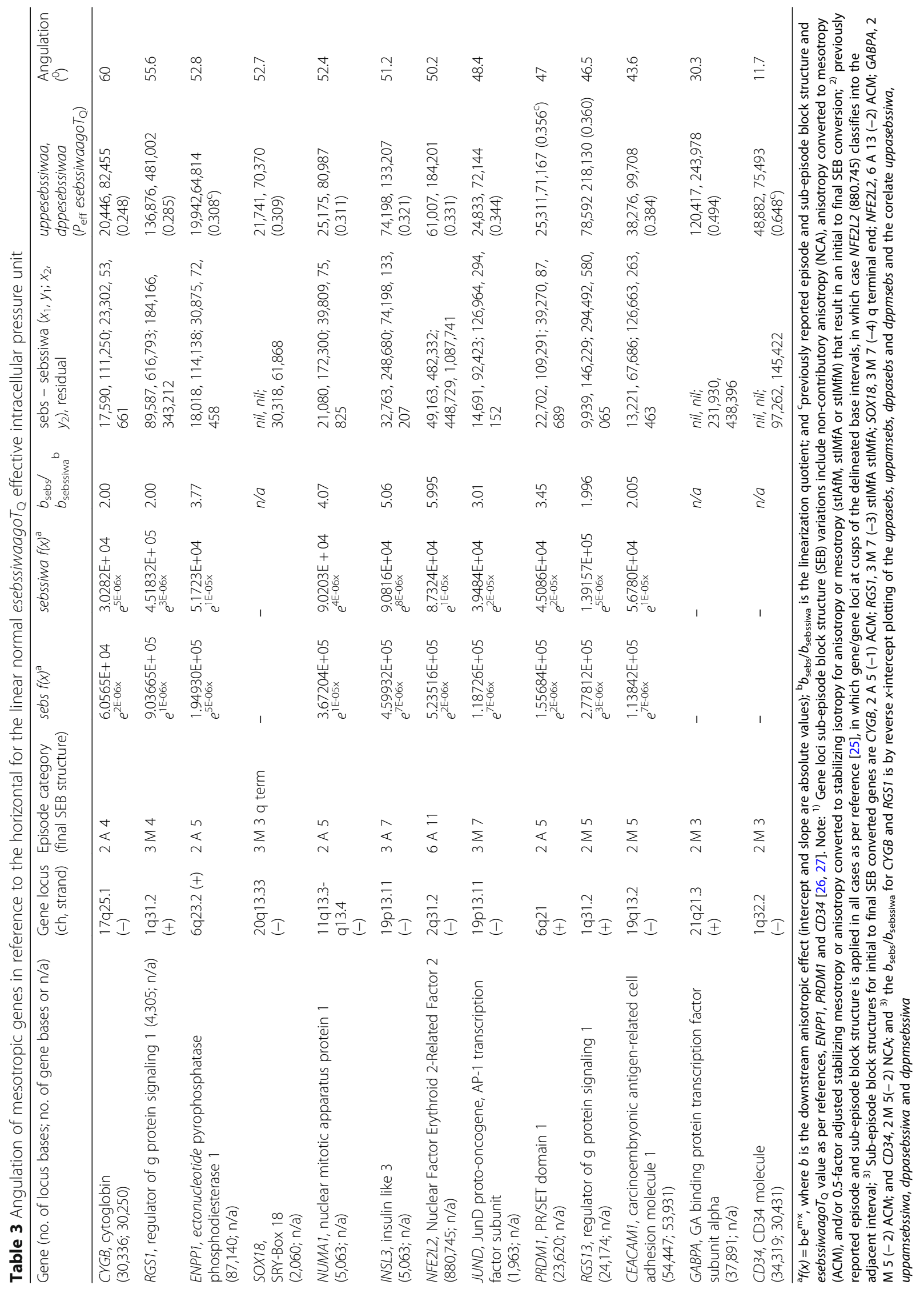


The uppasebs, dppasebs, uppmsebs and dppasebs for mesotropic gene locus SOX18 are 1.3165E + 04, 7.8872E $+04,6.0635 \mathrm{E}+04$ and 1.23734E + 05. The uppasebssiwa, dppasebssiwa, uppmsebssiwa and dppasebssiwa for mesotropic gene locus SOX18 are 1.3165E + 04, 7.8872E $+04,3.0318 \mathrm{E}+04$ and $6.1867 \mathrm{E}+04$. The $b_{\text {sebs }} / b_{\text {sebssiwa }}$ linearization quotient for $S O X 18$ is not applicable. The sebs - sebssiwa residual for mesotropic gene locus SOX18 is nil, nil, 30,318 and 61,868. The uppesebssiwaa and dppesebssiwaa for mesotropic gene locus SOX18 are $2.1741 \mathrm{E}+04$ and 7.0370E +04 . The esebssiwaago $T_{\mathrm{Q}}$ for mesotropic gene locus SOX18 is 0.309 . Mesotropic gene locus $S O X 18$ is positioned at angle $\Theta_{M}=52.7^{\circ}$ in the $z$, $y$-axis vertical plane (Table 3 ).

The uppasebs, dppasebs, uppmsebs and dppasebs for mesotropic gene locus NUMA1 are 3.1620E + 04, 2.58450E + 05, $7.9618 \mathrm{E}+04$ and 1.51649E + 05. The uppasebssiwa, dppasebssiwa, uppmsebssiwa and dppasebssiwa for mesotropic gene locus NUMA1 are 1.0540E + 04, 8.6150E + 04, 3.9809E +04 and $7.5825 \mathrm{E}+04$. The sebs and sebssiwa exponential function pair for mesotropic gene locus NUMA1 is $3.67204 \mathrm{E}+05 e^{1 \mathrm{E}-05 \mathrm{x}}$ and $9.0203 \mathrm{E}+04 e^{4 \mathrm{E}-06 \mathrm{x}}$. The $b_{\text {sebs }} / b_{\text {sebssiwa }}$ linearization quotient for mesotropic gene locus NUMA1 is 4.07. The sebs - sebssiwa residual for mesotropic gene locus NUMA1 is $21,080,172,300,39,809$ and 75,825 . The uppesebssiwaa and dppesebssiwaa for mesotropic gene locus NUMA1 are $2.5175 \mathrm{E}+04$ and $8.0987 \mathrm{E}+04$. The esebssiwaago $T_{\mathrm{Q}}$ for mesotropic gene locus NUMA1 is 0.311. Mesotropic gene locus NUMA1 is positioned at angle $\Theta_{M}=52.4^{0}$ in the $z, y$ axis vertical plane (Table 3 ).

The uppasebs, dppasebs, uppmsebs and dppasebs for mesotropic gene locus INSL3 are 4.3684E + 04, $3.31573 \mathrm{E}+05,1.11297 \mathrm{E}+05$ and $1.99810 \mathrm{E}+05$. The uppasebssiwa, dppasebssiwa, uppmsebssiwa and dppasebssiwa for mesotropic gene locus INSL3 are 1.0921E + $04,8.2893 \mathrm{E}+04,3.7099 \mathrm{E}+04$ and $6.6603 \mathrm{E}+04$. The sebs and sebssiwa exponential function pair for mesotropic gene locus INSL3 is $4.59932 \mathrm{E}+05 e^{7 \mathrm{E}-06 \mathrm{x}}$ and $9.0816 \mathrm{E}+04 e^{8 \mathrm{E}-06 \mathrm{x}}$. The $b_{\text {sebs }} / b_{\text {sebssiwa }}$ linearization quotient for mesotropic gene locus INSL3 is 5.06. The sebs sebssiwa residual for mesotropic gene locus INSL3 is 32, 763, 248,680; 74,198 and 133,207. The uppesebssiwaa and dppesebssiwaa for mesotropic gene locus INSL3 are $7.4198 \mathrm{E}+04$ and $1.33207 \mathrm{E}+05$. The esebssiwaago $T_{\mathrm{Q}}$ for mesotropic gene locus INSL3 is 0.321 . Mesotropic gene locus INSL3 is positioned at angle $\Theta_{M}=51.2^{0}$ in the $z, y$-axis vertical plane (Table 3 ).

The uppasebs, dppasebs, uppmsebs and dppasebs for mesotropic gene locus NFE2L2 are $5.8996 \mathrm{E}+04$, $5.78798 \mathrm{E}+05,5.60911 \mathrm{E}+05$ and 1.359677E + 06. The uppasebssiwa, dppasebssiwa, uppmsebssiwa and dppasebssiwa for mesotropic gene locus NFE2L2 are 9.833E + $03,9.6466 \mathrm{E}+04,1.12182 \mathrm{E}+05$ and $2.71935 \mathrm{E}+05$. The sebs and sebssiwa exponential function pair for mesotropic gene locus NFE2L2 is $5.23516 \mathrm{E}+05 e^{2 \mathrm{E}-06 \mathrm{x}}$ and $8.7324 \mathrm{E}+04$ $e^{1 \mathrm{E}-05 \mathrm{x}}$. The $b_{\text {sebs }} / b_{\text {sebssiwa }}$ linearization quotient for mesotropic gene locus NFE2L2 is 5.995. The sebs - sebssiwa residual for mesotropic gene locus NFE2L2 is 49,163, 482, 332, 448,729 and 1,087,741. The uppesebssiwaa and dppesebssiwaa for mesotropic gene locus NFE2L2 are 6.1007E +04 and $1.84201 \mathrm{E}+05$. The esebssiwaago $T_{\mathrm{Q}}$ for mesotropic gene locus NFE2L2 is 0.331. Mesotropic gene locus NFE2L2 is positioned at angle $\Theta_{M}=50.2^{0}$ in the $z, y$-axis vertical plane (Table 3 ).

The uppasebs, dppasebs, uppmsebs and dppasebs for mesotropic gene locus JUND are, 2.2037E + 04, $1.38709 \mathrm{E}+05,1.69285 \mathrm{E}+05$ and $3.92203 \mathrm{E}+05$. The uppasebssiwa, dppasebssiwa, uppmsebssiwa and dppasebssiwa for mesotropic gene locus JUND are 7.346E + $03,4.6236 \mathrm{E}+04,4.2321 \mathrm{E}+04$ and 9.8051E + 04. The sebs and sebssiwa exponential function pair for mesotropic gene locus JUND is $1.18726 \mathrm{E}+05 e^{7 \mathrm{E}-06 \mathrm{x}}$ and $3.9484 \mathrm{E}+04 e^{2 \mathrm{E}-05 \mathrm{x}}$. The $b_{\text {sebs }} / b_{\text {sebssiwa }}$ linearization quotient for mesotropic gene locus JUND is 3.01. The sebs sebssiwa residual for mesotropic gene locus JUND is 14, 691, 92,423, 126,964, and 294,152. The uppesebssiwaa and dppesebssiwaa for mesotropic gene locus JUND are $2.4833 \mathrm{E}+04$ and 7.2144E +04 . The esebssiwaago $T_{\mathrm{Q}}$ for mesotropic gene locus JUND is 0.344 . Mesotropic gene locus JUND is positioned at angle $\Theta_{M}=48.4^{\circ}$ in the $z, y$ axis vertical plane (Table 3 ).

The uppasebs, dppasebs, uppmsebs and dppasebs for mesotropic gene locus PRDM1 are 3.4053E + 04, $1.63936 \mathrm{E}+05,7.8539 \mathrm{E}+04$ and $1.75378 \mathrm{E}+05$. The uppasebssiwa, dppasebssiwa, uppmsebssiwa and dppasebssiwa for mesotropic gene locus PRDM1 are 1.1351E $+04,5.4645 \mathrm{E}+04,3.9270 \mathrm{E}+04$ and $8.7689 \mathrm{E}+04$. The sebs and sebssiwa exponential function pair for mesotropic gene locus PRDM1 is $1.55684 \mathrm{E}+05 e^{2 \mathrm{E}-06 \mathrm{x}}$ and $4.5086 \mathrm{E}+04 e^{2 \mathrm{E}-05 \mathrm{x}}$. The $b_{\text {sebs }} / b_{\text {sebssiwa }}$ linearization quotient for mesotropic gene locus PRDM1 is 3.45 . The sebs - sebssiwa residual for mesotropic gene locus PRDM1 is $2.2702 \mathrm{E}+04,1.09291 \mathrm{E}+05,3.9270 \mathrm{E}+04$ and $8.7689 \mathrm{E}$ +04 . The uppesebssiwaa and dppesebssiwaa for mesotropic gene locus PRDM1 are 2.5311E + 04 and 7.1167E + 04. The esebssiwaago $T_{\mathrm{Q}}$ for mesotropic gene locus PRDM1 is 0.356. Mesotropic gene locus PRDM1 is positioned at angle $\Theta_{M}=47.0^{\circ}$ in the $z, y$-axis vertical plane (Table 3).

The uppasebs, dppasebs, uppmsebs and dppasebs for mesotropic gene locus RGS13 are 1.9877E + 04, $2.92457 \mathrm{E}+05,4.41738 \mathrm{E}+05$ and $8.70097 \mathrm{E}+05$. The uppasebssiwa, dppasebssiwa, uppmsebssiwa and dppasebssiwa for mesotropic gene locus RGS13 are 9.939E + $03,1.46229 \mathrm{E}+05,1.47246 \mathrm{E}+05$ and $2.90032 \mathrm{E}+05$. The sebs and sebssiwa exponential function pair for mesotropic gene locus RGS13 is $2.77812 \mathrm{E}+05 e^{3 \mathrm{E}-06 \mathrm{x}}$ and $1.39157 \mathrm{E}+05 e^{5 \mathrm{E}-06 \mathrm{x}}$. The $b_{\text {sebs }} / b_{\text {sebssiwa }}$ linearization 
quotient for mesotropic gene locus RGS13 is 1.996. The sebs - sebssiwa residual for mesotropic gene locus RGS13 is 9,939, 146,229, 294,492 and 580,065. The uppesebssiwaa and dppesebssiwaa for mesotropic gene locus RGS13 are 7.8592E + 04 and 2.18130E + 05. The esebssiwaago $T_{\mathrm{Q}}$ for mesotropic gene locus RGS13 is 0.360 . Mesotropic gene locus $R G S 13$ is positioned at angle $\Theta_{M}=46.5^{\circ}$ in the $z, y$-axis vertical plane (Table 3).

The uppasebs, dppasebs, uppmsebs and dppasebs for mesotropic gene locus CEACAM1 are 2.6442E + 04, 1.35371E + 05, 1.89995E + 05 and 3.95194E + 05. The uppasebssiwa, dppasebssiwa, uppmsebssiwa and dppasebssiwa for mesotropic gene locus CEACAM1 are 13, $221,67,686,63,332$ and 131,731 . The sebs and sebssiwa exponential function pair for mesotropic gene locus CEACAM1 is $1.13842 \mathrm{E}+05 e^{2 \mathrm{E}-06 \mathrm{x}}$ and $5.6780 \mathrm{E}+04$ $e^{1 \mathrm{E}-05 \mathrm{x}}$. The $b_{\text {sebs }} / b_{\text {sebssiwa }}$ linearization quotient for mesotropic gene locus CEACAM1 is 2.005. The sebs sebssiwa residual for mesotropic gene locus CEACAM1 is $13,221,67,686,126,663$ and 263,463 . The uppesebssiwaa and dppesebssiwaa for mesotropic gene locus CEACAM1 are 3.8276E + 04 and 9.9708E + 04. The esebssiwaago $T_{\mathrm{Q}}$ for mesotropic gene locus CEACAM1 is 0.384 . Mesotropic gene locus CEACAM1 is positioned at angle $\Theta_{M}=43.6^{0}$ in the $z, y$-axis vertical plane (Table 3).

The uppasebs, dppasebs, uppmsebs and dppasebs for mesotropic gene locus GABPA are 8.904E + 03, $4.9560 \mathrm{E}+04,4.63859 \mathrm{E}+05$ and $8.76791 \mathrm{E}+05$. The uppasebssiwa, dppasebssiwa, uppmsebssiwa and dppasebssiwa for mesotropic gene locus GABPA are $8.904 \mathrm{E}+03,4.9560 \mathrm{E}+04,2.31930 \mathrm{E}+05$ and $4.38396 \mathrm{E}+05$. The $b_{\text {sebs }} / b_{\text {sebssiwa }}$ linearization quotient for GABPA is not applicable. The sebs - sebssiwa residual for mesotropic gene locus GABPA is nil, nil, 231,930 and 438,396. The uppesebssiwaa and dppesebssiwaa for mesotropic gene locus GABPA are 1.20417E + 05 and 2.43978E + 05. The esebssiwaago $T_{\mathrm{Q}}$ for mesotropic gene locus GABPA is 0.494 . Mesotropic gene locus GABPA is positioned at angle $\Theta_{M}=30.3^{0}$ in the $z, y$-axis vertical plane (Table 3 ).

The uppasebs, dppasebs, uppmsebs and dppasebs for mesotropic gene locus CD34 are 5.03E + 02, 5.565E + 03, 1.94524E + 05 and 2.90844E + 05. The uppasebssiwa, dppasebssiwa, uppmsebssiwa and dppasebssiwa for mesotropic gene locus CD34 are 5.03E + 02, 5.565E + $03,9.7262 \mathrm{E}+04$ and $1.45422 \mathrm{E}+05$. The $b_{\text {sebs }} / b_{\text {sebssiwa }}$ linearization quotient for $C D 34$ is not applicable. The sebs - sebssiwa residual for mesotropic gene locus CD34 is nil, nil, 97,262 and 145,422. The uppesebssiwaa and dppesebssiwaa for mesotropic gene locus CD34 are $4.8882 \mathrm{E}+04$ and 7.5493E +04 . The esebssiwaago $T_{\mathrm{Q}}$ for mesotropic gene locus CD34 is 0.648. Mesotropic gene locus $C D 34$ is positioned at angle $\Theta_{M}=11.7^{0}$ in the $z, y$ axis vertical plane (Table 3 ). $\boldsymbol{b}_{\text {sebs }} / \boldsymbol{b}_{\text {sebssiwa }}$ linearization quotient and sebs - sebssiwa residual statistical significance by effective intracellular pressure gene esebssiwaago $T_{\mathrm{Q}}$ stratum

The $b_{\text {sebs }} / b_{\text {sebssiwa }}$ linearization quotient is $3.143 \pm 0.688$ for tier $1\left(P_{\text {eff }} \leq 0.200, n=11\right)$. The $\Sigma$ intergene tropy for tier 1 is $1.162733 \mathrm{E}+06 \pm 497,383$ intergene bases. The $b_{\text {sebs }} / b_{\text {sebssiwa }}$ linearization quotient is $2.240 \pm 0.463$ for tier $2\left(P_{\text {eff }}>0.200\right.$ $\leq 0.300, n=6 ; p=0.006$ vs tier 1$)$. The $\Sigma$ intergene tropy for tier 2 is $7.34813 \mathrm{E}+05 \pm 856,523$ intergene bases $(p=0.103$ vs tier 1$)$. The $b_{\text {sebs }} / b_{\text {sebssiwa }}$ linearization quotient is $3.670 \pm$ 1.393 for tier $3\left(P_{\text {eff }}>0.300, n=8\right.$, non-nil; $p=0.145$ vs tier $1 ; p=0.017$ vs tier 2 ). The $\Sigma$ intergene tropy is $9.64537 \mathrm{E}+05$ $\pm 749,407$ intergene bases for tier 3 ( $p=0.248$ vs tier $1 ; p=$ 0.301 vs tier 2).

The uppasebs, uppasebssiwa residual is $4.4214 \mathrm{E}+04 \pm$ 24,373 for tier $1\left(P_{\text {eff }} \leq 0.200, n=11\right)$. The dppasebs, dppasebssiwa residual is $5.47340 \mathrm{E}+05 \pm 258,360$ for tier $1(n=11)$. The uppmsebs, uppmsebssiwa residual is $5.3053 \mathrm{E}+04 \pm 34,298$ for tier $1(n=11)$. The dppmsebs, dppmsebssiwa residual is $1.24074 \mathrm{E}+05 \pm 82,270$ for tier $1(n=11)$.

The uppasebs, uppasebssiwa residual is $2.5470 \mathrm{E}+04 \pm$ 32,476 for tier $2\left(P_{\text {eff }}>0.200 \leq 0.300, n=6 ; p=0.098\right.$ vs tier 1). The dppasebs, dppasebssiwa residual is $1.87595 \mathrm{E}+05 \pm 217,367$ for tier $2(n=6 ; p=0.006$ vs tier $1)$. The uppmsebs, uppmsebssiwa residual is $5.2179 \mathrm{E}+04$ $\pm 65,457$ for tier $2(n=6 ; p=0.486$ vs tier 1$)$. The dppmsebs, dppmsebssiwa residual is $1.21333 \mathrm{E}+05 \pm 112$, 712 for tier $2(n=6 ; p=0.477$ vs tier 1$)$.

The uppasebs, uppasebssiwa residual is $3.6877 \mathrm{E}+04 \pm$ 38,272 for tier 3 ( $P_{\text {eff }}>0.300, n=8$, non-nil; $p=0.308$ vs tier $1 ; p=0.284$ vs tier 2$)$. The dppasebs, dppasebssiwa residual is $2.03613 \mathrm{E}+05 \pm 129,187$ for tier 3 ( $n=8$, nonnil; $p=0.002$ vs tier $1 ; p=0.433$ vs tier 2$)$. The uppmsebs, uppmsebssiwa residual is $1.33445 \mathrm{E}+05 \pm 156,526$ for tier 3 $(n=8 ; p=0.057$ vs tier $1 ; p=0.129$ vs tier 2$)$. The dppmsebs, dppmsebssiwa residual is $2.99853 \mathrm{E}+05 \pm 364$, 084 for tier 3 ( $n=8$, non-nil; $p=0.068$ vs tier $1 ; p=0.136$ vs tier 2).

\section{Heterochromatinization parameters for differentiated neural axis gene angulation positioning in linear 2- dimensional $z, y$-vertical plane}

The uppasebs, dppasebs, uppmsebs and dppasebs for UNC13A are 5.888E + 03, 2.8975E + 04, 1.65112E + 05, $3.50047 \mathrm{E}+$ 05. The uppasebssiwa, dppasebssiwa, uppmsebssiwa and dppasebssiwa for UNC13A are $5.888 \mathrm{E}+03,2.8975 \mathrm{E}+04,8.2556 \mathrm{E}+04$ and $1.75024 \mathrm{E}+$ 05 . The $b_{\text {sebs }} / b_{\text {sebssiwa }}$ linearization quotient for $U N C 13 A$ is not applicable. The sebs - sebssiwa residual for UNC13A is nil, nil, 82,556 and 175,024. The uppesebssiwaa and dppesebssiwaa for UNC13A are 4.4222E + 04 and $1.01999 \mathrm{E}+05$. The esebssiwaago $T_{\mathrm{Q}}$ for $U N C 13 A$ is 
Sain Translational Medicine Communications

(2019) 4:13

Page 20 of 33

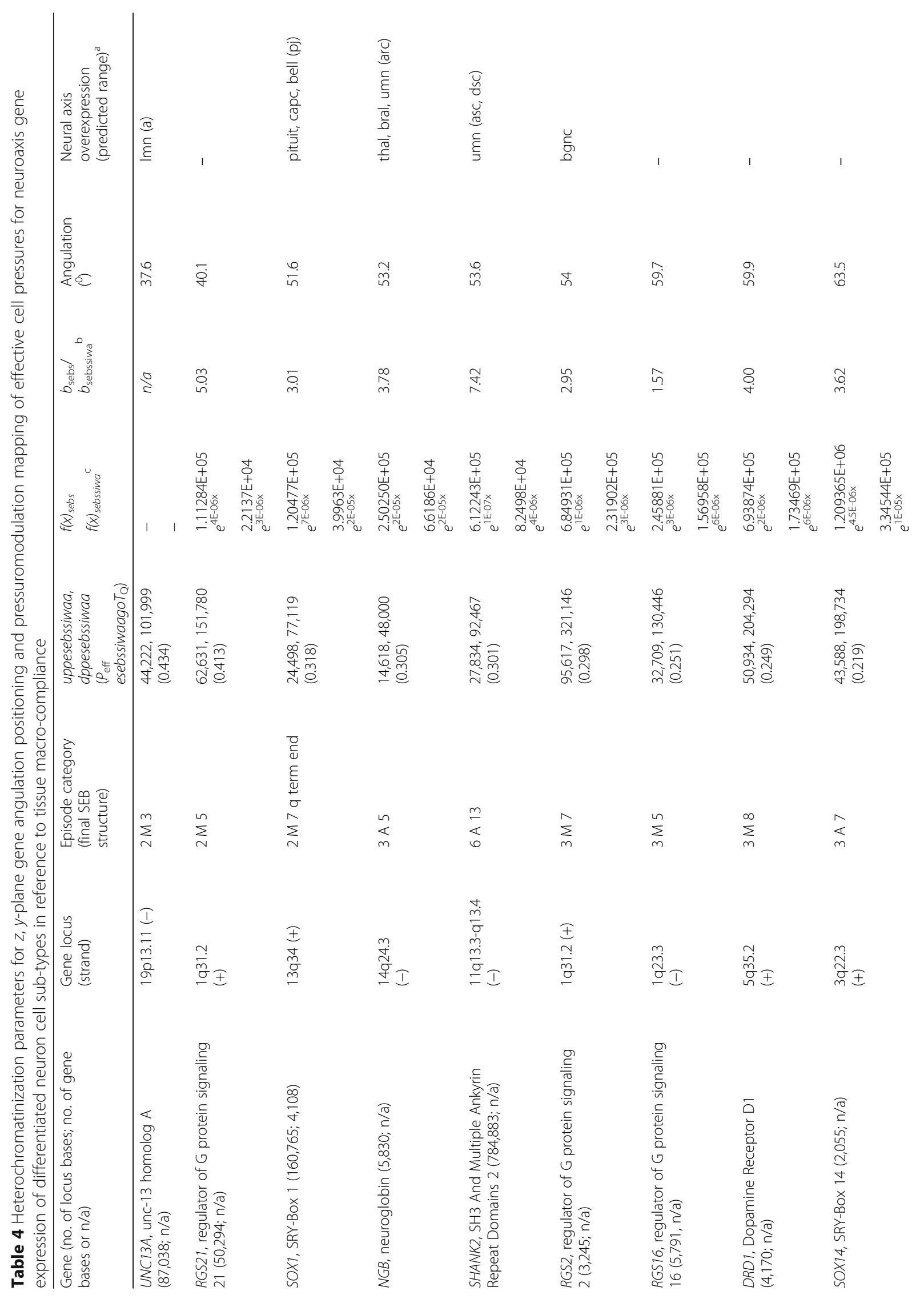




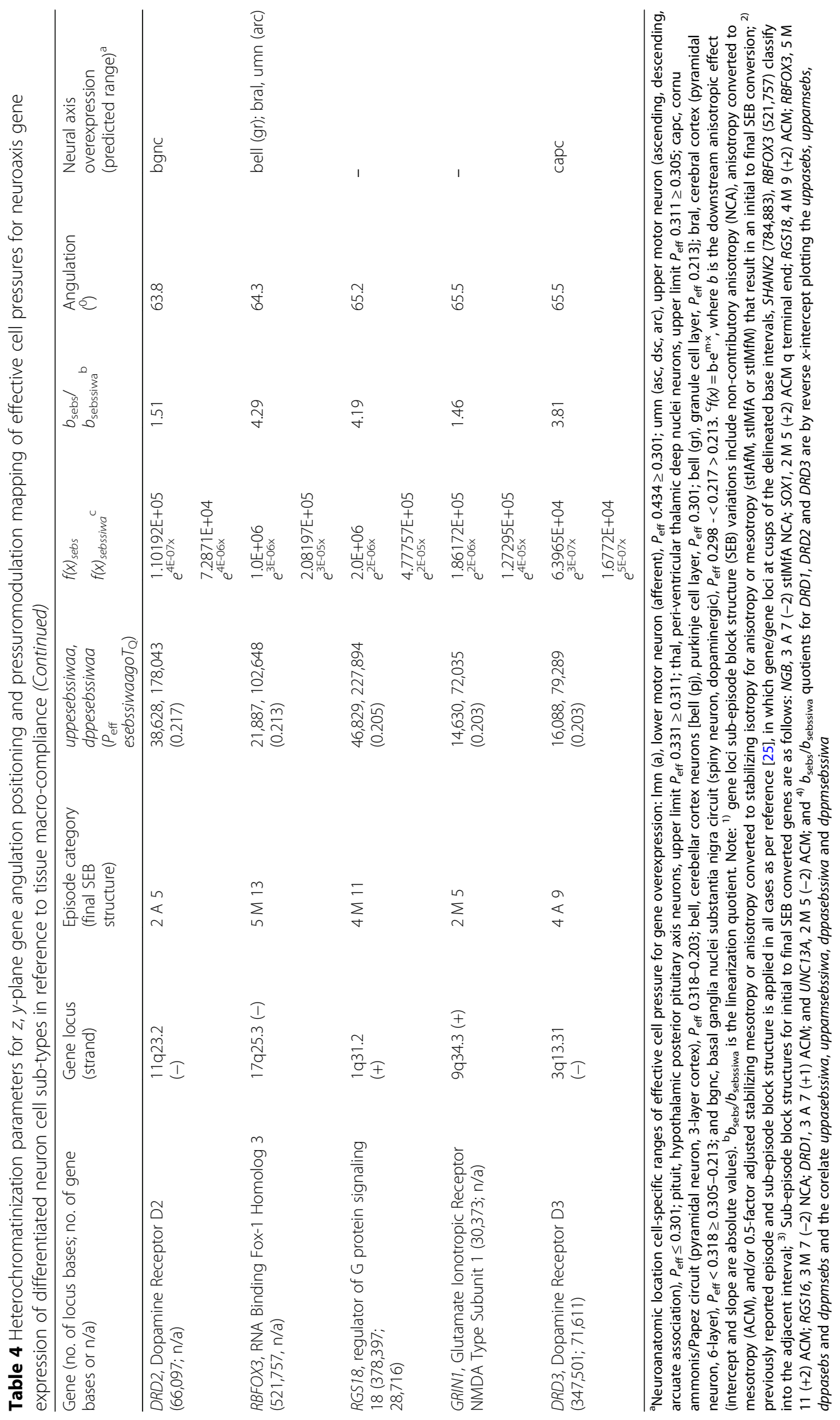


0.434. UNC13A is positioned at angle $\Theta_{\mathrm{M}}=37.6^{\circ}$ in the $z, y$-axis vertical plane.

The uppasebs, dppasebs, uppmsebs and dppasebs for RGS21 are 1.3087E + 04, 2.29159E + 05, 3.56158E + 05 and 5.66939E +05 . The uppasebssiwa, dppasebssiwa, uppmsebssiwa and dppasebssiwa for RGS21 are 6.544E + $03,1.14580 \mathrm{E}+05,1.18719 \mathrm{E}+05$ and $1.88980 \mathrm{E}+05$. The sebs and sebssiwa exponential function pair for RGS21 is $1.11284 \mathrm{E}+05 e^{4 \mathrm{E}-06 \mathrm{x}}$ and $2.2137 \mathrm{E}+04 e^{3 \mathrm{E}-06 \mathrm{x}}$. The $b_{\text {sebs }} / b_{\text {sebssiwa }}$ linearization quotient for $R G S 21$ is 5.03. The sebs - sebssiwa residual for RGS21 is 6,544 , 114,580, 237,439 and 377,959. The uppesebssiwaa and dppesebssiwaa for RGS21 are $6.2631 \mathrm{E}+04$ and $1.51780 \mathrm{E}+05$. The esebssiwaago $T_{\mathrm{Q}}$ for $R G S 21$ is 0.413 . RGS21 is positioned at angle $\Theta_{\mathrm{M}}=40.1^{0}$ in the $z, y$-axis vertical plane (Table 4; Additional file 1: Table S1).

The uppasebs, dppasebs, uppmsebs and dppasebs for SOX1 are 1.6642E + 04, 1.36246E + 05, 1.73795E and $4.35291 \mathrm{E}+05$. The uppasebssiwa, dppasebssiwa, uppmsebssiwa and dppasebssiwa for SOX1 are 5.547E + 03, 4.5415E + 04, 4.3449E + 04 and 1.08823E + 05. The sebs and sebssiwa exponential function pair for $S O X 1$ is $1.20477 \mathrm{E}+05 e^{7 \mathrm{E}-06 \mathrm{x}}$ and $3.9963 \mathrm{E}+04 e^{2 \mathrm{E}-05 \mathrm{x}}$. The $b_{\text {sebs }} /$ $b_{\text {sebssiwa }}$ linearization quotient for $S O X 1$ is 3.01 . The sebs - sebssiwa residual for SOX1 is 11,095, 90,830, 130,346 and 326,468. The uppesebssiwaa and dppesebssiwaa for SOX1 are 2.4498E + 04 and 7.7119E + 04. The esebssiwaago $_{\mathrm{Q}}$ for $S O X 1$ is 0.318 . SOX1 is positioned at angle $\Theta_{M}=51.6^{\circ}$ in the $z, y$-axis vertical plane (Table 4; Additional file 1: Table S1).

The uppasebs, dppasebs, uppmsebs and dppasebs for $N G B$ are $1.6465 \mathrm{E}+04,1.68356 \mathrm{E}+05,4.7494 \mathrm{E}+04$ and 7.9764E + 04. The uppasebssiwa, dppasebssiwa, uppmsebssiwa and dppasebssiwa for NGB are 5.488E + 03, 5.6119E + 04, 2.3747E + 04 and 3.9882E + 04. The sebs and sebssiwa exponential function pair for $N G B$ is $2.50250 \mathrm{E}+05 e^{2 \mathrm{E}-05 \mathrm{x}}$ and $6.6186 \mathrm{E}+04 e^{2 \mathrm{E}-05 \mathrm{x}}$. The $b_{\text {sebs }} /$ $b_{\text {sebssiwa }}$ linearization quotient for $N G B$ is 3.78 . The sebs - sebssiwa residual for $N G B$ is $10,977,112,238,23,747$ and 39,882. The uppesebssiwaa and dppesebssiwaa for $N G B$ are $1.4618 \mathrm{E}+04$ and $4.8000 \mathrm{E}+04$. The esebssiwaago $_{\mathrm{Q}}$ for $N G B$ is 0.305 . $N G B$ is positioned at angle $\Theta_{M}=53.2^{\circ}$ in the $z, y$-axis vertical plane (Table 4; Additional file 1: Table S1).

The uppasebs, dppasebs, uppmsebs and dppasebs for SHANK1 are 7.9764E + 04, 8.2330E + 04, 6.05471E + $05,2.63439 \mathrm{E}+05$ and $5.90625 \mathrm{E}+05$. The uppasebssiwa, dppasebssiwa, uppmsebssiwa and dppasebssiwa for SHANK1 are 1.1761E + 04, 8.6496E + 04, 4.3907E + 04 and $9.8438 \mathrm{E}+04$. The sebs and sebssiwa exponential function pair for SHANK1 is $6.12243 \mathrm{E}+05 e^{1 \mathrm{E}-07 \mathrm{x}}$ and $8.2498 \mathrm{E}+04 e^{4 \mathrm{E}-06 \mathrm{x}}$. The $b_{\text {sebs }} / b_{\text {sebssiwa }}$ linearization quotient for SHANK1 is 7.42. The sebs - sebssiwa residual for SHANK1 is $70,569,518,975,219,533$ and 492,188 .
The uppesebssiwaa and dppesebssiwaa for SHANK1 are $2.7834 \mathrm{E}+04$ and $9.2467 \mathrm{E}+04$. The esebssiwaagoT $T_{\mathrm{Q}}$ for SHANK1 is 0.301. SHANK1 is positioned at angle $\Theta_{M}=53.6^{\circ}$ in the $z$, $y$-axis vertical plane (Table 4; Additional file 1: Table S1).

The uppasebs, dppasebs, uppmsebs and dppasebs for RGS2 are 7.9267E + 04, 7.56237E + 05, 6.59244E + 05 and $1.560848 \mathrm{E}+06$. The uppasebssiwa, dppasebssiwa, uppmsebssiwa and dppasebssiwa for RGS2 are 2.6422E + $04,2.52079 \mathrm{E}+05,1.64811 \mathrm{E}+05$ and 3.90212E + 05 . The sebs and sebssiwa exponential function pair for $R G S 2$ is $6.84931 \mathrm{E}+05 e^{1 \mathrm{E}-06 \mathrm{x}}$ and $2.31902 \mathrm{E}+05 e^{3 \mathrm{E}-06 \mathrm{x}}$. The $b_{\text {sebs }} / b_{\text {sebssiwa }}$ linearization quotient for $R G S 2$ is 2.95. The sebs - sebssiwa residual for RGS2 is 52,845 , 504,158, 494,433 and 1,170,636. The uppesebssiwaa and dppesebssiwaa for RGS2 are 9.5617E + 04 and 3.21146E + 05. The esebssiwaago $T_{\mathrm{Q}}$ for $R G S 2$ is 0.298 . RGS2 is positioned at angle $\Theta_{M}=54^{0}$ in the $z, y$-axis vertical plane (Table 4; Additional file 1: Table S1).

The uppasebs, dppasebs, uppmsebs and dppasebs for RGS16 are 4.1927E + 04, 2.78410E + 05, 1.33362E + 05 and $6.5059 \mathrm{E}+04$. The uppasebssiwa, dppasebssiwa, uppmsebssiwa and dppasebssiwa for RGS16 are $2.0964 \mathrm{E}$ + 04, 1.39205E + 05, 4.4454E + 04 and 1.21686E + 05 . The sebs and sebssiwa exponential function pair for RGS16 is $2.45881 \mathrm{E}+05 e^{3 \mathrm{E}-06 \mathrm{x}}$ and $1.56958 \mathrm{E}+05 e^{6 \mathrm{E}-06 \mathrm{x}}$. The $b_{\text {sebs }} / b_{\text {sebssiwa }}$ linearization quotient for RGS16 is 1.57. The sebs - sebssiwa residual for RGS16 is 20,964, $139,205,88,908$ and 243,373. The uppesebssiwaa and dppesebssiwaa for RGS16 are 3.2709E + 04 and $1.30446 \mathrm{E}+05$. The esebssiwaago $T_{\mathrm{Q}}$ for $R$ RS16 is 0.251 . RGS16 is positioned at angle $\mathrm{M}=59.7^{0}$ in the $z, y$-axis vertical plane (Table 4; Additional file 1: Table S1).

The uppasebs, dppasebs, uppmsebs and dppasebs for DRD1 are 1.27930E + 05, 1.062852E + 06, 2.79538E + 05 and 5.71499E +05 . The uppasebssiwa, dppasebssiwa, uppmsebssiwa and dppasebssiwa for DRD1 are 3.1983E $+04,2.65713 \mathrm{E}+05,6.9885 \mathrm{E}+04$ and $1.42875 \mathrm{E}+05$. The sebs and sebssiwa exponential function pair for DRD1 is $6.93874 \mathrm{E}+05 e^{2 \mathrm{E}-06 \mathrm{x}}$ and $1.73469 \mathrm{E}+05 e^{6 \mathrm{E}-06 \mathrm{x}}$. The $b_{\text {sebs }} / b_{\text {sebssiwa }}$ linearization quotient for $D R D 1$ is 4.00. The sebs - sebssiwa residual for DRD1 is 95,948 , 797,139, 209,654 and 428,624. The uppesebssiwaa and dppesebssiwaa for DRD1 are 5.0934E + 04 and 2.04294E +05 . The esebssiwaago $T_{\mathrm{Q}}$ for $D R D 1$ is $0.249 . D R D 1$ is positioned at angle $\Theta_{M}=59.9^{0}$ in the $z, y$-axis vertical plane (Table 4; Additional file 1: Table S1).

The uppasebs, dppasebs, uppmsebs and dppasebs for SOX14 are 7.6621E + 04, 1.016347E + 06, 2.04065E + 05 and 4.30144E + 05. The uppasebssiwa, dppasebssiwa, uppmsebssiwa and dppasebssiwa for SOX14 are 1.9155E $+04,2.54087 \mathrm{E}+05,6.8022 \mathrm{E}+04$ and 1.43381E + 05 . The sebs and sebssiwa exponential function pair for SOX14 is 1.209365E+06 $e^{4.5 \mathrm{E}-06 \mathrm{x}}$ and $3.34544 \mathrm{E}+05$ 
$e^{1 \mathrm{E}-05 \mathrm{x}}$. The $b_{\text {sebs }} / b_{\text {sebssiwa }}$ linearization quotient for SOX14 is 3.62. The sebs - sebssiwa residual for SOX14 is $57,466,762,260,136,043$ and 286,763. The uppesebssiwaa and dppesebssiwaa for SOX14 are 4.3588E + 04 and $1.98734 \mathrm{E}+05$. The esebssiwaago $T_{\mathrm{Q}}$ for SOX14 is 0.219 . SOX14 is positioned at angle $\Theta_{\mathrm{A}}=63.5^{\circ}$ in the $z, y$-axis vertical plane (Table 4; Additional file 1: Table S1).

The uppasebs, dppasebs, uppmsebs and dppasebs for DRD2 are 7.8907E + 04, 7.90658E + 05, 1.01906E + 05 and $1.85067 \mathrm{E}+05$. The uppasebssiwa, dppasebssiwa, uppmsebssiwa and dppasebssiwa for DRD2 are 2.6302E $+04,2.63553 \mathrm{E}+05,5.0953 \mathrm{E}+04$ and 9.2533E + 04 . The sebs and sebssiwa exponential function pair for DRD2 is $1.10192 \mathrm{E}+05 e^{4 \mathrm{E}-07 \mathrm{x}}$ and 7.2871E+04 $e^{4 \mathrm{E}-06 \mathrm{x}}$. The $b_{\text {sebs }} / b_{\text {sebssiwa }}$ linearization quotient for DRD2 is1.51. The sebs - sebssiwa residual for DRD2 is $52,605,527$, 106, 50,953 and 92,533. The uppesebssiwaa and dppesebssiwaa for DRD2 are 3.8628E + 04 and 1.78043E + 05. The esebssiwaago $T_{\mathrm{Q}}$ for $D R D 2$ is $0.217 . D R D 2$ is positioned at angle $\Theta_{\mathrm{A}}=63.8^{\circ}$ in the $z, y$-axis vertical plane (Table 4; Additional file 1: Table S1).

The uppasebs, dppasebs, uppmsebs and dppasebs for RBFOX3 are 7.7745E + 04, 7.99501E + 05, 2.15712E + 05 and $5.04325 \mathrm{E}+05$. The uppasebssiwa, dppasebssiwa, uppmsebssiwa and dppasebssiwa for RBFOX3 are 1.2957E + 04, 1.33250E + 05, 3.0816E + 04 and 7.2046E +04 . The sebs and sebssiwa exponential function pair for $R B F O X 3$ is $1.10192 \mathrm{E}+05 e^{4 \mathrm{E}-07 \mathrm{x}}$ and $7.2871 \mathrm{E}+04$ $e^{4 \mathrm{E}-06 \mathrm{x}}$. The $b_{\text {sebs }} / b_{\text {sebssiwa }}$ linearization quotient for RBFOX3 is 4.80. The sebs - sebssiwa residual for RBFOX3 is $64,787,666,251,184,896$ and 432,278 . The uppesebssiwaa and dppesebssiwaa for RBFOX3 are $2.1887 \mathrm{E}+04$ and $1.02648 \mathrm{E}+05$. The esebssiwaago $T_{\mathrm{Q}}$ for $R B F O X 3$ is 0.213 . RBFOX3 is positioned at angle $\Theta_{\mathrm{A}}=$ $64.3^{0}$ in the $z, y$-axis vertical plane (Table 4; Additional file 1: Table S1).

The uppasebs, dppasebs, uppmsebs and dppasebs for RGS18 are 1.53005E + 05, 1.438692E + 06, 3.78343E + 05 and 1.008303E + 06. The uppasebssiwa, dppasebssiwa, uppmsebssiwa and dppasebssiwa for RGS18 are $3.0601 \mathrm{E}+04,2.87738 \mathrm{E}+05,6.3057 \mathrm{E}+04$ and $1.68050 \mathrm{E}+05$. The sebs and sebssiwa exponential function pair for $R G S 18$ is $2.0 \mathrm{E}+06 e^{2 \mathrm{E}-06 \mathrm{x}}$ and $4.77757 \mathrm{E}+05$ $e^{2 \mathrm{E}-05 \mathrm{x}}$. The $b_{\text {sebs }} / b_{\text {sebssiwa }}$ linearization quotient for RGS18 is 4.19. The sebs - sebssiwa residual for RGS18 is $122,404,1,150,953,315,285$ and 840,252. The uppesebssiwaa and dppesebssiwaa for RGS18 are 4.6829E + 05 and $2.27894 \mathrm{E}+05$. The esebssiwaago $T_{\mathrm{Q}}$ for $R G S 18$ is 0.205 . RGS18 is positioned at angle $\Theta_{\mathrm{A}}=65.2^{0}$ in the $z, y$-axis vertical plane (Table 4; Additional file 1: Table S1).

The uppasebs, dppasebs, uppmsebs and dppasebs for GRIN1 are 1.7024E + 04, 1.79509E + 05, 6.2241E + 04 and 1.62947E + 05. The uppasebssiwa, dppasebssiwa, uppmsebssiwa and dppasebssiwa for GRIN1 are 8.512E +
03, 8.9755E + 04, 2.0747E + 04 and 5.4316E + 04. The sebs and sebssiwa exponential function pair for GRIN1 is $1.86172 \mathrm{E}+05 e^{2 \mathrm{E}-06 \mathrm{x}}$ and $1.27295 \mathrm{E}+05 e^{4 \mathrm{E}-05 \mathrm{x}}$. The $b_{\text {sebs }} / b_{\text {sebssiwa }}$ linearization quotient for GRIN1 is 1.46 .

The sebs - sebssiwa residual for GRIN1 is 8,512, 89, $755,41,494$ and 108,632. The uppesebssiwaa and dppesebssiwaa for GRIN1 are 1.4630E + 04 and 7.2035E + 04. The esebssiwaago $T_{\mathrm{Q}}$ for GRIN1 is 0.203 . GRIN1 is positioned at angle $\Theta_{\mathrm{A}}=65.5^{\circ}$ in the $z, y$-axis vertical plane (Table 4; Additional file 1: Table S1).

The uppasebs, dppasebs, uppmsebs and dppasebs for DRD3 are 7.8218E + 04, 6.57108E + 05, 6.6128E + 04 and $1.08626 \mathrm{E}+05$. The uppasebssiwa, dppasebssiwa, uppmsebssiwa and dppasebssiwa for DRD3 are 1.5644E $+04,1.31422 \mathrm{E}+05,1.6532 \mathrm{E}+04$ and 2.7157E + 04. The sebs and sebssiwa exponential function pair for $D R D 3$ is $6.3965 \mathrm{E}+04 e^{3 \mathrm{E}-07 \mathrm{x}}$ and $1.6772 \mathrm{E}+04 e^{5 \mathrm{E}-07 \mathrm{x}}$. The $b_{\text {sebs }} / b_{\text {sebssiwa }}$ linearization quotient for DRD3 is 3.81 . The sebs - sebssiwa residual for DRD3 is $62,574,525$, 686, 49,596 and 81,470. The uppesebssiwaa and dppesebssiwaa for DRD3 are 1.6088E + 04 and 7.9289E + 04 . The esebssiwaago $T_{\mathrm{Q}}$ for $D R D 3$ is 0.203 . DRD3 is positioned at angle $\Theta_{\mathrm{A}}=65.5^{\circ}$ in the $z, y$-axis vertical plane (Table 4; Additional file 1: Table S1).

\section{Discussion}

\section{Linear normalized determination of gene positioning} angulation in the $z, y$-plane by the esebssiwaago $T_{\mathrm{Q}}$ method effective intracellular pressure unit

The $b_{\text {sebs }} / b_{\text {sebssiwa }}$ sebs intercept-to-sebssiwa intercept quotient and residual adjustments have been determined in this study by $x-, y$ - or hybrid intercept exponential function plotting for specific detection of the predominant paired linearization effect as either the dppasebs, dppmsebs, uppasebs, uppmsebs, or dual uppasebs, uppmsebs, dppasebs, dppmsebs due to normalizing primary weighted averaging. Since the $b_{\text {sebs }} / b_{\text {sebssiwa }}$ linearization quotient for tier 1 sub-group analysis genes within the $P_{\text {eff }}$ stratum $\leq 0.200$ is $3.143 \pm 0.688(n=11)$, and that for tier 3 sub-group analysis genes within the $P_{\text {eff }}$ stratum $>0.300$ is $3.670 \pm 1.393(n=8 ; p=0.145$ vs tier 1), whereas that for tier 2 sub-group analysis genes within the $P_{\text {eff }}$ stratum $>0.200 \leq 0.300$ is $2.240 \pm 0.463$ ( $n=6 ; p=0.006$ vs tier 1$)$; these pairwise comparisons are consistent with primary linearization of the $d p p a-$ sebs, dppmsebs anisotropy effect for tier $1 \leq 0.200 P_{\text {eff }}$ genes and of the uppasebs, uppamsebs mesotropy effect for tier $3>0.300 P_{\text {eff }}$ genes, in contrast to dual linearization for tier 2 intermediate $P_{\text {eff }}$ stratum genes due to the presence of downstream and upstream tropy effects of equivalence. The pairwise statistical significance of the subtractive sebs, sebssiwa residual comparisons between tier 2 and tier 1 genes $(p=0.098$, $p=0.006, p=0.486, p=0.477)$, and between tier 3 and 
tier 1 genes $(p=0.308, p=0.002, p=0.057, p=0.068)$ is further consistent with the primary weighted averaging linearization due to uppmsebs and dppmsebs normalizing of the uppasebs and uppmsebs effects in tier 3 $>0.300 P_{\text {eff }}$ genes as probability for significance approaches alpha $(\alpha=0.05)$. Therefore, primary linearization adheres to the rule of split-integrated averaging to linearization of mutually exclusive upstream $(u p p-)$ and downstream (dpp-) parts within the respective anisotropic or mesotropic gene category inclusive of SEB interconversions; in which case, normalization of the dppasebs, dppmsebs effect predominates in anisotropic gene MYC $\left(b_{\text {sebs }} / b_{\text {sebssiwa }}: 3.63\right)$, the uppasebs, uppmsebs effect predominates in mesotropic gene PRDM1 ( $\left.b_{\text {sebs }} / b_{\text {sebssiwa }}: 3.45\right)$, while both the dppasebs, dppmsebs and uppasebs, uppmsebs effects are linear normalized in PRKCH ( $\left.b_{\text {sebs }} / b_{\text {sebssiwa }}: 3.17\right)$.

Secondary linearization of the anisotropic effect for both types of genes is by the mesotropic effect at the second weighted averaging stage of the uppesebssiwaa and dppesebssiwaa; as in the example of mesotropic gene INSL3 $\left(b_{\text {sebs }} / b_{\text {sebssiwa: }}: 5.06\right)$ in which there is further linearization of the split-integrated final anisotropic effect of 1.0921E + 04 (uppasebssiwa) and 8.2893E + 04 intergene bases (dppmsebssiwa) by the mesotropic effect of 3.7099E + 04 (dppasebssiwa) and 6.6603E + 04 (dppmsebssiwa), which results in an uppasebssiwaa, dppesebssiwaa of $2.4010 \mathrm{E}+04$ and 7.4748E $+04\left(P_{\text {eff }}\right.$, $0.321)$ for horizontal alignment from the $z, y$-plane $\left(\theta_{\mathrm{M}}=51.2^{0}\right)$; and as another example, anisotropic gene $C C N 2\left(b_{\text {sebs }} / b_{\text {sebssiwa: }}: 4.00\right)$ in which there is the further linearization of the split-integrated final anisotropic effect of $3.0356 \mathrm{E}+04$ and $2.79275 \mathrm{E}+05$ with a mesotropic effect of $4.2913 \mathrm{E}+04$ and $1.13936 \mathrm{E}+05$ intergene bases that results in an uppasebssiwaa, dppesebssiwaa of 30293E +04 and $1.82468 \mathrm{E}+05\left(P_{\text {eff, }}, 0.166\right)$ for $z, x$-plane transcriptive alignment $\left(\theta_{\mathrm{A}}=70.0^{\circ}\right)$.

Therefore, since the esebssiwaago $T_{\mathrm{Q}}$ method is based on the normalization of the anisotropy effect at two distinct stages and predicts the temporality of gene expression in linear normal effective intracellular pressure units $\left(P_{\text {eff }}\right)$ at which eukaryotic heterochromatin strand segments of DNA horizontally align for transcription with respect to the gene it can be applied to study gene positioning angulation in linear normal 2-D space, which implies that the process of horizontal $z, x$-plane alignment of a gene is linear normalized in the nucleoplasm of an eukaryotic cell.

Arrangement of genes in native positions is pressurotopic by heterochromatin gene loop segments of differing nano-compliance

The upstream 5' end intergene and downstream 3' end intergene base segments with respect a gene are subject

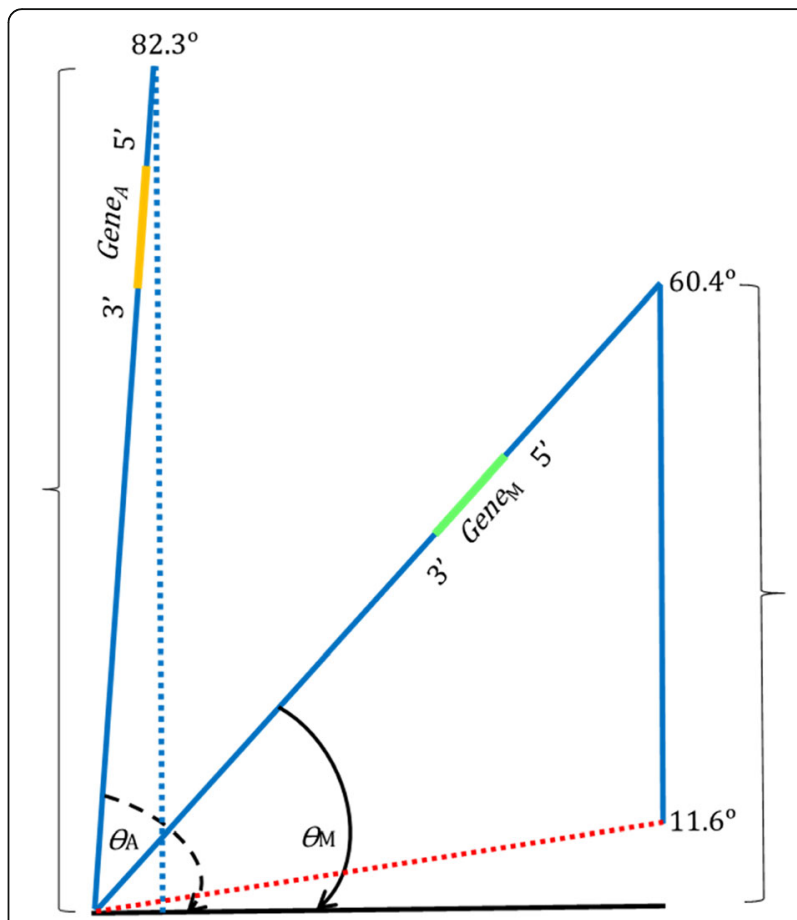

Fig. 4 Vectormetry for horizontal alignment of anisotropic and mesotropic genes by heterochromatin strand structural pressurotopy. Anisotropic gene loci are positioned between angles 82.3 and $60.5^{\circ}$ in the $z, y$-vertical plane encounter the chromatin-associated protein viscosity effect at intergene segments. The effective momentum $\left(\boldsymbol{m}_{\text {eff }}\right)$ in anisotropic gene alignment to the $z, x$-horizontal plane is $\boldsymbol{m}_{\mathrm{A}}=\boldsymbol{m}_{\mathrm{ch}}$ tropy $\left(-\boldsymbol{m}_{\text {pro-grav ch tropy }}\right)$ as indicated by the left bracket. Mesotropic gene loci are positioned between angles 60.4 and $11.7^{0}$ in the $z, y$-vertical plane encounter dual chromatin-associated protein viscosity effect at intergene segments and the nuclear membrane nucleoplasm chromatinassociated protein viscosity effect at intergene segments. The effective momentum $\left(\boldsymbol{m}_{\text {eff }}\right)$ in mesotropic gene alignment to the $z, x$-horizontal plane is $\boldsymbol{m}_{\mathrm{M}}=\boldsymbol{m}_{\mathrm{ch} \text { tropy }}+\boldsymbol{m}_{\mathrm{ch} \text { nmn tropy }}\left(-\boldsymbol{m}_{\text {pro-grav ch tropy }}\right)$ as indicated by the right bracket. The effective momentum $\left(\boldsymbol{m}_{\text {eff }}\right)$ in gene

transcription will be inversely proportional to the effective cell pressure $\left(P_{\text {eff }}\right)$ required for horizontal alignment of gene intergene loop segment tropy, $P_{\text {eff }}(0.064 \geq x<0.245) \cdot \boldsymbol{m}_{\mathrm{A}}=P_{\text {eff }}(0.245 \geq x \leq 0.648) \cdot \boldsymbol{m}_{\mathrm{M}}$. The initial momentum vector for anisotropic gene alignment, $\boldsymbol{m}_{\mathrm{ch}}$ tropy, will be greater as the origination point of anisotropic genes is 7.7 degrees $\left({ }^{0}\right)$ from the $z, y$-vertical, which require lesser applied pressure for horizontal alignment; whereas, the initial momentum vector for mesotropic gene alignment, $\boldsymbol{m}_{\mathrm{ch}}$ tropy $+\boldsymbol{m}_{\mathrm{ch} \text { nmn tropy }}\left(\boldsymbol{m}_{\mathrm{M}}\right)$, will be lesser as the origination point of mesotropic genes is between $29.6^{\circ}$ and 78.3 degrees $\left({ }^{9}\right)$ to the $z, y$-vertical plane, which require lesser applied pressure for horizontal alignment. Therefore, the effective momentum $\left(\boldsymbol{m}_{\text {eff; }} \boldsymbol{m}_{\mathrm{A}}, \boldsymbol{m}_{\mathrm{M}}\right)$ for gene transcription is inversely proportional to the effective cell pressure $\left(P_{\text {eff }}\right)$ required for horizontal alignment of gene intergene loop segment tropy. Legend. $\boldsymbol{m}_{\mathrm{ch} \text { tropy, }}$ left bracket; $\boldsymbol{m}_{\mathrm{ch} \text { tropy }}+\boldsymbol{m}_{\mathrm{ch} \text { nmn tropy, }}$ right bracket; $\boldsymbol{m}_{\text {pro-grav ch tropy, }}$ pro-gravitational momentum vector (not shown);

$P_{\text {effective intracellular pressure }}\left(P_{\text {eff }}\right)=P_{\text {effective intranuclear pressure }}$

to peptide, microRNA and functional pseudogene RNA affinity binding viscosity weighting effects in both forward transcribing and reverse anti-transcribing directions that are asymmetric [25], in which case each gene exists at angulation with reference to the $z, x$-axis 


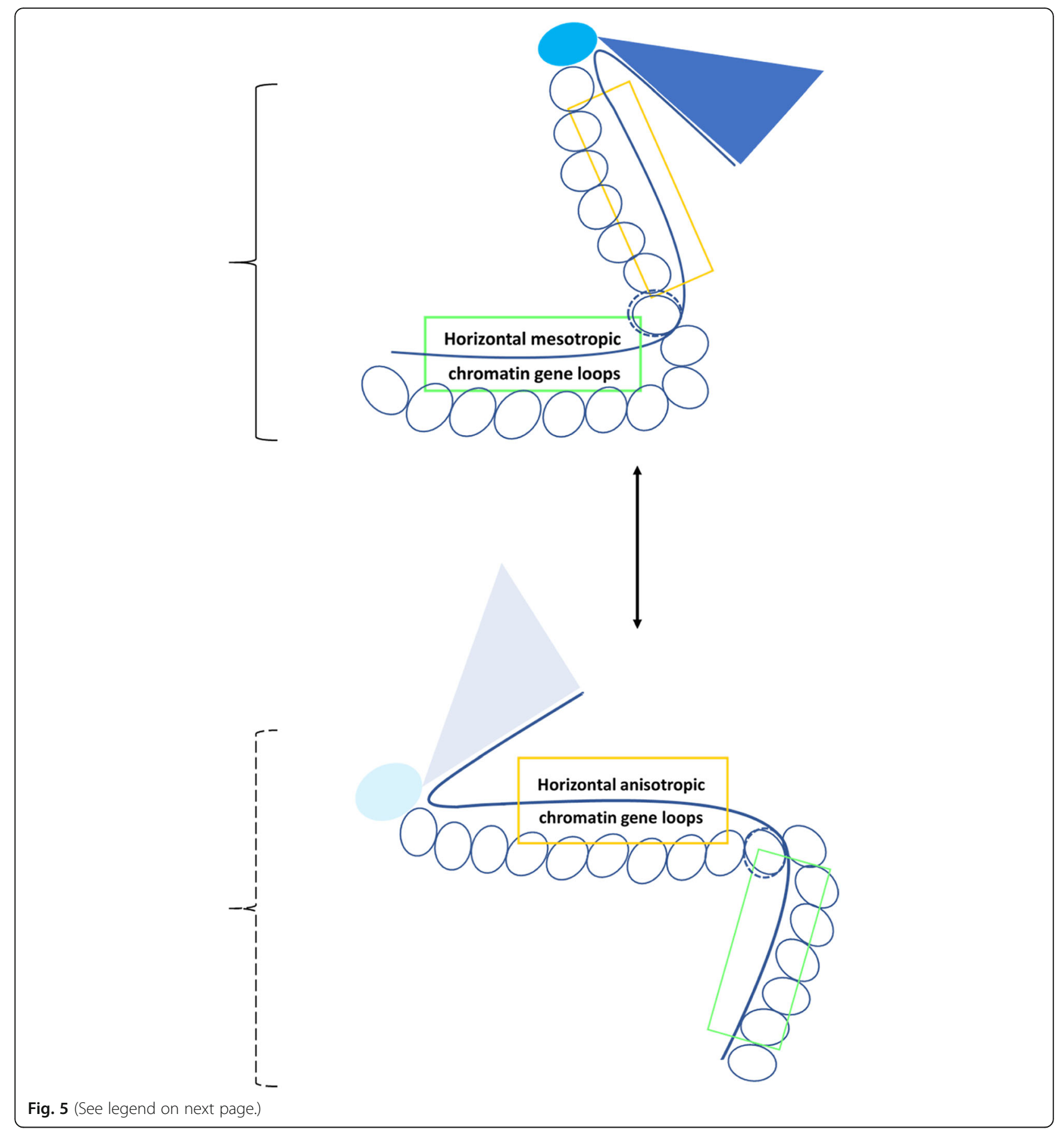


(See figure on previous page.)

Fig. 5 Pressurotopic model for binomial always-on heterochromatin gene transcription by anisotropic or mesotropic DNA strand loop microstructural segmentation. In the binomial always-on model of gene transcription by micro-structural segmentation pressurotopy, mesotropy and amorphousity loop form heterochromatin loop tropy strand genes positioned between 11.7 and $60.4^{0}$ degrees in the $z$, $y$-vertical plane perceiving asymmetric viscosity effects of the same align for transcription during increases of $P_{\text {eff }}$ to between 0.245 and 0.648 esebssiwaago $T_{Q}$ units within inner nuclear membrane (INM)-associated heterochromatin; whereas, anisotropy and amorphousity loop form heterochromatin loop tropy strand genes positioned between 60.5 and $82.3^{\circ}$ in the $z, y$-vertical plane perceiving lesser grade asymmetric viscosity effects of the same align for transcription during decreases in $P_{\text {eff }}$ to between 0.064 and 0.2445 esebssiwaago $T_{Q}$ units within peripheral nucleoplasm heterochromatin in association with un-limiting nuclear pore subunits. Heterochromatin shifts towards the inner nuclear envelope margin following the transcription of EMD $\left(P_{\text {eff }}, 0.234 ; \theta_{\mathrm{A}}=61.7^{\circ}\right)$ during which positive pressuromodulation at the cell membrane regulates mechanotransduction apparatus sensitivity for linear increases in nuclear effective pressure $\left(P_{\text {eff }}\right)$ and resultant mesotropic gene transcription; whereas, heterochromatin shifts towards the central peripheral nucleoplasm edge due to negative pressuromodulation at the cell membrane and mitochondrial oxidative challenge-exothermy, during which transcription of inner nuclear envelope peptide-coding genes $L M N B 1\left(P_{\text {eff, }} 0.197 ; \theta_{\mathrm{A}}=66.2^{\circ}\right) \rightarrow L M N A\left(P_{\text {eff }}\right.$ 0.184; $\left.\theta_{\mathrm{A}}=67.8^{\circ}\right)$ to $L M N B 2\left(P_{\text {eff }} 0.167 ; \theta_{\mathrm{A}}=69.8^{\circ}\right)$ regulates sensitivity for linear increases (or decreases) in mechanotransduction pressure esebssiwaagoto units. Legend. Cyan oval, complete nuclear pore complex with all subunits; light cyan oval, partial nuclear pore complex with some subunits; dark blue triangle, lamin and lamin-associated proteins; light blue triangle, lamin and lamin-associated proteins; transparent ovals, nucleosome with histone proteins; solid gold rectangle, anisotropic chromatin strand loop segment DNA with transcription ready infrapressuromodulated genes; bright green rectangle, mesotropic chromatin strand loop segment DNA with transcription ready suprapressuromodulated genes; solid bracket, nuclear membrane nucleoplasm chromatin; dashed bracket, central peripheral edge nucleoplasm chromatin

horizontal plane at the line of unity $\left(\theta_{\mathrm{H}}\right)$ as a result of forward paired point tropy fulcrum weighting $\left(\operatorname{prp} T_{\mathrm{Q}}\right)$ with underlying baseline reverse anisotropy.

The segmentation of strand heterochromatin for positive strand $(+)$ native configuration genes of human 1q22 located between position -12 and +15 in reference to $L M N A$ (pos 0 ) has been studied by the determinations of the esebssiwaago $T_{\mathrm{Q}}$ of sequentially situated genes. As it has been determined herein, the gene loop segment structure for the LMNA gene $\left(P_{\text {eff }}, 0.184 ; \theta_{\mathrm{A}}=\right.$ $\left.68.4^{\circ}\right)$-containing forward strand $(+)$ from $5^{\prime}$ to $3^{\prime}$ has been determined is: 5'-0.234- $\left(\mathrm{a}_{-12}\right)-0.272\left(\mathrm{~m}_{-11}\right)-0.229$ $\left(\mathrm{a}_{-10}\right)-0.211 \quad\left(\mathrm{a}_{-9}\right)-0.269 \quad\left(\mathrm{~m}_{-8}\right)-0.144 \quad\left(\mathrm{a}_{-7}\right)-0.314 \quad\left(\mathrm{~m}_{-6}\right)-$ $0.268 \quad\left(\mathrm{~m}_{-5}\right)-0.176 \quad\left(\mathrm{a}_{-4}\right)-0.260 \quad\left(\mathrm{~m}_{-3}\right)-0.259 \quad\left(\mathrm{~m}_{-2}\right)-0.270$

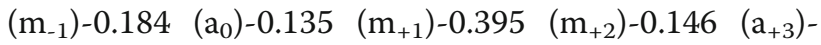
$0.212 \quad\left(\mathrm{a}_{+4}\right)-0.336 \quad\left(\mathrm{~m}_{+5}\right)-0.287 \quad\left(\mathrm{~m}_{+6}\right)-0.153 \quad\left(\mathrm{a}_{+7}\right)-0.283$ $\begin{array}{lll}\left(\mathrm{m}_{+8}\right)-0.193 & \left(\mathrm{a}_{+9}\right)-0.269 \quad\left(\mathrm{~m}_{+10}\right)-0.199 \quad\left(\mathrm{a}_{+11}\right)-0.146\end{array}$ $\left(a_{+12}\right)-0.190 \quad\left(a_{+13}\right)-0.188 \quad\left(a_{+14}\right)-0.243 \quad\left(a_{+15}\right)-3$, which begins at the $5^{\prime}$ end with DAP3 $\left(P_{\text {eff }} 0.234\right)$ in the form of a 9-in series anisotropy alternating mesotropy amorphous loop segment (a-m-a-a-m-a-m-m-a) followed by a 3-in series mesotropy loop segment $(\mathrm{m})$, and then a 11-in series anisotropy alternating anisotropy amorphous loop segment (a-m-m-a-a-mm-a-m-a-m) with LMNA followed by a 5-in series anisotropy loop segment (a) with 3 ' end BCAN ( $P_{\text {eff }}$ 0.234 ). These findings of the study are further supported by the retrospective analysis of micro-segmentation of negative strand (-) human 14q32.3 B-cell heavy chain immunoglobin locus genes in native positions $(n=42)[26$, 27], in which there are two instances of sequential alternating tropy in-series amorphousity $(n=5, n=4)$, two instances of sequential mesotropy in-series $(n=8, n=$ 3 ), as well as several instances of sequential microstructural anisotropy $(n=5, n=3,3,3)$.
Therefore, based on the findings of this study on the micro-segmentation of a $0.73-\mathrm{mm}$ length plus $(+)$ strand LMNA gene-containing heterochromatin strand loop segment and a $0.25 \mathrm{~mm}$ length minus (-) strand $I G H_{-}$ locus-containing DNA strand loop segment, there is segmental difference in DNA strand nano-compliance, in which case intergene tropy loop segments with differences nano-compliance overlap as there exists micron $(\mu \mathrm{m})$ scale segmentation of alternating mesotropy and anisotropy; as such, heterochromatin DNA strand loops can be characterized as anisotropy, mesotropy or amorphousity loop forms with micro-segmentation perceiving various grades of the asymmetric tropy viscosity effect for genes in juxtaposition separated by intergene base distance of between 11.6 and 14 nanometers (nm; 13 15 bases), if two nucleic acid bases and a primed halfphosphodiester bond in-tandem is considered to be $\sim 1.75 \mathrm{~nm}$ in length.

\section{Anglemetry of gene positioning angulation in the $z, y$ - plane and vectormetry for $z, x$-plane horizontal alignment in two-dimensional linear space}

Gene intergene tropy anglemetry is performed in 2-D linear angulation space utilizing the strand specific effective intracellular pressure unit $\left(P_{\text {eff }}\right)$-to-angle regression conversion, based on which it has been determined that anisotropic genes are situated between 60.5 and $82.3^{\circ}$ in the $z, y$-vertical plane and mesotropic genes are situated between 60.4 and $11.7^{0}$ in the $z, y$-vertical axis plane; in which case the initial momentum vector for anisotropic gene alignment, $\boldsymbol{m}_{\mathrm{ch}}$ tropy, from origination is between 82.3 and $60.5^{\circ}$ in the $z, y$-vertical, whereas the initial momentum vector for mesotropic gene alignment, $\boldsymbol{m}_{\text {ch tropy }}+\boldsymbol{m}_{\mathrm{ch} \text { nmn tropy }}\left(\boldsymbol{m}_{\mathrm{M}}\right)$, from origination is 60.4 and $11.7^{\circ}$ from above the $z, x$-horizontal plane. 
Therefore, the effective momentum $\left(\boldsymbol{m}_{\mathrm{eff}} ; \boldsymbol{m}_{\mathrm{A}}, \boldsymbol{m}_{\mathrm{M}}\right)$ for gene transcription is inversely proportional to the effective cell pressure $\left(P_{\text {eff }}\right)$ required for horizontal alignment of gene intergene loop segment tropy (Fig. 4).

Based on these findings of the study, sequentially located anisotropic genes in a gene intergene tropy segment of the same will transition into the $z, x$-horizontal plane reading frame for gene transcription from between origination angulations of between 60.5 and $82.3^{\circ}$ in the $z, y$-vertical plane where the originating momentum vector ( $\boldsymbol{m}$ ch tropy) will encounter a singular viscosity effect at intergene base tropy segments, in comparison to mesotropic genes situated between 60.4 and $11.7^{\circ}$ in the $z, y$-vertical axis plane that will align within the inner nuclear membrane (INM) nucleoplasm where dual viscosity effects are encountered at intergene base tropy segments, in which case the additional inner nuclear membrane nucleoplasm chromatin viscosity tropy effect for mesotropic gene alignment is attributable to the additive effect of nuclear pore traffic-related to peptide synthesis rough endoplasmic reticular network of the inner nuclear envelope. Therefore, the pressurotopic model for a binomial always-on heteroeuchromatin transcription is proposed in which mesotropic DNA loop segments of supra-pressuromodulated genes are transcriptionally active at the inner nuclear membrane (INM), while anisotropic DNA loop segments of infrapressuromodulated genes are transcriptionally active at the at the nucleolar peripheral nucleoplasm interface. The pressurotopic loop segment-dependent eukaryotic gene transcription builds on the static heterochromatindynamic euchromatin model in which chromatin is inactive at the nuclear envelope and active in the nucleoplasm in proximity to mobile nuclear pore complex subunits [11, 14-16] (Fig. 5).

There exists significant variance of $\Sigma$ intergene base segment loop tropy, although genes are positioned at similar angulation in the $z, y$-vertical plane as has been determined in the study; for example, the $\Sigma$ intergene base segment loop tropy for CYGB is $4.11804 \mathrm{E}+05\left(P_{\text {eff }}\right.$ 0.248 ), whereas that for $D R D 1$ is $2.041819 \mathrm{E}+06$ intergene bases $\left(P_{\text {eff }} 0.249\right)$, which align to $\theta_{\mathrm{H}}=0^{0}$ from angulations of $60.0^{\circ}$ and $59.9^{\circ}$. Therefore, based on such determinations gene angulation distances to the $z, x$ horizontal plane line of unity can be determined from the hypotenusal tropy inclusive of the interposed gene bases, as in the example of MIR4537, a 3 A 7 gene positioned at an angle of $82.3^{\circ}\left(P_{\text {eff }} 0.064\right)$, for which the hypotenusal tropy length inclusive of intervening genes is $3.55373 \mathrm{E}+05$ bases, and thus the reverse extrapolated arc tropy distance from angulation to the $z, x$-horizontal plane $(H o)$ is $2.465 \mathrm{E}+02$ microns. Therefore, study findings are applicable to further study of heteroeuchromatin loop segment $z, x$-plane alignment kinetics when the inverse relationship between effective pressure and momentum, $P_{\text {eff }}(0.064 \geq x<0.245) \cdot \boldsymbol{m}_{\mathrm{A}}=P_{\text {eff }}$ $(0.245 \geq \mathrm{x} \leq 0.648) \cdot \boldsymbol{m}_{\mathrm{M}}\left(P_{\text {eff }} \cdot \boldsymbol{m}_{\mathrm{ch} \text { tropy }}=P_{\mathrm{eff}} \cdot \boldsymbol{m}_{\mathrm{ch}}\right.$ tropy $+\boldsymbol{m}_{\mathrm{ch}}$ nmn tropy $)$ for DNA strand loop alignment in nuclear protoplasm.

\section{Differentiated neuron cell sub-types differ in the range of effective cell pressures for neuroaxis gene expression in reference to tissue macro-compliance}

During retinoic acid-mediated neural differentiation of NT2/D1embryonal lineage pluripotent cells $\left(\mathrm{SOX}^{+}{ }^{+} /\right.$ SOX14 ${ }^{-}$in vitro [42], it has been shown that SOX1 ( $P_{\text {eff }}$ $\left.0.318 ; \theta_{\mathrm{M}}=51.6^{0}\right)$, expression re-increases at 2-weeks in response to RA, while $\operatorname{SOX14}\left(P_{\text {eff }} 0.219 ; \theta_{\mathrm{A}}=63.5^{\circ}\right)$ expression increases over the same 4-week period, which is plasmid-expressed in HeLa cells at anisotropic pressure. Since $S O X 1$ determines neuronal lineage analogous to $S O X 2$, and $S O X 14$ determines neural differentiation state analogous to homolog TUBB3 in differentiated radial pre-cursor cells (RPs) [43], the $P_{\text {eff }}$ interval for differentiating neural cells can be delineated as being between 0.219 and 0.318 esebssiwaago $T_{\mathrm{Q}}$ units, in which case the $P_{\text {eff }}$ interval for differentiated neuron sub-types from distal to proximal in the neuroaxis is between a $P_{\text {eff }}$ of 0.434 to 0.203 esebssiwaago $T_{\mathrm{Q}}$ units based on pressuromodulation mapping. Furthermore, since glial cell marker, $B C A N\left(P_{\text {eff }} 0.243, \theta_{\mathrm{A}}=60.6^{\circ}\right)[44,45]$, and neuronal markers, SOX14 and RBFOX3 ( $P_{\text {eff }} 0.213 ; \theta_{\mathrm{M}}=$ $\left.59.7^{0} ; \mathrm{NeuN}\right)$, are differentially expressed in symbiotic cell types; brain-specific protein of the Aggrecan class, Brevican (BCAN, $\left.\mathrm{P}_{\text {eff }} 0.243 ; \theta_{\mathrm{A}}=60.6^{\circ}\right)$, is proposed to be the CNS hyaluronic acid-stabilizing chondroitin sulfate proteoglycan that increases the $P_{\text {eff }}$ interval for certain differentiated neuronal cell types (ie hippocam$\mathrm{pal} /$ Papez circuit).

The upper limit of effective intracellular pressure for proprioceptive afferent lower motor neuron [ $\operatorname{lmn}(\mathrm{a})]$ gene expression is at that of gene UNC13A ( $P_{\text {eff }} 0.434$; $\left.\theta_{\mathrm{M}}=37.6^{0}\right)$; ortholog, munc13-1), a nuclear membraneassociated heterochromatinized gene required for presynaptic vesicle docking exocytosis, which has been shown to be under-expressed following application of sodium channel blocker tetrodotoxin (TTX) in a standard in vitro culture model for study of pre-to-post synaptic neuronal activity [46]. In addition, post-synaptic scaffold protein SHANK2 $\left(P_{\text {eff }} \leq 0.301 ; \theta_{\mathrm{M}}=53.6^{0}\right)$ has been shown to be over-expressed in the model, and represents the effective intracellular pressure upper limit for gene expression in secondary upper motor neurons [umn (asc)] to thalamic nuclei. Furthermore, since it has been shown in a murine model of regulator of $G$ protein signaling gene differential expression in the corpus striatum basal ganglia nigral mesencephalic dopaminergic circuit (bgnc) in response to D1R antagonist/D2R 
agonist pharmacological modulation in vivo [47], and RGS2 $\left(P_{\text {eff }} 0.298 ; \theta_{\mathrm{M}}=54.0^{\circ}\right)$ shown to be differentially expressed by high density array following synaptogenesis of plated neuronal precursors in vitro [46], the effective cellular pressure interval range for gene expression in basal ganglia nigral circuit deep brain nuclei neurons includes genes RGS2 and RGS16 ( $\left.P_{\text {eff }} 0.251 ; \theta_{\mathrm{M}}=59.7^{\circ}\right)$, which implies that RGS4 $\left(P_{\text {eff }} 0.118 ; \theta_{\mathrm{M}}=75.8^{0}\right)$ is the murine paralog for the human $R G S 16$ gene based on the findings of this study. Dopamine receptor 1 gene DRD1 $\left(P_{\text {eff }} 0.249 ; \theta_{\mathrm{M}}=59.7^{\circ}\right)$ co-expresses with RGS16, and $D R D 2$ is expressed at a $P_{\text {eff }}$ of $\left.0.217\left(\theta_{\mathrm{A}}=63.8^{\circ}\right)\right]$, the effective intracellular pressure range for basal ganglia nigral neuronal circuit neuronal gene expression is delineable as being between 0.217 and 0.298 esebssiwaa$g o T_{\mathrm{Q}}$ units, which are overexpressed on spiny neurons of the basal ganglia circuit by the late telencephalic development stage [48].

Neuronal nuclei protein (NeuN; RBFOX3, $\left.P_{\text {eff }} 0.213\right)$ has been shown to be expressed in pyramidal neuron layers (I-VI) of the cerebrum [bral, pyr umn (arc)], granule cell layer neurons (gr) of the cerebellum (bell) and 3layered hippocampal formation Papez circuit (capc) by high affinity antibody histochemistry [49]. In the murine So $x 1^{\text {lacz } /+}$ model, early neuronal differentiation gene SOX1 $\left(P_{\text {eff }} 0.318 ; \theta_{\mathrm{M}}=51.6^{0}\right)$ is maximally expressed in the periventricular zone and hippocampal Papez circuit [50], but does not appear to be expressed in the cerebral cortex (bral), while $N G B\left(P_{\text {eff }} 0.305 ; \theta_{\mathrm{M}}=53.2^{0}\right)$ globin is minimally expressed in human brain cortex and $C Y G B$ $\left(P_{\text {eff }} 0.248 ; \theta_{\mathrm{M}}=60^{\circ}\right)$ globin shows positive expression in the hippocampus [51]. Thus, the effective intracellular pressure interval for cortical telencephalon neuronal gene expression is determined to range between 0.213 and 0.305 esebssiwaago $T_{\mathrm{Q}}$ units (bral); whereas, the $P_{\text {eff }}$ range for hippocampal formation Papez circuit (capc) neuronal gene expression is delineated as being between a $P_{\text {eff }}$ of 0.318 and the effective cell pressure for expression of dopaminergic receptor DRD3 $\left(P_{\text {eff }} 0.203 ; \theta_{\mathrm{A}}=\right.$ $65.2^{0}$ ) [52], which is also the $P_{\text {eff }}$ for expression of GRIN1 $\left(P_{\text {eff }} 0.203 ; \theta_{\mathrm{A}}=65.2^{0}\right)$, a NFE2L2 $\left(P_{\text {eff }} 0.331 ; \theta_{\mathrm{M}}=50.2^{0}\right)$ target gene, as has been shown by DNA complex/ transcription factor to NRF-1 antibody by electromobility super-shift assay [53]. Furthermore, since NUMA1 $\left(P_{\text {eff }} 0.311 ; \theta_{\mathrm{M}}=52.4^{\circ}\right)$ is shown to be differentially upregulated in cryptorchidism by qRT-PCR $[54,55]$, and ovarian theca cell origin INSL3 ( $P_{\text {eff }}$ 0.321; $\theta_{\mathrm{M}}=51.2^{0}$ ) is shown to be expressed in the hypothalamic neuron projections to the posterior pituitary by in situ hybridization [56], the upper limit of the $P_{\text {eff }}$ range for gene transcription for peri-ventricular thalamic deep nuclei neurons will be in-between a $P_{\text {eff }}$ of 0.305 and 0.311 , whereas that for the hypothalamic pituitary axis (pituit) will be inclusive to $0.331 P_{\text {eff }}$ esebssiwaago $T_{\mathrm{Q}}$ units.
Based on the pressuromapping findings of the study, the upper limit interval for peripheral lower motor neuron $(\mathrm{lmn})$ gene expression is definable as being between a $P_{\text {eff }}$ of 0.434 and $0.311(>0.305)$; whereas, the range for gene expression is between a $P_{\text {eff }}$ of 0.305 and 0.213 for cerebrocortical upper motor neurons, between a $P_{\text {eff }}$ of 0.318 and 0.203 for hippocampocortical neurons, and between a $P_{\text {eff }}$ of 0.298 and 0.217 for basal ganglia spiny neurons. Therefore, there exists an inverse relationship between effective range of whole cell compliance and tissue macro-compliance $\left(R_{\text {effective whole cell }}\right.$ compliance $\cdot T_{\text {macro-compliance }}=\mathrm{k}$ ), which is attributable to differences in regional negative macro-pressuromodulation in a tissue with cell populations arranged in the form of nuclear groups (ie hyaluronate matrix), and attributable to differences in the same across tissue types with differences in stromal stiffness (ie calcified matrix). In corollary, the effective cell pressure range for mesenchymal stem cell (MSC) gene expression is delineable as being between a Peff of 0.648 and $<=0.118$, in which case the upper limit is attraibutable to cell-to-cell focal adhesion formation within myeloid bone caverns. Furthermore, based on the study findings, RGS18 ( $P_{\text {eff }}$ 0.205; $\left.\theta_{\mathrm{M}}=65.2^{0}\right), \operatorname{RGS16}\left(P_{\text {eff }} 0.251 ; \theta_{\mathrm{M}}=59.7^{0}\right.$; human paralog of murine $R G S 4)$, lnc-RXFP4-5 ( $P_{\text {eff }}, 0.314 ; \theta_{\mathrm{M}}=$ $52.1^{0}$; pituit), RGS13 ( $P_{\text {eff }}$ 0.360, $\left.\theta_{\mathrm{M}}=46.5^{0}\right), C E A C A M 1$ $\left(P_{\text {eff }}, 0.384 ; \theta_{\mathrm{M}}=43.6^{0}\right), \operatorname{SLC} 25 A 44\left(P_{\text {eff }}, 0.395 ; \theta_{\mathrm{M}}=\right.$ $\left.42.3^{0}\right)$ and $R G S 21\left(P_{\text {eff }}, 0.413 ; \theta_{\mathrm{M}}=40.1^{\circ}\right)$ are expressed within the lower motor neuron (lmn)-upper motor neuron (umn) neural cell axis; and TSACC ( $P_{\text {eff }}$ 0.336; $\left.\theta_{\mathrm{M}}=49.4^{\circ}\right)$ and JUND $\left(P_{\text {eff }}, 0.344 ; \theta_{\mathrm{M}}=48.4^{\circ}\right)$ are noncell specific developmental biomarkers.

\section{Expression of inner nuclear envelope and anti-apoptosis pathway genes in response to dynamic strain-mediated alterations in cellular compliance}

Micropipette aspiration studies on nuclear envelope elasticity utilizing fluorescent nuclear protein expression plasmid transfectants to study rates of DNA displacement over time and resultant changes in the surface area expansion alpha power $(\alpha)$ as a measure of alterations in nuclear envelope deformability [29-31]. Study of nuclear stress response to tonicity in TC7 renal epithelial cell transfectants in which sub-nuclear displacement rates of GFP-lamin B1 during constant aspiration pressure application $\left(J\right.$, creep compliance; $\left.\mathrm{kPa}^{-1} \cdot \mathrm{sec}^{-1}\right)$ [30] has shown more significant heterochromatin displacement in hypertonic and isotonic nuclei $(\alpha=0.28-0.32)$ in comparison to hypotonic nuclei $(\alpha=0.21)$, in which case shrunken and unswollen nuclei are less deformable at the onset $\left(U_{\text {initial }}=0.1\right)$ in comparison to swollen nuclei $U_{\text {initial }}=1$, $\left.\mathrm{kPa}^{-1}\right)$ with a greater initial elastic dilation modulus $(K$, $\mathrm{mN} / \mathrm{m}$ ), implying that hypo-osmolar nuclear swelling increases cell membrane compliance. And, subsequent 
study of sub-nuclear GFP-fibrillarin (or upstream binding factor 1, UBF1-GFP) displacement in which whole cells, Saos-2 carcinoma, HeLa and human venous endothelial $(\mathrm{HuVec})$, exposed to shear stress from 10 to 40 dyn $/ \mathrm{cm}^{2}$ (1 to $4 \mathrm{~Pa}$ ) or to compressive stress of $0.1 \mathrm{MPa}$ over 60 minutes [31] have shown discordant results in alpha power $(\alpha)$ response to $10 \mathrm{dyn} / \mathrm{cm}^{2}$ physiologic shear strain for HeLa cells as compared to in HuVec cells in which there is a parabolic comparative increase in mean standard displacement (MSD) alpha power at $40 \mathrm{dyn} / \mathrm{cm}^{2}$, as the equivalently-increased alpha response due to $10 \mathrm{dyn} / \mathrm{cm}^{2}$ of shear stress in HeLa cells or 100 $\mathrm{kPa}$ of compressive stress in the same will be a result of mitochondrial challenge oxidative stress-exothermy due to differences in the initial effective cell pressure $\left(P_{\text {eff }}\right)$ setpoints of Hela carcinoma cells and HuVec endothelial cells. Furthermore, by the study of nucleus mechanical properties in $E M D$ gene-deficient $(-/ y)$ differentiated embryonic fibroblasts, it has been determined that sexlinked deficient MEFs have a lower nuclear membrane dilation modulus $(K)$-to shear modulus $(\mu)$ ratio than wild-type (WT) fibroblasts, 2.1 as compared to 5.1 [32], in which case it has been shown that EMD gene-deficient cell nuclear envelope is more rigid in mechanical stain-free conditions, as it has a more significant decay exponential $\left(e^{-a \mid K / \mu}\right)$ than that for the wild-type fibroblast (WT), -0.21 and -0.04 , based on nuclear GFP-lamin $\mathrm{A} / \mathrm{C}$ signal intensity. Therefore, since EMD gene-deficient fibroblasts are less sensitive to mechanotransduction in comparison to wild-type MEFs, and the $E M D^{+/ y}$ wild-type fibroblast gene $P_{\text {eff }}$ is $0.234\left(E M D, \theta_{\mathrm{A}}=61.7^{0}\right)$, the cellular effective pressure in $E M D^{-/ y}$ is predictable as being relatively constant at a $P_{\text {eff }}$ of $\leq 0.234$ esebssiwaa$g o T_{\mathrm{Q}}$ units during mitochondrially-mediated apoptosis.

Cell nucleus deformability in dynamic strain conditions has been studied in LMNA gene (-/-)- or EMD gene $(-/ y)$-deficient fibroblasts as compared to wildtype (WT) fibroblasts, in which anti-apoptosis pathway-related gene expression has been studied in MEFs subject to low-frequency $(1 \mathrm{~Hz})$ low-grade biaxial mechanical strain (4 to 10\%) at for one to 24 hours and [33-35]. Based on the findings of studies considered altogether, both $L M N A$ gene- and EMD gene-deficient MEFs are mechanotransduction-impaired [34]; however, in the former due to increased nuclear envelope deformability as nuclear envelope perceived mechanical strain correlates with applied strain in lamin A/C-deficient cells, whereas in wildtype MEFs applied strain is cell membrane perceived and mechanotranduced to comparatively less deformable nucleus of WT fibroblasts. Furthermore, based on cells studied over in mechanical strain-free conditions by phase contrast time-lapse [33], of the two inner nuclear envelope protein deficient cell types with discordant nuclear envelope rigidity, lamin A/
C-deficient cells show increased nuclear dynamics as early as 1 hour, during which neither LMNA gene-deficient nor WT fibroblasts express immediate early response 3 (IER3, IEX-1 homolog; $\left.P_{\text {eff }} 0.204, \theta_{\mathrm{A}}=65.4^{\circ}\right)$ or early growth response- 1 (EGR1; $P_{\text {eff }} 0.199, \theta_{\mathrm{A}}=66.0^{\circ}$ ), whereas emerin $(E M D)$-deficient fibroblasts express IER3 as they must transcribe at a $P_{\text {eff }}$ of between 0.204 and 0.199 at baseline. In fibroblasts subject to between 2 to 4 hours of $4 \%$ biaxial cyclic strain, qRT-PCR shows significantly increased expression of both NF$\kappa \mathrm{B}$ pathway genes IER3 and EGR1 in WT MEFs [33], which indicates that mechanical strain decreases $P_{\text {eff }}$ from > 0.234 to in-between 0.199 and 0.204 units in mechanotransduction-sensitive $E M D^{+/ y} / L M N A^{+/+}$fibroblasts at which IER3 and EGR1 gene transcription occurs; whereas, $L M N A$ gene $\left(P_{\text {eff }} 0.184 ; \theta_{\mathrm{A}}=67.8^{0}\right)$-deficient fibroblasts transcribe at a relatively constant $P_{\text {eff }} \leq 0.184$ units during which neither IER3 nor EGR1 is transcribed similar to WT fibroblasts. Since $L M N A^{-1-}$ fibroblasts become qRT-PCR positive for IER3 and EGR1 in response to mechanical strain, then it can be supposed that cellular pressure initially is around a $P_{\text {eff }}$ of 0.167 with applied dynamic stain during which LMNB2 $\left(\theta_{\mathrm{A}}=69.8^{\circ}\right)$ is expressed in the mechanotransduction in-sensitive interval, followed by an increase in $P_{\text {eff }}$ into the $0.197-0.204$ units range in which $L M N B 1\left(P_{\text {eff }}, 0.197 ; \theta_{\mathrm{A}}=66.2^{\circ}\right)$ is expressed, due to which the mechanotransduction sensitivity of the LMNA gene-deficient fibroblast nuclear envelope is maintained within the same. Based on these findings considered together, the $P_{\text {eff }}$ interval between $0.172-0.184$ esebssiwaggo $T_{\mathrm{Q}}$ units would be the mechanotransduction insensitive range for cellular gene expression.

\section{Expression of inner nuclear envelope and extracellular matrix pathway genes in response to substrate stiffness}

The effect of gel stiffness on cell morphology has been studied in vitro for contrasting cells grown on collagen I or fibronectin-coated 3 to $7.5 \%$ poly-acrylamide gels varying with shear elastic moduli for cross-linked stiffness (G', Pa) ranging between 0.002 to $55 \mathrm{kPa}$, in which it has been determined that actin stress fibers begin to develop in GFP-actin expressing fibroblasts (MEFs) at a stiffness of between 1.6 and $3.6 \mathrm{kPa}$ or in synergism with EGFP-actin wildtype (WT) transfectants of the same [36]. Based on these findings on altered cellular phenotype as a result of gel stiffness mechanotransduction force (G'), it can be inferred that the physiologic range of effective cellular pressure is between 0.180 and $2.9 \mathrm{kPa}$ in-between the $G_{0}$ to $S$ phase of the cell cycle during which endothelial cell (EC) sprouting occurs during formation of cytoskeletal stress fibers; and that an additional increase in cellular pressure to between 2.9 and 28.6 $\mathrm{kPa}$ results in progression to binucleation followed by 
EC diaphragmed fenestration-associated with mitogenesis multi-nucleation. Based on MMTV-Her2/neu, $m y c$, ras mammary tumor stiffness studied in situ ( $E$, $\mathrm{kPa}$ ) and tensional homeostasis studied in response to applied shear force in vitro (dynes $/ \mathrm{cm}^{2}$ ) [37], when solid tumor tissue pressure is at $4.05 \mathrm{kPa}$, then it can be inferred that $1.59 \mathrm{kPa}$ of synergistic positive mechanotransduction pressure will be attributable to secreted collagen I fibril matrix if maximum concentration is $4.0 \mathrm{mg} / \mathrm{mL}$, which will be expressed at an effective cell pressure $\left(P_{\text {eff }}\right)$ range of $0.235-0.241$ for the expression of tumor tissue collagen ligand genes COL1A1 $\left(P_{\text {eff }} 0.241 ; \theta_{\mathrm{A}}=60.9^{\circ}\right)$ and COL6A1 $\left(P_{\text {eff }}\right.$ $\left.0.235 ; \theta_{\mathrm{A}}=61.6^{0}\right)$ preceded by expression of integrin receptor (ie $\alpha v \beta 3$ ) that requires between 1.1 and 1.6 $\mathrm{kPa}$ of applied force for ectopic vector expression [36, 37]. Additionally, since an applied shear force of 140 dynes $/ \mathrm{cm}^{2}$ that results in focal adhesion formation $\left(\mathrm{FAK}^{+}\right)$parallels an increase in fibronectin (FN) matrix rigidity $\left(G^{\prime}\right)$ with an increase in Ki67 proliferative index during MEK inhibitor application (ie PD98059) [37], therefore the shear force interval between 40 and 140 dynes $/ \mathrm{cm}^{2}$ will be the effective intracellular pressure interval between the $G_{2}$ and $S$ cell cycle phase, which is between 0.235 to 0.283 esebssiwaago $T_{\mathrm{Q}}$ units $[26,27]$. Furthermore, since during the differentiation of human adipose tissue stromal progenitor cells (HADSCs) or myeloid marrow mesenchymal stem cells (MSC) into chondroblasts results in the spatial expression of COL2A1 isoforms 1 and 2 as early day 5 as chondrocyte cellspecific marker $[57,58]$, then the transcriptional activation of COL2A1 $\left(P_{\text {eff }}, 0.118 ; \theta_{\mathrm{A}}=75.8^{0}\right)$ both directly and indirectly by Sox 1 and $\mathrm{Nkx} 3.2$ respectively [59] will be the initial positive pressuromodulation event that increases effective cell pressure in MSCs upwards and then to an $P_{\text {eff }}$ of around 0.184 esebssiwaago $T_{\mathrm{Q}}$ units (LMNA) with resultant chondrocyte lineage differentiation, after an initial decrease in $P_{\text {eff }}$ by retinoic acid (RA) pathway activation [38].

The relationship between stoichiometry of lamin A/C to lamin-B1 protein and mRNA expression across tissue cell types (ie MSC, HSCP; U251, brain) and cellular microelasticity $\left(\mathrm{kPa}^{-1}\right)$ has been studied in parallel with modeling of the time constant $\left(1 / \tau\right.$; $\left.\sec ^{-1}\right)$ for lamin $\mathrm{A}: \mathrm{B}$ expression relationship [38], in which it has been determined that the lamin $\mathrm{A} / \mathrm{C}$ : lamin $\mathrm{B} 1$ expression ratio follows $E^{0.6}$ with lamin B1 expression follows $E^{0.2}$ for the spectrum of cell types, and in parallel that the lamin A:B time constant $(\tau)$ proportionality is viscosity/elasticity. Based on the findings of this study, osteo-prone human mesenchymal stem cells from marrow (MSC) express LMNA $\left(P_{\text {eff }}, 0.184 ; \theta_{\mathrm{A}}=67.8^{0}\right)$ but at a substrate stiffness of $12 \mathrm{kPa}$, which would be due to synergistic negative macro-pressurization, which further implies that cellular focal adhesionogenesis is required for expression of toti-pluripotency marker $C D 34\left(P_{\text {eff }}, 0.648\right.$; $\left.\theta_{\mathrm{M}}=11.7^{0}\right)$ in the myeloid marrow cavern [26, 27], for a cell type that is functional over a wider range of cellular compliance. Hematopoietic stem cell progenitors from marrow (HSCP), normal brain cells (unspecific) and orthotopic xenograft GBM (U251) express $L M N B 1$ ( $P_{\text {eff }}$ 0.197, $\theta_{\mathrm{A}}=66.2^{0} ; \sim$ constant $\left.L M N B 2, P_{\text {eff }} 0.167\right)$ at a substrate pressure between 0.1 and $0.2 \mathrm{kPa}$; moreover, based on the correlation between application of synergistic pressure and $L M N B 1$ gene expression across the spectrum of cell types inclusive of osteo-prone cell types $\left(E^{0.2}\right)$ [38], the effective intracellular pressure $\left(P_{\text {eff }}\right)$ at baseline is greater than extracellular stromal pressure in osteo-prone mesenchymal stem cells (MSC), whereas the effective intracellular pressure $\left(P_{\text {eff }}\right)$ at baseline approximates extracellular stromal pressure in the latter. Furthermore, the lamin A/C: lamin B1 expression ratio that favors $($ cart $>$ ) skull $>$ femur $>$ MSC for comparative osteo-prone cell types in response to $12 \mathrm{kPa}$ of MSC equivalent applied pressure for $L M N B 1$ expression $\left(P_{\text {eff }}\right.$ 0.197 ) is attributable to a narrower functional range of cellular compliance in comparative cell types inclusive of osteocytes and chondrocytes.

\section{Nuclear envelope mechanotransduction in response to dynamic strain and pharmacological signaling}

The dynamic strain responsiveness of the cell nucleus in mesenchymal stem cells (MSCs) subject to 0.2 to 2 $\mathrm{Hz}$ cyclic dynamic loading ( $3 \%$ strain, $10 \mathrm{~min}$ ) has been studied with the application of inhibitors of molecular signaling such as lysophosphatidic acid (LPA), myosin light chain kinase inhibitor (ML-7), F-actin inhibitor (cytochalasin D) and rho-associated protein kinase inhibitor (Y-27632); studies in which nuclear deformability has been measured with the nuclear aspect ratio and index (NAR, b/a, a/b; NDI, \%) in combination with ATP exocytosis and sarcolemmal $\mathrm{Ca}^{2+}$ release measurements, and the condensation chromatin parameter (CCP, \%) utilized to detect nuclear mechanotransduction sensitivity in parallel [39-41] in pluripotent stem cells (MSC) cultured on hydrogels with a substrate stiffness of between 5 and $10 \mathrm{kPa}$.

Based on the study of mechanotransduction strain transfer in load-stressed MSCs following pre-treatment with ML-7, nuclear deformability (NDI) is increased and the yes-associated protein (YAP) pathway is activated as during dynamic loading (DL), in contrast to with the application of LPA, Y-27632 or CytoD during which nuclear deformability is decreased, and in the case of lysophosphatidic acid (LPA), pERK/ERK ratio trends towards decrease between control and dynamic loading comparison groups [39] as does matrix stiffness [38]; 
and by the study of alteration in chromatin condensation in dynamic strain-loaded (DL) MSCs following pre-treatment ML-7 and Y27632, CCP is indifferent at $30 \mathrm{sec}$ in comparison to conditioned media $(\mathrm{CM})+\mathrm{DL}$ controls however cellular traction force $(\mathrm{nN})$ decreases in response to TGF $\beta$ inhibitors or Y-27632, whereas LPA + DL increases the chromatin condensation by 1.64 -fold during mitochondrial ATP exocytosis, intracellular $\mathrm{Ca}^{2+}$ oscillation and increase in autocrine TGF- $\beta$ [40]. Therefore, these findings considered together are consistent with the heterochromatinization of DNA effect of LPAR agonist, lysophosphatidic acid (LPA) during dynamic loafing, being towards the inner nuclear membrane due to increased rigidity of the nuclear envelope as result of the positive pressurization effect of LPA; and furthermore, the increase in nuclear envelope deformability however an indifferent heterochromatinization DNA effect of cell membrane (CM) receptor inverse agonist myosin light chain kinase inhibitor (ML-7) being a result of the negative pressurization effect of ML-7 in synergism with dynamic loading (DL) that remains in the anisotropic pressure range, $P_{\text {eff }}<0.245$.

Mechanotransduction sensitivity alterations due to dynamic loading and resultant changes in lamin $\mathrm{A} / \mathrm{C}$ protein expression have been studied under during the treatment of MSCs cultured in vitro with positive pressuromodulators HDAC inhibitor trichostatin A (TSA), CytoD and D-mannitol [41], in which it has been determined that deformation of the undifferentiated MSC nucleus in response to applied dynamic strain is lessened within the lamin-A/C protein transcription interval, $L M N A\left(P_{\text {eff }}, 0.184 ; \theta_{\mathrm{A}}\right.$ $\left.=67.8^{\circ}\right)$, as determined in the study. Since in dynamic strain-stressed cells there is a cell membrane compliance-mediated decrease in nuclear $P_{\text {eff }}$ into the nadir pressure range for mesenchymal stem cells as determined by pressuromodulation mapping [24, 26], COL2A1 gene transcription occurs $\left(P_{\text {eff }}, 0.118\right.$; $\left.\theta_{\mathrm{A}}=75.8^{\circ}\right)$ with resultant MSC origin CTGF gene CCN2 $\left(P_{\text {eff }}, 0.166 ; \theta_{\mathrm{A}}=70^{\circ}\right)$ transcription within the mechanotransduction in-sensitive cellular $P_{\text {eff }}$ range ( $>0.118 \leq 0.167$ esebssiwaago $_{\mathrm{Q}}$ units); therefore, the $P_{\text {eff }}$ pressuromodulation setpoint in toti-pluripotent cells (ie MSCs) will be at that for transcription factor $E S R R B$ gene transcription $\left(P_{\text {eff }}, 0.172\right)$, which is required for re-initiation of pluripotency in a differentiated cell $[60,61]$, from which $P_{\text {eff }}$ decreases to a peri-nadir $P_{\text {eff }}$ around 0.118 esebssiwaago $T_{\mathrm{Q}}$ units in part by mitochondrial oxidative stress-mediated exothermy, or increases to a peak at 0.648 esebssiwaago $_{\mathrm{Q}}$ units during the expression of a MSC origin matched limiting focal adhesion component (ie integrin subunit : collagen fibril subunit).

\section{Conclusions}

In this research, heterochromatin shift during euchromatin gene transcription has been studied by parallel determinations of DNA strand loop segmentation tropy nano-compliance (esebssiwaago $T_{\mathrm{Q}}$ units, linear $\mathrm{nl}$ ), gene positioning angulation in linear normal two-dimensional (2-D) $z, y$-vertical plane (anglemetry, ${ }^{0}$ ), horizontal alignment to the $z, x$-plane (vectormetry; $\boldsymbol{m}_{\mathrm{A}}, \boldsymbol{m}_{\mathrm{M}}$, a.u.), and by pressuromodulation mapping of differentiated neuron cell sub-class operating range for neuroaxis gene expression in reference to tissue macro-compliance $\left(P_{\text {eff }}\right)$.

Heterochromatin strand DNA loop micro-segmentation structural nano-compliance is either amorphousity, anisotropy or mesotropy loop segment forms perceiving various grades of the asymmetric tropy viscosity effect, where between 3-to-5 and 8-to-11 genes are arranged as one or two in-tandem alternating anisotropic and mesotropic gene(s), or as in-tandem anisotropic or mesotropic genes in juxtaposition separated by intergene tropy base distance; for example, the amorphousity loop segment form between positions -12 to -4 in reference LMNA ( $\left.P_{\text {eff }}, 0.184 ; \theta_{\mathrm{A}}=68.4^{\circ}\right)$ on human 1q22 (+) is $5^{\prime}-0.234-\left(\mathrm{a}_{-12}\right)-0.272\left(\mathrm{~m}_{-11}\right)$ $0.229 \quad\left(\mathrm{a}_{-10}\right)-0.211 \quad\left(\mathrm{a}_{-9}\right)-0.269 \quad\left(\mathrm{~m}_{-8}\right)-0.144 \quad\left(\mathrm{a}_{-7}\right)-0.314$ $\left(\mathrm{m}_{-6}\right)-0.268\left(\mathrm{~m}_{-5}\right)-0.176\left(\mathrm{a}_{-4}\right)-3$ '. Based on this arrangement of stranded chromatin DNA, an always-on pressurotopic model for gene transcription is proposed, in which either mesotropy loop form genes positioned between 11.7 and $60.4^{\circ}(C D 34)$ in the $z, y$-vertical plane are transcriptionally active when heterochromatin shifts towards the inner nuclear envelope margin following the transcription of $E M D\left(P_{\mathrm{eff}}, 0.234 ; \theta_{\mathrm{A}}=\right.$ $61.7^{\circ}$ ), during which mechanotransduction apparatus sensitivity for linear increases in nuclear effective pressure $\left(P_{\text {eff }}\right)$ into the expression range for collagen fibril genes COL6A1 $\left(P_{\text {eff }} \quad 0.235 ; \theta_{\mathrm{A}}=61.6^{\circ}\right)$ and COL1A1 $\left(P_{\text {eff }} 0.241 ; \theta_{\mathrm{A}}=60.9^{0}\right)$ for focal adhesion (FA) formation and resultant cell specific increases in nuclear pressure; or, anisotropy loop form genes positioned between 60.5 and $82.3^{\circ}$ (MIR4537) in the $z, y$ vertical plane are transcriptionally active when heterochromatin shifts towards the central peripheral nucleoplasm edge, during which transcription of inner nuclear envelope peptide-coding genes LMNB1 ( $P_{\text {eff }}$, $\left.0.197 ; \theta_{\mathrm{A}}=66.2^{0}\right) \rightarrow \operatorname{LMNA}\left(P_{\mathrm{eff}}, 0.184 ; \theta_{\mathrm{A}}=67.8^{0}\right)$ to LMNB2 $\left(P_{\text {eff }}, \quad 0.167 ; \quad \theta_{\mathrm{A}}=69.8^{0}\right)$ regulates sensitivity for linear increases (or decreases) in mechanotransduction pressure esebssiwaago $T_{\mathrm{Q}}$ units. Based on momentum vectormetry, the relationship between effective pressure and momentum is inverse proportionality, $P_{\text {eff }}(0.064 \geq x<0.245) \cdot \boldsymbol{m}_{\mathrm{A}}=P_{\text {eff }}(0.245 \geq \mathrm{x}$ $\leq 0.648) \cdot \boldsymbol{m}_{\mathrm{M}}\left(P_{\text {eff }} \cdot \boldsymbol{m}_{\mathrm{ch} \text { tropy }}=P_{\text {eff }} \cdot \boldsymbol{m}_{\mathrm{ch} \text { tropy }}+\boldsymbol{m}_{\mathrm{ch} \mathrm{nmn}}\right.$ tropy) for DNA strand loop alignment in nuclear 
protoplasm, which are applicable to further study of heteroeuchromatin loop segment $z, x$-plane alignment kinetics.

The episodic sub-episode block sums (SEB) split-integrated weighted average-averaged gene overexpression tropy quotient is a linear normal measure of effective intracellular pressure $\left(P_{\text {eff }}\right)$ for determination of gene positioning anglemetry due to primary and secondary linearization effects, validation of the primary linearization effect is the sebs intercept-to-sebssiwa intercept linearization quotient $\left(b_{\text {sebs }} / b_{\text {sebssiwa }}\right)$; in which case, normalization of the dppasebs, dppmsebs effect predominates in anisotropic gene $M Y C\left(b_{\text {sebs }} / b_{\text {sebssiwa }}: 3.63 ; P_{\text {eff }} 0.157 ; \theta_{\mathrm{A}}=71^{0}\right)$, the uppasebs, uppmsebs effect predominates in mesotropic gene PRDM1 $\left(b_{\text {sebs }} / b_{\text {sebssiwa }}: 3.45 ; P_{\text {eff }} 0.356 ; \theta_{\mathrm{M}}=47^{\circ}\right)$, while both the dppasebs, dppmsebs and uppasebs, uppmsebs effects are linear normalized in PRKCH $\left(b_{\text {sebs }} / b_{\text {sebssiwa }}: 3.17\right.$; $\left.P_{\text {eff }} 0.200 ; \theta_{\mathrm{A}}=65.8^{\circ}\right)$ as examples.

Based on the findings of this study considered together, the precise mechanistic basis for alterations in chromatin gene transcription eukaryotic stranded heterochromatin arranged by structural pressurotopy nano-compliance in DNA stand loop segments is effective cell pressure $\left(P_{\text {eff }}\right)$ regulated shifting of transcriptionally active DNA in-between the inner nuclear envelope margin and the peripheral nucleoplasm edge and the $z, x$-plane horizontal alignment of a gene by gene specific $P_{\text {eff }}$ within the cell specific effective range of whole cell compliance in reference to tissue macro-compliance. The findings of this study are therefore applicable to the further study of changes in gene transcription in response to applied mechanical strain-mediated alterations in nuclear envelope deformability in silico.

\section{Additional file}

Additional file 1: Table S1. Sequential episodic sub-episode block sum split-integrated weighted average gene overexpression tropy quotients to final esebssiwaago $T_{\mathrm{Q}}$ for predicted neural axis gene overexpression ${ }^{1)}$ Gene loci sub-episode block structure variations include non-contributory anisotropy (NCA), anisotropy converted to mesotropy (ACM), and/or 0.5-factor adjusted stabilizing mesotropy or anisotropy converted to stabilizing isotropy for anisotropy or mesotropy (stIAfM, stIMfA or stIMfM) that result in an initial to final SEB conversion; and ${ }^{2)}$ previously reported episode and sub-episode block structure is applied in all cases as per reference [25], in which gene/ gene loci at cusps of the delineated base intervals, SHANK2 $(784,883)$, RBFOX3 $(521,757)$ classify into the adjacent interval. (DOC 66 kb)

\section{Abbreviations}

ACM: Anisotropy converted to mesotropy; $b_{\text {sebs }} / b_{\text {sebssiwa: }}$ Intercept sebs/ intercept sebssiwa linearization quotient; $d_{,} d_{M}, d_{A}$ : Distance of gene intergene base tropy; dppasebs: Downstream part anisotropic sub-episode block sum; dppasebs: Downstream part anisotropic sub-episode block sum; dppasebssiwa: Downstream part anisotropic sub-episode block sum split integrated weighted average; dppasebssiwa: Downstream part anisotropic sub-episode block sum split integrated weighted average; NCA: Noncontributory anisotropy; $P_{\text {eff: }}$ Effective intracellular pressure, esebssiwaago $T_{\mathrm{Q}}$; $\operatorname{prpT}_{\mathrm{Q}}$ : Paired point tropy quotient; SEB: Sub-episode block; stIAfM, stIMfA or stIMfM: 0.5-factor adjusted stabilizing isotropy for anisotropy or mesotropy; uppasebs: Upstream part anisotropic sub-episode block sum; uppasebssiwa: Upstream part anisotropic sub-episode block sum split integrated weighted average; uppmsebs: Upstream part mesotropic sub -episode block sum; uppmsebssiwa: Upstream part mesotropic sub-episode block sum split integrated weighted average; $\Theta, \Theta_{M}, \Theta_{A}, \Theta_{H}$ : Gene angle; $m_{\text {eff, }}$ $m_{\mathrm{A}}\left(m_{\mathrm{ch}}\right.$ tropy $), m_{\mathrm{M}}\left(m_{\mathrm{ch}}\right.$ tropy $+m_{\mathrm{ch}}$ nmn tropy $)$ : Effective momentum

\section{Acknowledgements}

Not applicable

\section{Authors' contributions}

HS conceptualized the research, developed the methodology, analyzed the data, and wrote the manuscript. The author read and approved the final manuscript.

\section{Funding}

No funding was applied for this research.

Availability of data and materials

All data analysed in this study are included in the table files of this article.

Ethics approval and consent to participate

Not applicable

Consent for publication

Not applicable.

\section{Competing interests}

The author declares that he has no competing interests.

Received: 5 April 2019 Accepted: 22 July 2019

Published online: 02 August 2019

\section{References}

1. German J. The pattern of dna synthesis in the chromosomes of human red blood cells. J Cell Biol. 1964;20(1):37-55.

2. Comings DE. The rationale for an ordered arrangement of chromatin in the interphase nucleus. Am J Hum Genet. 1968;34(5):757-80.

3. Camargo M, Cervenka J. Patterns of DNA replication of human chromosomes. II. Replication map and replication model. Am J Hum Genet. 1982;34(5):757-80.

4. Holmquist GP. Role of replication time in the control of tissue-specific gene expression. Am J Hum Genet. 1987:40:153-73.

5. Rocchi A. On the heterogeneity of heterochromatin. Caryologia. 1982;35(2):169-89.

6. Sarin H. Permeation thresholds for hydrophilic small biomolecules across microvascular and epithelial barriers are predictable on the basis of conserved biophysical properties. In Silico Pharmacol. 2014;3:5.

7. Comings DE, Wallack AS. DNA-binding properties of nuclear matrix proteins. J Cell Sci. 1978;34(1):233-46.

8. Fawcett DW. On the occurrence of a fibrous lamina on the inner aspect of the nuclear envelope in certain cells of vertebrates. Am J Anat. 1966;119(1):129-45.

9. Markovics J, Glass L, Maul GG. Pore patterns on nuclear membranes. Exp Cell Res. 1974;55(2):443-51.

10. Gerace L, Blum A, Blobel G. Immunocytochemical localization of the major polypeptides of the nuclear pore complex-lamina fraction: interphase and mitotic distribution. J Cell Biol. 1978;79(3):545-66.

11. Blobel G. Gene gating: a hypothesis. Proc Natl Acad Sci U S A. 1985;82:8527-9.

12. Fisher DZ, Chaudhary N, Blobel G. CDNA sequencing of nuclear lamins A and $C$ reveals primary and secondary structural homology to intermediate filament proteins. Proc Natl Acad Sci U S A. 1986;83:6450-4.

13. Wydner KL, McNeil JA, Lin F, Worman HJ, Lawrence JB. Chromosomal assignment of human nuclear envelope protein genes LMNA, LMNB1, and LBR by fluorescencein in situ hydridization. Genomics. 1996;32(3):474-8.

14. Kavlverda B, Roling MD, Fornerod M. Chromatin organization in relation to the nuclear periphery. FEBS Lett. 2008;582:2017-22.

15. Finlan LE, Sproul D, Thomson I, Boyle S, Kerr E, Perry P, Yistra B, Chubb JR, Bickmore WA. Recruitment to the nuclear periphery can alter expression of genes in human cells. PLoS Genet. 2008;4(3):e1000039. 
16. Kalverda B, Pickersgill H, Shloma W, Fornerod M. Nucleoporins directly stimulate expression of developmental and cell-cycle genes inside the nucleoplasm. Cell. 2010;140(3):360-71.

17. Miroshnikova YA, Nava MM, Wickstrom SA. Emerging roles of mechanical forces in chromatin regulation. J Cell Sci. 2017;130:2243-50.

18. Berk JM, Tift KE, Wilson KL. The nuclear envelope LEM-domain protein emerin. Nucleus. 2013;4(4):298-314.

19. Macgregor HC, Callan HG. The actions of enzymes on lampbrush chromosomes. J Cell Sci. 1962;s3-103:173-203.

20. Laemmli UK, Marsden MPF. Metaphase chromosome structure: evidence for a radial loop model. Cell. 1979;17(4):849-58.

21. Gall JG. Are lampbrush chromosomes unique to meiotic cells? Chromosom Res. 2012;20(8):905-9.

22. Kołowerzo-Lubnau A, Niedojadło J, Świdziński M, Bednarska-Kozakiewicz E, Smoliński DJ. Transcriptional activity in Diplotene larch microsporocytes, with emphasis on the diffuse stage. PLoS One. 2015;10(2):e0117337.

23. Sobecki M, Mrouj K, Camasses A, Parisis N, Nicolas E, Llères D, Gerbe F, Prieto S, Krasinska L, David A, Eguren M, Birling M-C, Urbach S, Hem S, Déjardin J, Malumbres M, Jay P, Dulic V, Lafontaine DLJ, Feil R, Fisher D. The cell proliferation antigen Ki-67 organises heterochromatin. eLife. 2016;5:e13722.

24. Sarin H. Pressuromodulation at the cell membrane as the basis for small molecule hormone and peptide regulation of cellular and nuclear function. J Transl Med. 2015;13:372.

25. Sarin $\mathrm{H}$. Horizontal alignment of $5^{\prime}->3^{\prime}$ intergene distance segment tropy with respect to the gene as the conserved basis for DNA transcription. Future Sci OA. 2016;3(1):FSO160.

26. Sarin H. B-cell differentiation is pressuromodulated as determined by pressuromodulation mapping: part I, cell differentiation. Trans Med Comms. 2018;3(3).

27. Sarin, H. B-cell antibody class switchings are pressuromodulated events: part II, gene recombination. Trans Med Comms. 2018;3(2).

28. Belaadi N, Aurene J, Guilluy C. Under pressure: mechanical stress management in the nucleus. Cells. 2016;5(2):E27.

29. Dahl KN, Engler AJ, Pajerowski DJ, Discher DE. Power-law rheology of isolated nuclei with mapping of nuclear substructures. Biophys J. 2005;89:2855-4.

30. Booth-Gauthier EA, Alcoser TA, Yang G, Dahl KN. Force-induced changes in subnuclear movement and rheology. Biophys J. 2012;103(12):2423-31.

31. Dahl KN, Kahn SM, Wilson KL, Discher DE. The nuclear envelope lamina network has elasticity and a compressibility limit suggestive of a molecular shock absorber. J Cell Sci. 2004;117:4779-86.

32. Rowat AC, Lammerding J, Ipsen JH. Mechanical properties of the cell nucleus and the effect of emerin deficiency. Biophys J. 2006;91:4649-64.

33. Lammerding J, Schulze CP, Takahashi T, Kozlov S, Teresa Sullivan T, Kamm RD, Stewart CL, Lee RT. Lamin A/C deficiency causes defective nuclear mechanics and mechanotransduction. J Clin Invest. 2004;113:370-8.

34. Lammerding J, Hsiao J, Schulze PC, Kozlov S, Stewart CL, Lee RT. Abnormal nuclear shape and impaired mechanotransduction in emerin-deficient cells. J Cell Biol. 2005;170:781-91.

35. Rowat AC, Foster LJ, Nielsen MM, Weiss M, Ipsen JH. Characterization of the elastic properties of the nuclear envelope. J R Soc Interface. 2005;2:63-9.

36. Yeung T, George PC, Flanagan LA, Marg B, Ortiz M, Funak M, Zahir N, Ming W, Weaver $V$, Janmey PA. Effects of substrate stiffness on cells morphology cytoskeletal structure and adhesion. Cell Motil Cytoskeleton. 2005;60:24-34.

37. Paszek MJ, Zahir N, Johnson KR, Lakins JN, Rozenberg GL, Gefen A, Reinhart-King CA, Margulies SS, Dembo M, Boettiger D, Hammer DA, Weaver VM. Tensional homeostasis and the malignant phenotype. Cancer Cell. 2005;8:241-54.

38. Swift J, Ivanovska IL, Buxboim A, Harada T, Dingal PC, Pinter J, Pajerowski JD, Spinler KR, Shin J-W, Manorama T, Rehfeldt F, Speicher DW, Discher DE. Nuclear Lamin-A scales with tissue stiffness and enhances matrix-directed differentiation. Science. 2013;341(6149):1240104.

39. Driscoll TP, Cosgrove BD, Heo S-J, Shurden ZE, Mauck RL. Cytoskeletal to nuclear strain transfer regulates YAP signaling in mesenchymal stem cells. Biophys J. 2015;118:2783-93.

40. Heo S-J, Han WM, Szczesny SE, Cosgrove BD, Elliot DM, Lee DA, Duncan RL, Mauck RL. Mechanically induced chromatin condensation requires cellular contractility in mesenchymal stem cells. Biophys J. 2016;111:864-74.

41. Heo S-J, Driscoll TP, Thorpe SD, Nerurkar NL, Baker BM, Yang MT, Chen CS, Lee DA, Mauck RL. Differentiation alters stem cell nuclear architecture, mechanics, and mechano-sensitivity. eLife. 2016;5:e18207.
42. Popovic J, Stanisavljevic D, Schwirtlich M, Klajn A, Marjanovic J, Stevanovic M. Expression analysis of SOX14 during retinoic acid induced neural differentiation of embryonal carcinoma cells and assessment of the effect of its ectopic expression on SOXB members in HeLa cells. PLoS One. 2014;9(3):e91852.

43. Yuzwa S, Borrett MJ, Innes BT, Voronova A, Ketela T, Kaplan DR, Bader GD, Miler FD. Developmental emergence of adult neural cells as revealed by single-cell transcriptional profiling. Cell Rep. 2017;21:3970-86.

44. Yamada H, Fredette B, Shitara K, Hagihara K, Miura R, Ranscht B, Stallcup WB, Yamaguchi $Y$. The brain chondroitin sulfate proteoglycan brevican associates with astrocytes ensheathing cerebellar glomeruli and inhibits neurite outgrowth from granule neurons. J Neurosci. 1997;17(20):7784-95.

45. Ruoslahti E. Brain extracellular matrix. (1996). Glycobiology. 1996;6(5):489-92.

46. Kitamura C, Takahashi M, Kondoh Y, Tashiro H, Tashiro T. Identification of synaptic activity-dependent genes by exposure of cultured cortical neurons to tetrodotoxin followed by its withdrawal. J Neurosci Res. 2007;85(11):2385-99.

47. Taymans JM, Leysen JE, Langlois X. Striatal gene expression of RGS2 and RGS4 is specifically mediated by dopamine D1 and D2 receptors: clues for RGS2 and RGS4 functions. J Neurochem. 2003;84(5):1118-27.

48. Straccia M, Barriga G-D, Phil Sanders P, Bombau G, Carrere J, Mairal PB, Vinh N-N, Yung S, Kelly CM, Svendsen CN, Kemp PJ, Arjomand J, Schoenfeld RC, Alberch J, Allen ND, Rosser AE, Canals JM. Quantitative high-throughput gene expression profiling of human striatal development to screen stem cell-derived medium spiny neurons. Mol Ther Methods Clin Dev. 2015;2: 15030.

49. Mullen RJ, Buck CR, Smith AM. NeuN, a neuronal specific nuclear protein in vertebrates. Development. 1992;116:201-11.

50. Lixin K, Jalali A, Zhao L-R, Zhou X, McGuire T, Kazanis I, Episkopou V, Bassuk AG, Kessler JA. Dual function of Sox1 in Telencephalic progenitor cells. Dev Biol. 2007;310(1):85-98.

51. Hundahl CA, Kelsen J, Hay-Schmidt A. Neuroglobin and cytoglobin expression in the human brain. Brain Struct Funct. 2013;218(2):603-9.

52. Heintz N. Gene expression nervous system atlas (GENSAT). Nature Neurosci. 2004;7(5):483.

53. Dhar SS, Wong-Riley MTT. Coupling of energy metabolism and synaptic transmission at the transcriptional level: role of nuclear respiratory factor 1 in regulating both cytochrome c oxidase and NMDA glutamate receptor subunit genes. J Neurosci. 2009;29(2):483-92.

54. Kojima Y, Kurokawa S, Maruyama T, Sasaki S, Kohri K, Hayashi Y. Identification of differentially expressed genes in human cryptorchid testes using suppression subtractive hybridization. J of Urology. 2009;181(3):1330-7.

55. Homem CCF, Knoblich JA. Drosophila neuroblasts: a model for stem cell biology. Development. 2012;139:4297-310.

56. Carol B, Hanna CB, Yao S, Patta MC, Jensen JT, Wu X. Expression of insulin -like 3 (INSL3) and differential splicing of its receptor in the ovary of rhesus macaques. Reprod Biol Endocrinol. 2010;8:150.

57. McAlinden A, Johnstone B, Kollar J, Kazmi N, Hering TM. Expression of two novel alternatively spliced Col2a1 isoforms during chondrocyte differentiation. Matrix Biol. 2008;27(3):254-66.

58. Zhao Q, Eberspaecher $\mathrm{H}$, Lefebvre V, Crombrugghe BE. Parallel expression of Sox9 and Col2a1 in cells undergoing chondrogenesis. Dev Dynam. 1997; 209:377-86

59. Kawato Y, Hirao M, Ebina K, Shi K, Hashimoto J, Honjo Y, Yoshikawa H, Myoui A. NkX3.2 promotes primary chondrogenic differentiation by upregulating Col2a1 transcription. PLoS One. 2012;7(4):e34703.

60. Festuccia N, Osorno R, Halbritter F, Karwacki-Neisius V, Navarro P, Colby D, Wong F, Yates A, Tomlinson SR, Chambers I. Esrrb is a direct Nanog target gene that can substitute for Nanog function in pluripotent cells. Cell Stem Cell. 2012;11:477-90.

61. Takahashi K, Tanabe K, Ohnuki M, Narita M, Ichisaka T, Tomoda K, Yamanaka S. Induction of pluripotent stem cells from adult human fibroblasts by defined factors. Cell. 2007;131(5):861-72.

\section{Publisher's Note}

Springer Nature remains neutral with regard to jurisdictional claims in published maps and institutional affiliations. 